\title{
Behavioral trainings and manipulations to reduce delay discounting: A systematic review
}

\author{
Hanneke Scholten ${ }^{1}$ (D) Anouk Scheres ${ }^{1} \cdot$ Erik de Water $^{1,2} \cdot$ Uta Graf $^{1} \cdot$ Isabela Granic $^{1} \cdot$ Maartje Luijten ${ }^{1}$
}

Published online: 3 July 2019

(C) The Author(s) 2019

\begin{abstract}
In everyday decision-making, individuals make trade-offs between short-term and long-term benefits or costs. Depending on many factors, individuals may choose to wait for larger delayed reward, yet in other situations they may prefer the smaller, immediate reward. In addition to within-subject variation in the short-term versus long-term reward trade-off, there are also interindividual differences in delay discounting (DD), which have been shown to be quite stable. The extent to which individuals discount the value of delayed rewards turns out to be associated with important health and disorder-related outcomes: the more discounting, the more unhealthy or problematic choices. This has led to the hypothesis that DD can be conceptualized as transdisease process. The current systematic review presents an overview of behavioral trainings and manipulations that have been developed to reduce DD in human participants aged 12 years or older. Manipulation studies mostly contain one session and measure DD directly after the manipulation. Training studies add a multiple session training component that is not per se related to DD, in between two DD task measurements. Ninety-eight studies (151 experiments) were identified that tested behavioral trainings and manipulations to decrease DD. Overall, results indicated that DD can be decreased, showing that DD is profoundly context dependent and changeable. Most promising avenues to pursue in future research seem to be acceptance-based/mindfulness-based trainings, and even more so manipulations involving a future orientation. Limitations and recommendations are discussed to identify the mechanistic processes that allow for changes in discount rate and behavior accordingly.
\end{abstract}

Keywords Delay discounting $\cdot$ Temporal discounting $\cdot$ Trainings $\cdot$ Manipulations $\cdot$ Health behaviors $\cdot$ Trans-disease process

\section{Glossary of acronyms in text and tables}

$\begin{array}{ll}\text { ADHD } & \text { Attentional-deficit/hyperactivity disorder } \\ \text { ATM } & \text { Advisor-teller money manager } \\ \text { BMT } & \text { Brief motivational training } \\ \text { BS } & \text { Between-subject design } \\ \text { C } & \text { Control condition } \\ \text { CBT } & \text { Cognitive behavioral therapy } \\ \text { CDE } & \text { Cancer death experience } \\ \text { CLT } & \text { Construal level theory }\end{array}$

Part of this research was presented at a Thematic Meeting on Addiction in Marquette, Michigan, USA at 9 September 2016.

Hanneke Scholten

h.scholten@bsi.ru.nl

1 Behavioural Science Institute, Radboud University, P.O. Box 9104, 6500, HE Nijmegen, The Netherlands

2 Icahn School of Medicine at Mount Sinai, New York, NY, USA

$\begin{array}{ll}\text { CM } & \begin{array}{l}\text { Contingency management } \\ \text { CO }\end{array} \\ \text { DD } & \begin{array}{l}\text { Delay monoxide } \\ \text { Diascounting }\end{array} \\ \text { DSM } & \begin{array}{l}\text { Diagnostic and Statistical Manual } \\ \text { of Mental Disorders }\end{array} \\ \text { E } & \begin{array}{l}\text { Experimental condition } \\ \text { Episodic future thinking }\end{array} \\ \text { EFT } & \text { Episodic past thinking } \\ \text { EPT } & \text { Fixed delayed reward } \\ \text { FDR } & \text { Future focus } \\ \text { FF } & \text { Fixed immediate reward } \\ \text { FIR } & \text { Fill-in-the-blank } \\ \text { FITB } & \text { Healthy controls } \\ \text { HC } & \text { Hypothetical delay discounting task } \\ \text { HYP DD } & \text { Investment } \\ \text { I } & \text { Internet gaming disorder } \\ \text { IGD } & \text { No investment } \\ \text { NI } & \text { Nontemporal focus } \\ \text { NTF } & \text { Present focus } \\ \text { PF } & \text { Potentially real delay discounting task } \\ \text { PR DD } & \end{array}$




$\begin{array}{ll}\text { PSA } & \text { Polysubstance dependent alcoholics } \\ \text { REAL DD } & \text { Real delay discounting task } \\ \text { SDT } & \text { Social delay discounting task } \\ \text { SFAS } & \text { Substance-free activity session } \\ \text { SFT } & \text { Semantic future thinking } \\ \text { STI } & \text { Sexually transmitted infection } \\ \text { VDR } & \text { Variable delayed reward } \\ \text { VIR } & \text { Variable immediate reward } \\ \text { WM } & \text { Working memory } \\ \text { WS } & \text { Within-subject design }\end{array}$

Life is full of choices between options that are immediately rewarding and options that are only rewarding in the future. For example, shall I smoke a cigarette right now, or shall I refrain from smoking to stay healthier in the future? Individuals have the tendency to prefer immediate, smaller rewards over larger, but delayed rewards (Logue, 1988). This phenomenon is described as delay discounting (DD)also referred to as temporal discounting or time discounting and is often viewed as a measure of impulsive choice (e.g., Ainslie, 1975; Monterosso \& Ainslie, 1999; Rachlin, 1989). DD refers to the decrease in the subjective value of a reward as the delay to its receipt increases (Ainslie, 1992; Critchfield \& Kollins, 2001; L. Green \& Myerson, 1993; Hamilton et al., 2015; Rachlin, 1989). The extent to which individuals discount the value of delayed rewards turns out to be associated with important health and disorder-related outcomes, and there is growing interest in trainings and manipulations that decrease heightened DD. The current systematic review presents an overview of behavioral trainings and manipulations that have been developed to reduce DD.

A DD task in which participants have to choose between a series of smaller-sooner (e.g., $\$ 5$ today) and larger-later rewards (e.g., $\$ 10$ in 2 weeks) is commonly used to assess these preferences (L. Green \& Myerson, 2004; Stanger, Budney, \& Bickel, 2013). The magnitude of the smallersooner reward and the delay preceding the larger reward are varied across choices in DD tasks, to determine an individual's indifference point for each delay (Critchfield $\&$ Kollins, 2001). The indifference point, or subjective value, is defined as the magnitude of the smaller-sooner reward at which an individual shows no clear preference for either the smaller-sooner or later-larger reward. These indifference points/subjective values are used to define the rate at which individuals discount delayed rewards (Bickel, Jarmolowicz, Mueller, Koffarnus, \& Gatchalian, 2012b; Scheres, de Water, \& Mies, 2013a).

The choices in DD tasks can either be hypothetical, potentially real, or real. In hypothetical DD tasks, participants do not receive the rewards they choose, and they do not experience the waiting times (Scheres, de Water, et al., 2013a). In potentially real DD tasks, participants are informed that one choice will be selected at the end of the task, and participants are paid accordingly. This task relies on the assumption that participants will choose on each trial as if that trial is the one that will be selected. In real tasks, all chosen rewards are paid, and all delays are experienced during the test session (Scheres, de Water, et al., 2013a). Another method to assess DD, is the fill-in-the-blank (FITB) task (Chapman, 1996). In this task, participants answer only one question at each given delay, in comparison to the titrating procedures used in DD tasks (Weatherly \& Derenne, 2011; Weatherly \& Terrell, 2010). Specifically, for each choice participants indicate themselves what amount they are willing to accept immediately rather than having to wait for the full amount of the outcome that will be delayed for X amount of time (Weatherly \& Derenne, 2011).

Frequently, unhealthy or problematic behaviors have a delayed effect on health - for example, smoking a cigarette right now has detrimental effects on one's health in the long run. This has led researchers to believe that an individual's tendency to make unhealthy or problematic choices is related to his or her discount rate. Supporting this belief, discount rate is highly correlated with a variety of health behaviors and disorders, with medium effect sizes across studies (Amlung, Petker, Jackson, Balodis, \& MacKillop, 2016; Jackson \& MacKillop, 2016; MacKillop et al., 2011). Specifically, increased DD rates are characteristic of maladaptive and unhealthy behaviors including alcohol dependence (e.g., Bobova, Finn, Rickert, \& Lucas, 2009; Mitchell, Fields, D'Esposito, \& Boettiger, 2005), drug dependence (e.g., Bickel, Landes, et al., 2011a; Kirby \& Petry, 2004; Monterosso et al., 2007), gambling problems (e.g., Reynolds, 2006), tobacco use (e.g., Audrain-McGovern et al., 2009; Baker, Johnson, \& Bickel, 2003; Bickel, Yi, Kowal, \& Gatchalian, 2008; Fields, Leraas, Collins, \& Reynolds, 2009), overeating (e.g., Amlung et al., 2016; Weller, Cook, Avsar, \& Cox, 2008), attention-deficit/ hyperactivity disorder (ADHD; Demurie, Roeyers, Baeyens, \& Sonuga-Barke, 2012; Jackson \& MacKillop, 2016; Patros et al., 2016; Scheres, Tontsch, Thoeny, \& Kaczkurkin, 2010), conduct disorder (White et al., 2014), and risky sexual behaviors (Chesson et al., 2006). For example, as a group, individuals who smoke consistently show higher DD rates than controls do (Amlung \& MacKillop, 2014; MacKillop et al., 2011). Thus, DD is consistently linked with a variety of problematic and unhealthy behaviors, and there is initial evidence from developmental studies that increased discounting rates contribute to the development and maintenance of these behaviors (Audrain-McGovern et al., 2009; Ayduk et al., 2000; Breaux, Griffith, \& Harvey, 2016; Campbell \& Von Stauffenberg, 2009; Khurana et al., 2013; Krishnan-Sarin et al., 2007; Passetti, Clark, Mehta, Joyce, \& King, 2008; Sheffer et al., 2012; Stanger et al., 2012). Although more studies are needed to replicate these effects, AudrainMcGovern et al. (2009), for example, showed with a prospective longitudinal cohort study spanning midadolescence to young adulthood (ages 15-21 years old) that heightened 
baseline DD rates were a significant predictor of smoking initiation over time $(11 \%$ increase in the odds of smoking uptake).

This body of evidence has led to the hypothesis that DD can be conceptualized as a trans-disease process that is shared across different disorders (Bickel et al., 2012b., ; Bickel, Quisenberry, Moody, \& Wilson, 2015). Consequently, intervening in such a trans-disease process could be very promising for various reasons. First and foremost, if higher discount rates function as a behavioral marker of health behaviors and disorders, then manipulating discount rates might change multiple health behaviors and disorders as well (Koffarnus, Jarmolowicz, Mueller, \& Bickel, 2013). Furthermore, it offers the opportunity to better understand and investigate comorbidity (i.e., the co-occurrence of two or more disorders). The presence of two or more disorders is not unexpected when both are originating from the same trans-disease process.

Interindividual differences in discounting rates are highly stable. This had led some to argue that the discounting rate should be viewed as a personality trait (Odum, 2011) — namely, someone's relative DD rate is highly stable. At the same time, there is a growing number of studies that suggest that intraindividual differences in DD rate are substantial as well: Within individuals, DD rate changes as a function of contextual/situational factors (Bickel, 2015; Gray \& MacKillop, 2015; Odum, 2011). Therefore, there is growing attention for trainings and manipulations that successfully target and decrease heightened DD (e.g., Bickel, Quisenberry, Moody, \& Wilson, 2015; Koffarnus et al., 2013). Instead of focusing on specific disorders to identify trainings and manipulations that work, a more successful approach might be to develop trainings and manipulations that are effective across a variety of disorders.

While attention to the topic of reducing DD is growing, little is understood about effective ways to alter heightened discount rates. Understanding which trainings and manipulations are worth pursuing in the future, and which of those seem less effective in reducing DD, can help us optimize the application of this body of work. Although the literature provides a small number of important narrative reviews discussing the promise of DD trainings and manipulations (e.g., Bickel et al., 2015; Gray \& MacKillop, 2015; Koffarnus et al., 2013; Lempert \& Phelps, 2016), a systematic review was not performed at the time of our search. However, recently, a systematic review and meta-analysis was published on the same topic (Rung and Madden, b). Compared with the current systematic review, Rung and Madden (b) took a more methodological and meta-analytic approach to determine the efficacy of different methods to reduce DD, whereas we took a more theoretical approach to identify promising routes for future research. Furthermore, Rung and Madden (2018b) included a review and analysis of animal studies, studies with child populations, and studies before 1990 , but did not report on possible effects of DD trainings or manipulations on behavior. The purpose of the current systematic review is to present an overview of behavioral trainings and manipulations available in the literature to reduce DD, and improve behavior accordingly, in human adolescent and adult participants.

Studies included in the review will be separated in two main categories. On the one hand, there are studies using manipulations: These studies manipulate the DD task (e.g., change wording in task) or add a priming procedure shortly before the DD task. Most of these studies include only one session and one moment of measuring DD rates. On the other hand, there are studies applying trainings: These studies add a training component that is not directly related to DD in between two DD task measurements. In most studies, these trainings are delivered in multiple sessions, but some studies include only one session of training. Within these two main categories, studies will be further classified based on the content of the training or manipulation. DD is the main outcome that is evaluated in the current systematic review, although secondary behavioral outcomes, such as smoking or eating behaviors, will also be discussed. The central research questions in this systematic review are whether there are effective ways of decreasing DD and whether there are associated effects on behavioral outcomes. This systematic review is a first step in systematically summarizing the research regarding decreasing DD. As this literature is rather diverse and large, we are not aiming to offer a coherent theoretical framework or compare effectiveness of studies by computing effect sizes. Yet we hope to identify promising routes for future research and classify overarching mechanistic processes that allow for changes in discount rate and behavior accordingly.

\section{Method}

\section{Inclusion criteria}

Studies were included in the systematic review if (1) they included human participants; (2) the participants were 12 years or older; (3) (one of) the outcome measure represented monetary DD; (4) a training or manipulation was employed; (5) the training or manipulation was behavioral in nature (no medication or neuromodulation studies are included); (6) the study aimed to decrease DD (instead of increase); (7) DD choices were made for the self instead of for others; (8) they included a training or manipulation that had training and/or clinical potential - for example, the mere manipulation of placing an individual in a certain environment (gambling vs. nongambling), or the experimental manipulation of reward magnitude or sign (gains vs. losses) were manipulation 
categories excluded from this review; (9) the sample size was $>10$; (10) they were published between 1990 and April 2017; and (11) were published in an English-language peerreviewed journal. To reduce heterogeneity, we narrowed our search by including only studies using monetary outcomes that aimed to decrease DD via behavioral trainings or manipulations.

\section{Search strategies}

Literature search and selection were carried out according to the Preferred Reporting Items for Systematic Reviews and Meta-Analyses (PRISMA; Moher, Liberati, Tetzlaff, Altman, \& The PRISMA Group, 2009). A three-step procedure was used to identify relevant studies. First, we searched relevant databases (i.e., Pubmed, PsychInfo, and Web of Science) to identify studies that met inclusion criteria summarized above. All synonyms of the word delay discounting (i.e., delay discount*, temporal discount*, inter temporal choice and time discount*) and all possible variants of words like change and decrease (alter*, reduc*, manipulate*, train*, modify*, adjust*, transform*, convert*, reform*, diminish*, attenuate*, declin*, adapt*, improv*, amend*, ameliorat*, learn*, develop*) were entered in the databases. We included title, abstract, keywords, and topic as search areas. Second, to further identify relevant studies, the reference lists of all studies classified in step one were reviewed. Finally, we checked the reference lists of already existing reviews (i.e., Gray \& MacKillop, 2015; Koffarnus et al., 2013; Lempert \& Phelps, 2016) for additional studies.

\section{Search results}

The literature search in Pubmed, PsychInfo, and Web of Science resulted in 8,969 hits $(1,101 ; 6,584$; and 1,284 hits, respectively). We detected 1,520 duplicates, and removing these resulted in 7,449 unique references. The reference lists of the identified studies yielded eight additional studies. No extra studies were identified when checking the reference lists of the already existing reviews. Authors H.S. and U..G independently determined whether the inclusion criteria were met by reading the titles and abstracts. We identified a total of 178 potentially relevant studies at this point. Next, all 178 full-text studies were screened using the same inclusion criteria, and this resulted in a final number of 98 studies relevant for the review. The selected studies cover a wide variety of behavioral trainings and manipulations that change DD in adolescents and adults. The whole literature search and selection process is displayed in Fig. 1.

\section{Results}

\section{Characteristics of included studies}

Characteristics and results of the 98 studies included in this systematic review are summarized in Table 1 and 2 . Table 1 covers all studies applying a training, with a total of 19 studies (each covering one experiment; thus 19 experiments) published between 2008 and 2017. The majority $(n=14 ; 74 \%)$ of these studies included a clinical population, specifically smokers, individuals with Internet gaming disorder (diagnosed based on Diagnostic and Statistical Manual of Mental Disorders, Fifth Edition [DSM5] "condition for further study" symptoms), individuals dependent on marijuana, opioids, alcohol, cocaine, stimulants, or individuals on polysubstance and methadone maintenance. The remaining $26 \%(n=5)$ of studies tested their training in healthy controls. Seven out of the 19 studies $(37 \%)$ also reported effects of their training on actual behavior such as smoking or cocaine abstinence, in addition to results on DD.

All studies using manipulations to change DD are displayed in Table 2, with a total of 79 studies published between 2001 and 2017. A total of 132 experiments were conducted within these 79 studies. Most experiments $(n=$ $118 ; 89 \%$ ) included healthy controls as their target population; however, 14 experiments (11) included clinical populations (sometimes in combination with a healthy control sample). These clinical populations included smokers, individuals with Internet gaming disorder, obese individuals, alcoholdependent or substance-dependent individuals, and ADHD or amnestic patients. Of the experiments, $5 \%(n=6)$ reported effects of the manipulations on actual behavior, such as caloric intake, in addition to the effect on DD. For clarification purposes, we divided the manipulations in four main categories broadly covering the variety of manipulations in the literature and discuss them accordingly: future, social factors, emotion, and framing. Please note that this division is purely subjective, and some studies combine multiple manipulation categories.

There are far more manipulation experiments available in the literature ( $n=132 ; 87 \%)$, compared to trainings ( $n=19$; $13 \%$ ). Almost all experiments included adults; only two experiments (Fassbender et al., 2014, Study 5; Radu, Yi, Bickel, Gross, \& McClure, 2011, Study 2) also included participants younger than 18. Inspecting the samples more carefully, it becomes clear that more than a third of all manipulation experiments $(n=52 ; 39 \%)$ has tested its manipulation in healthy control college student samples with a higher percentage of female than male participants $(>60 \%)$. In the training experiments, the percentage of healthy control college student samples with more female than male participants was much lower $(n=4 ; 21 \%)$. 


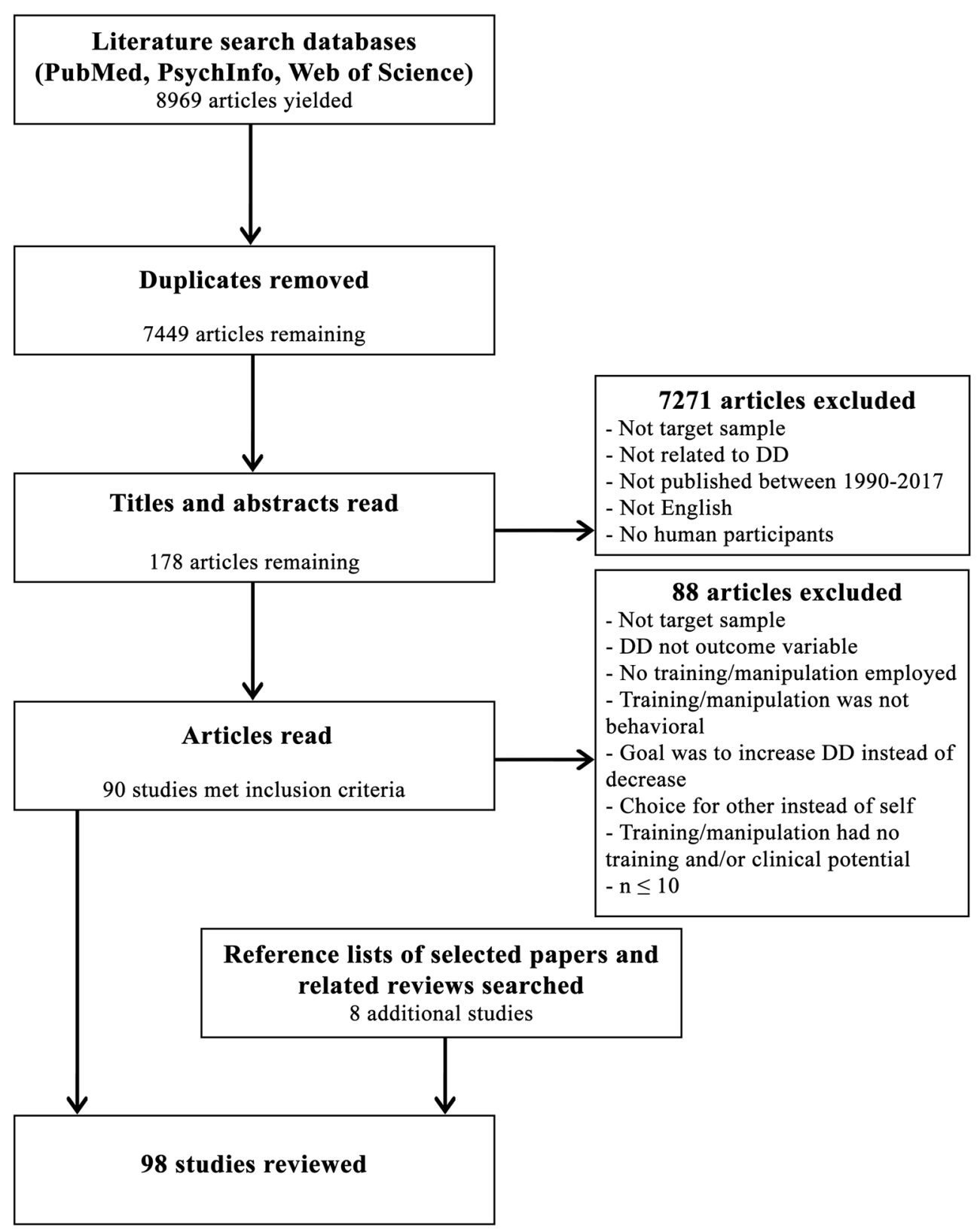

Fig. 1 PRISMA flow diagram of literature search and selection process for inclusion in the systematic review

With regard to measuring DD as the main outcome variable, most experiments employed either a hypothetical DD task $(n=77 ; 51 \%)$, a potentially real DD task $(n=46$; $30 \%)$ or a hypothetical FITB task $(n=22 ; 15 \%)$. A small number of experiments used a real DD task $(n=2 ; 1 \%)$, a potentially real FITB task $(n=1 ; 1 \%)$ or combined two methods within one experiment $(n=3 ; 2 \%)$. One experiment combined a real DD and a hypothetical DD task, one experiment combined a potentially real DD task with a hypothetical DD task, and another experiment combined a hypothetical DD task with a hypothetical FITB task.

\section{General results}

Results of the current review show that $26 \%(n=5)$ of the experiments evaluating the effects of trainings find the expected reductions in $\mathrm{DD}$, whereas $58 \%(n=11)$ found null results or unexpected increases in DD. The remainder three studies (16\%) found mixed results; these studies found the expected reductions in DD on a substance-related DD task, but not on a monetary DD task. Of the experiments that included a secondary behavioral outcome $(n=7)$ all found the expected positive effects on behavior. 


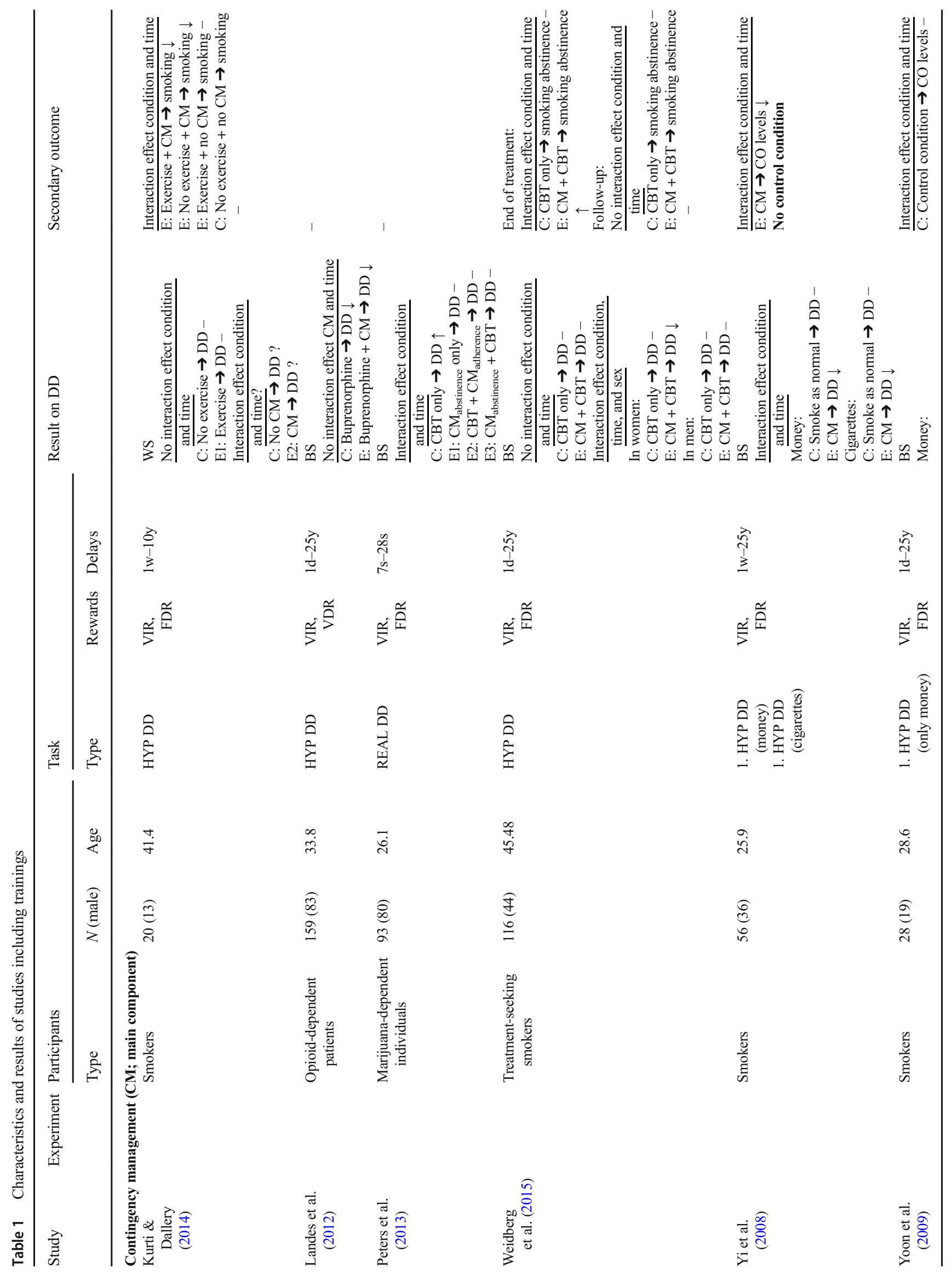




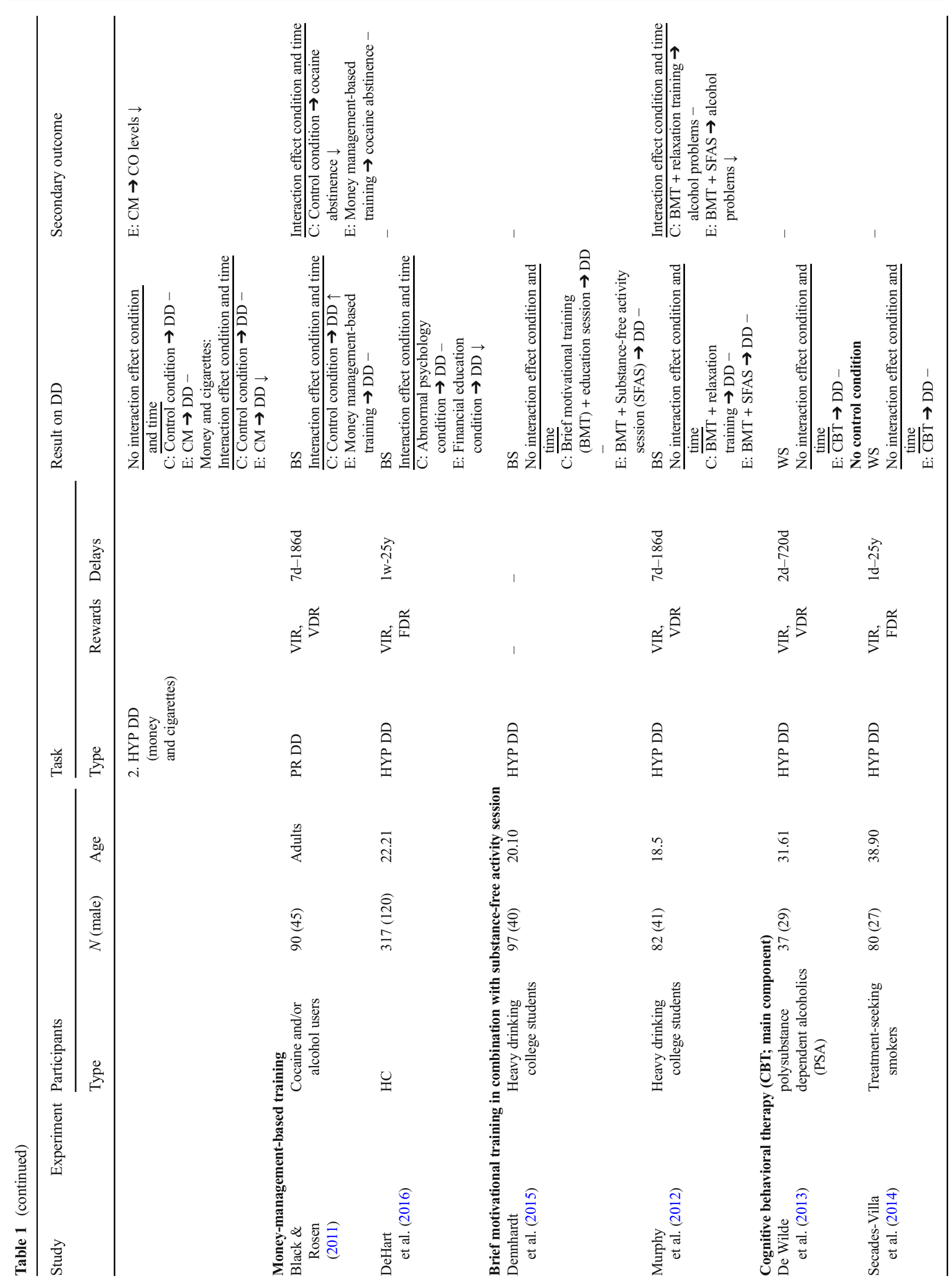




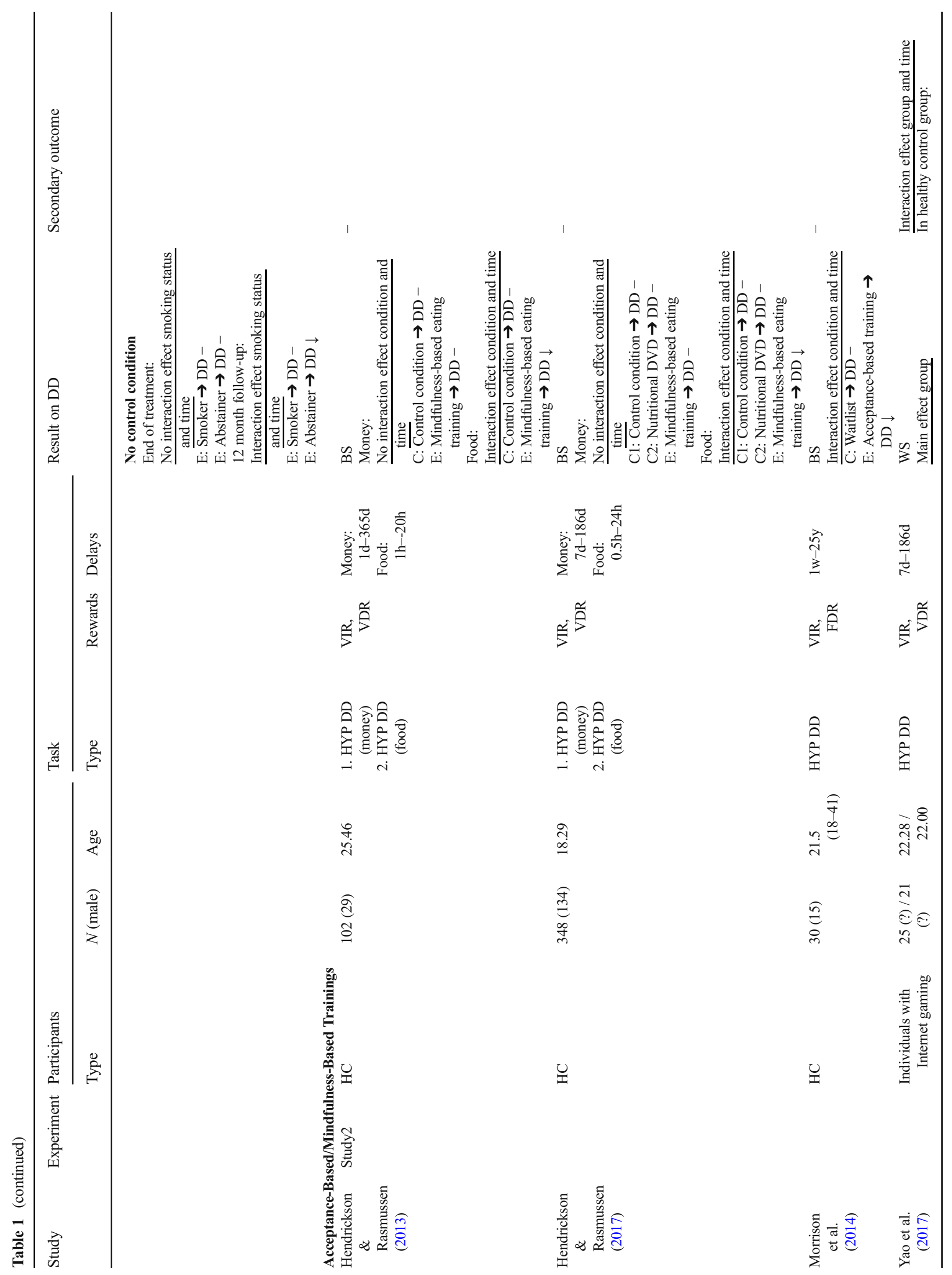




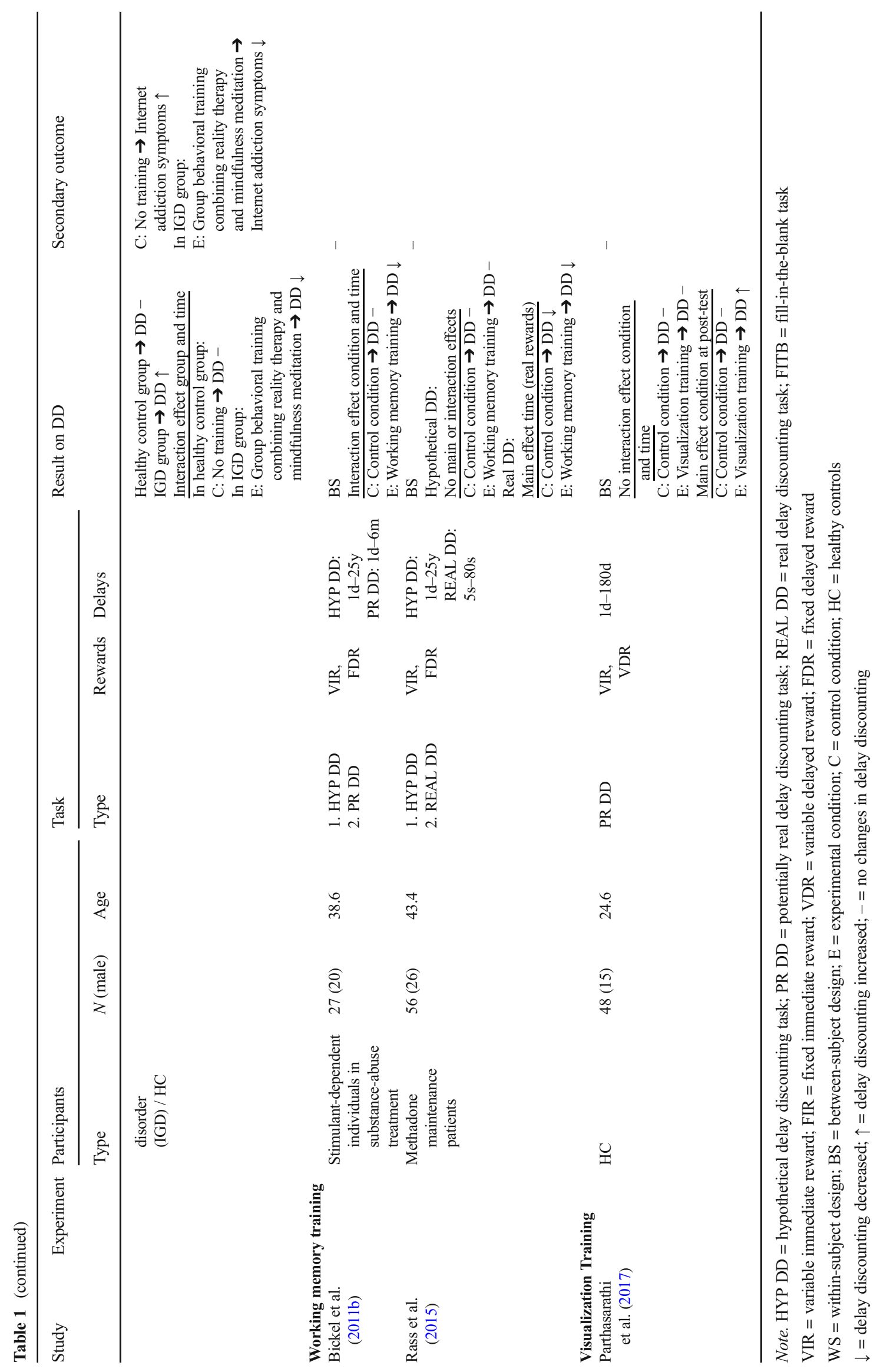




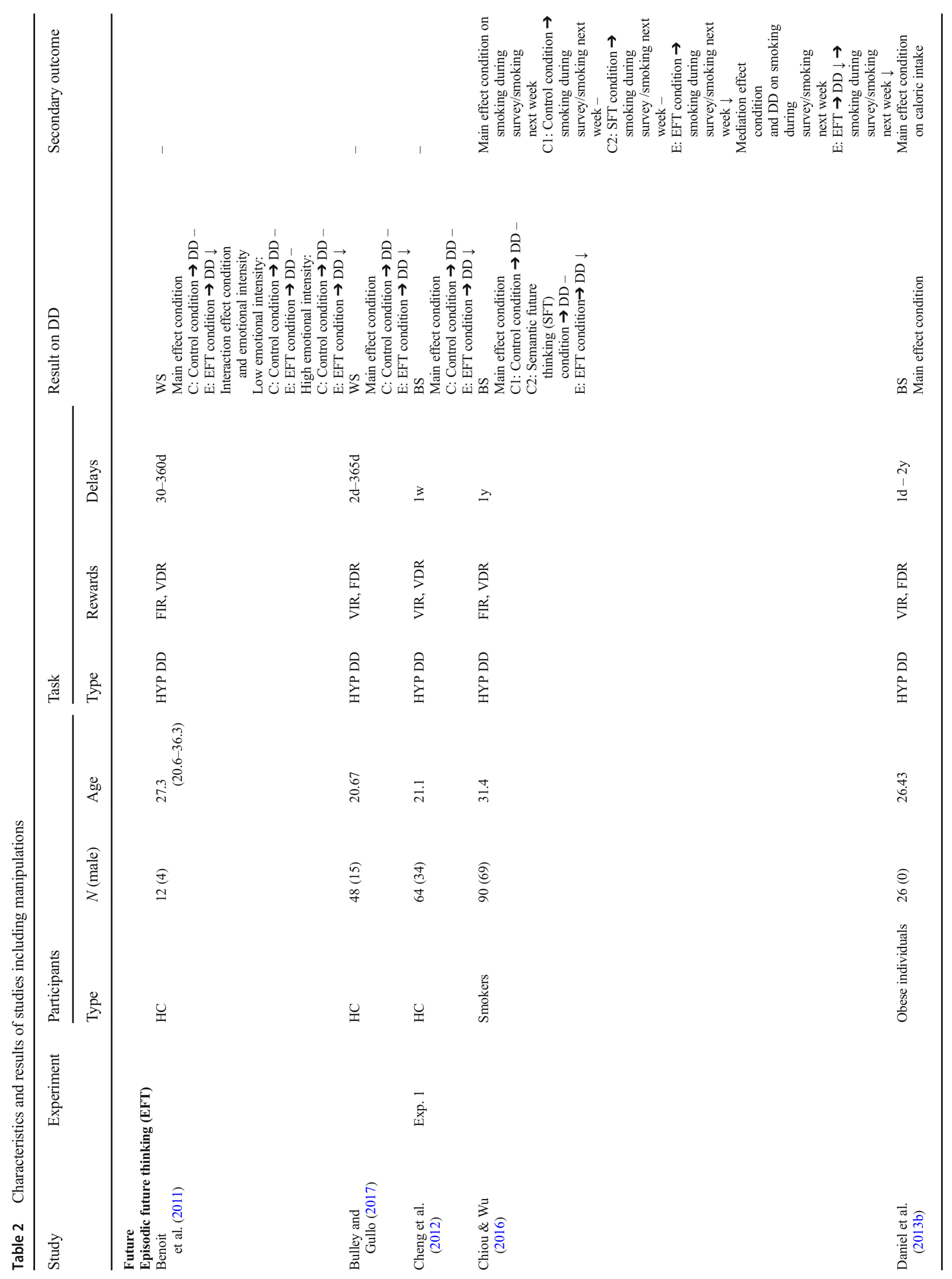




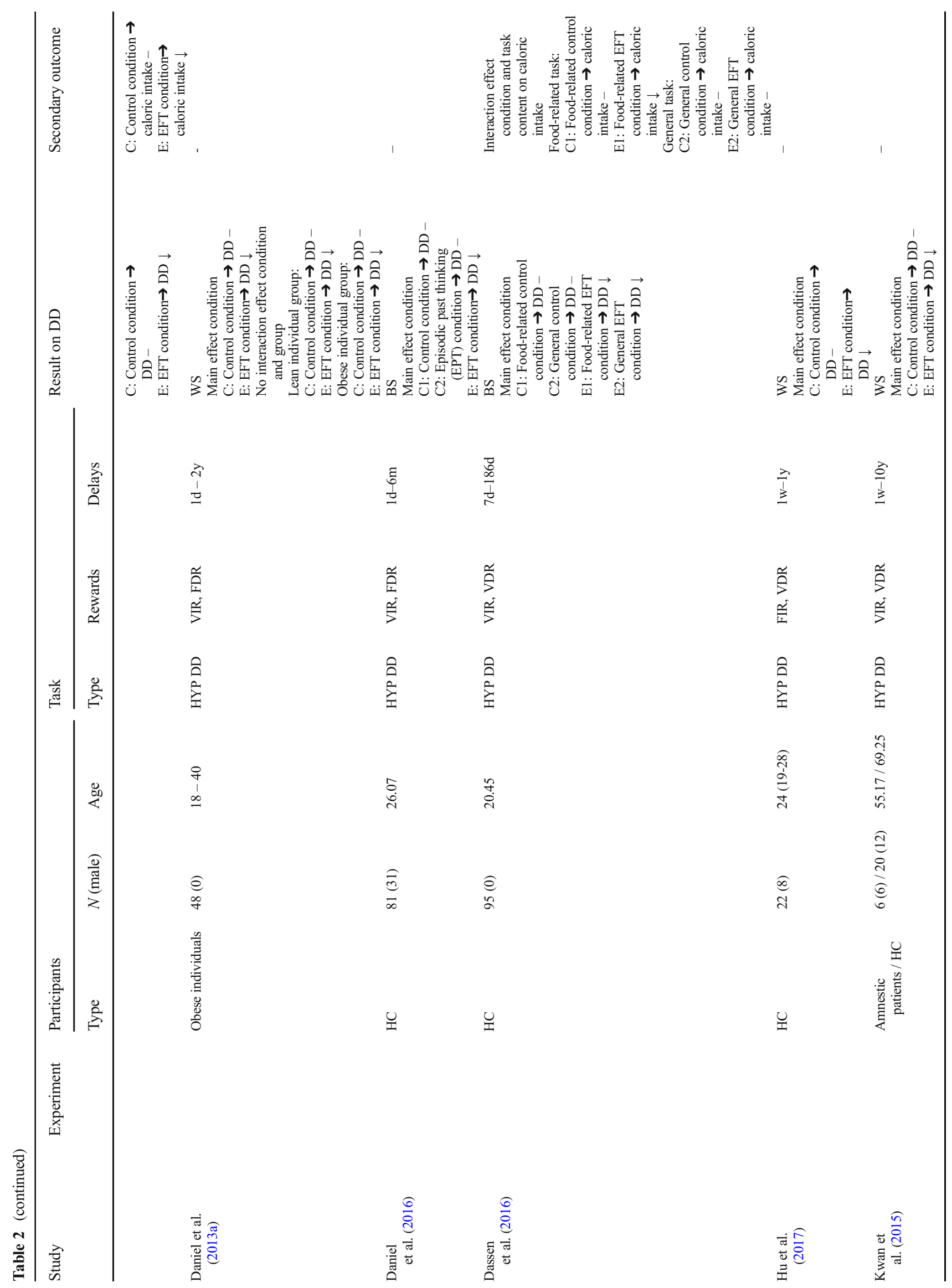




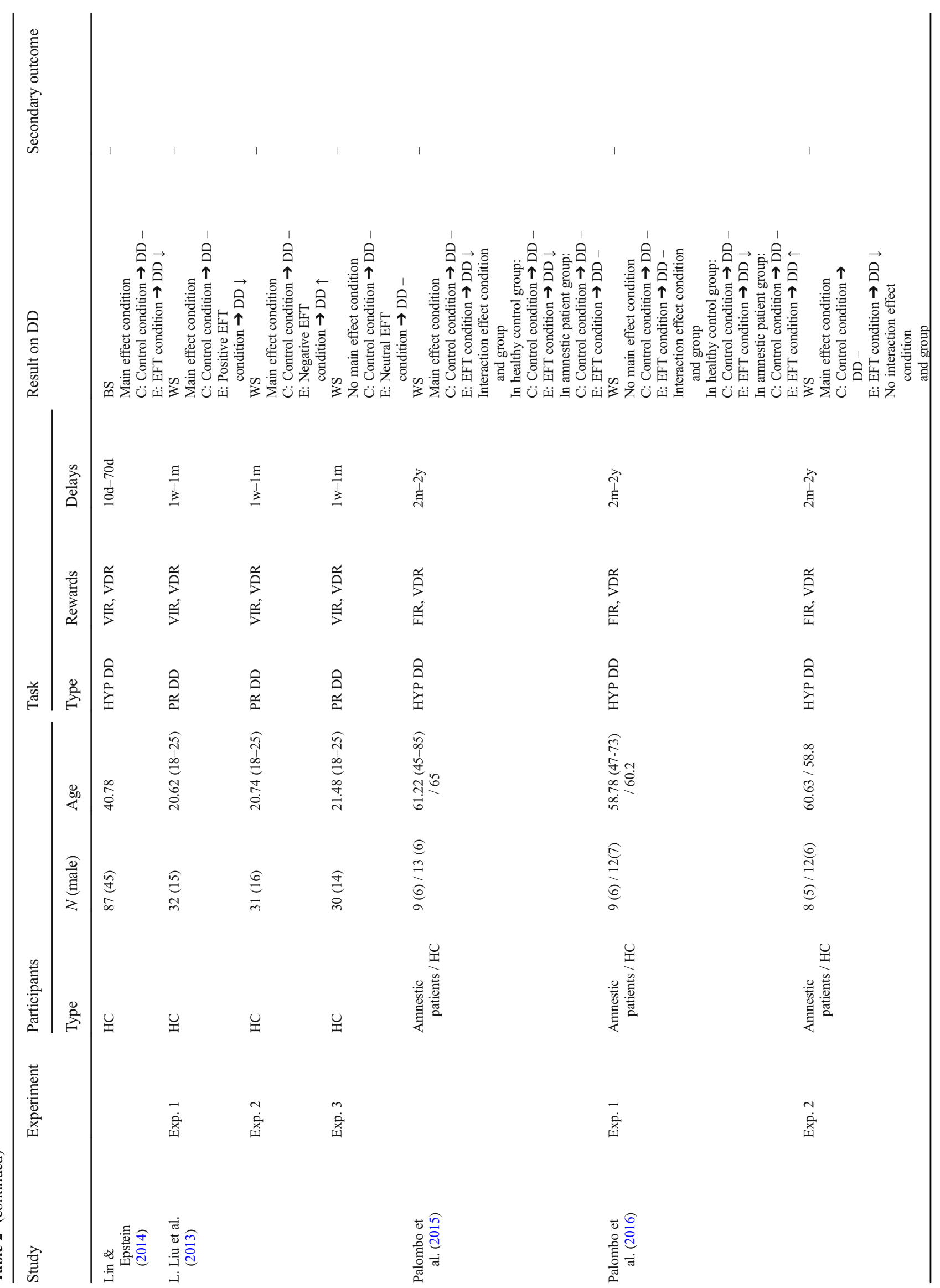




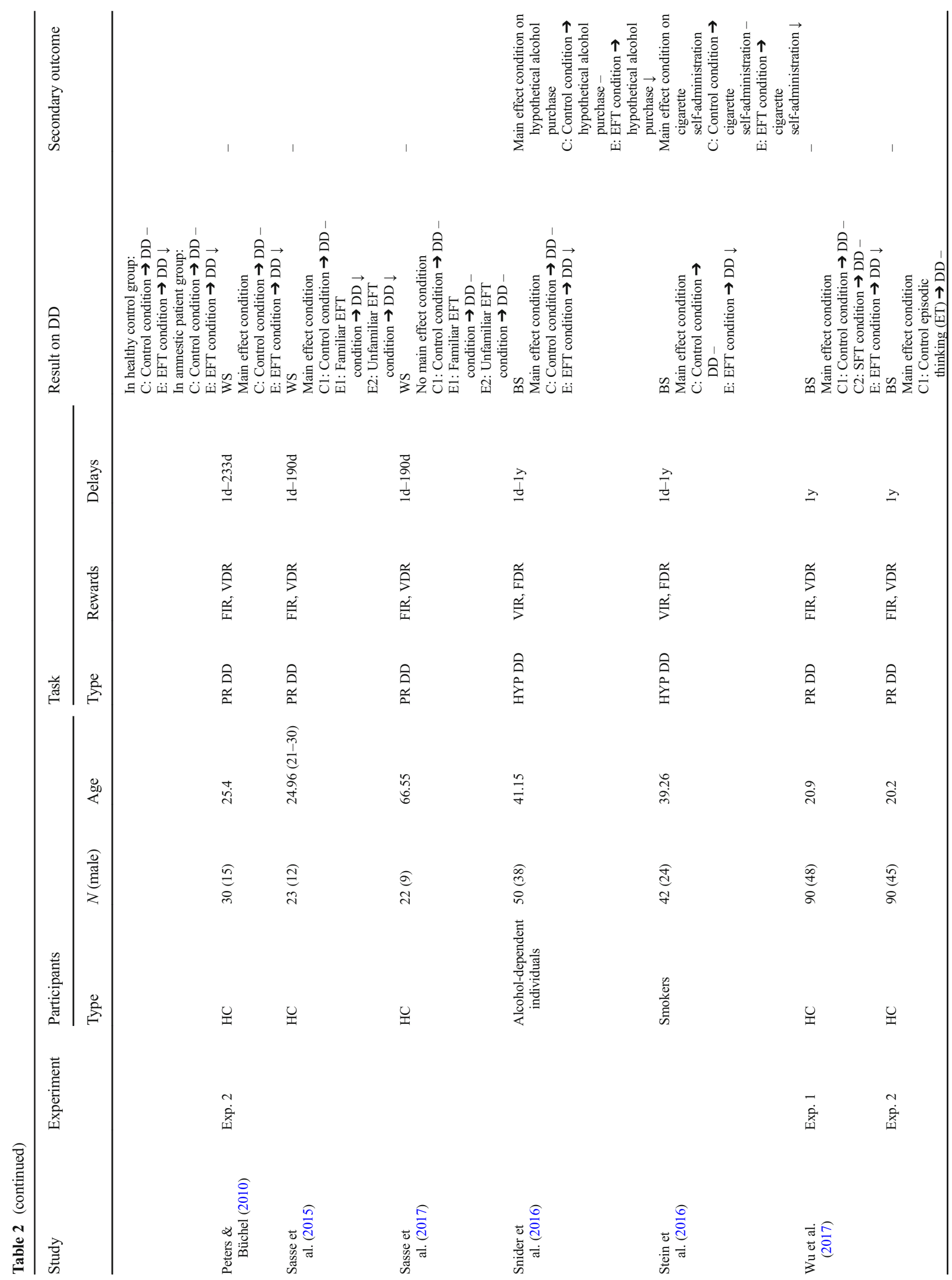




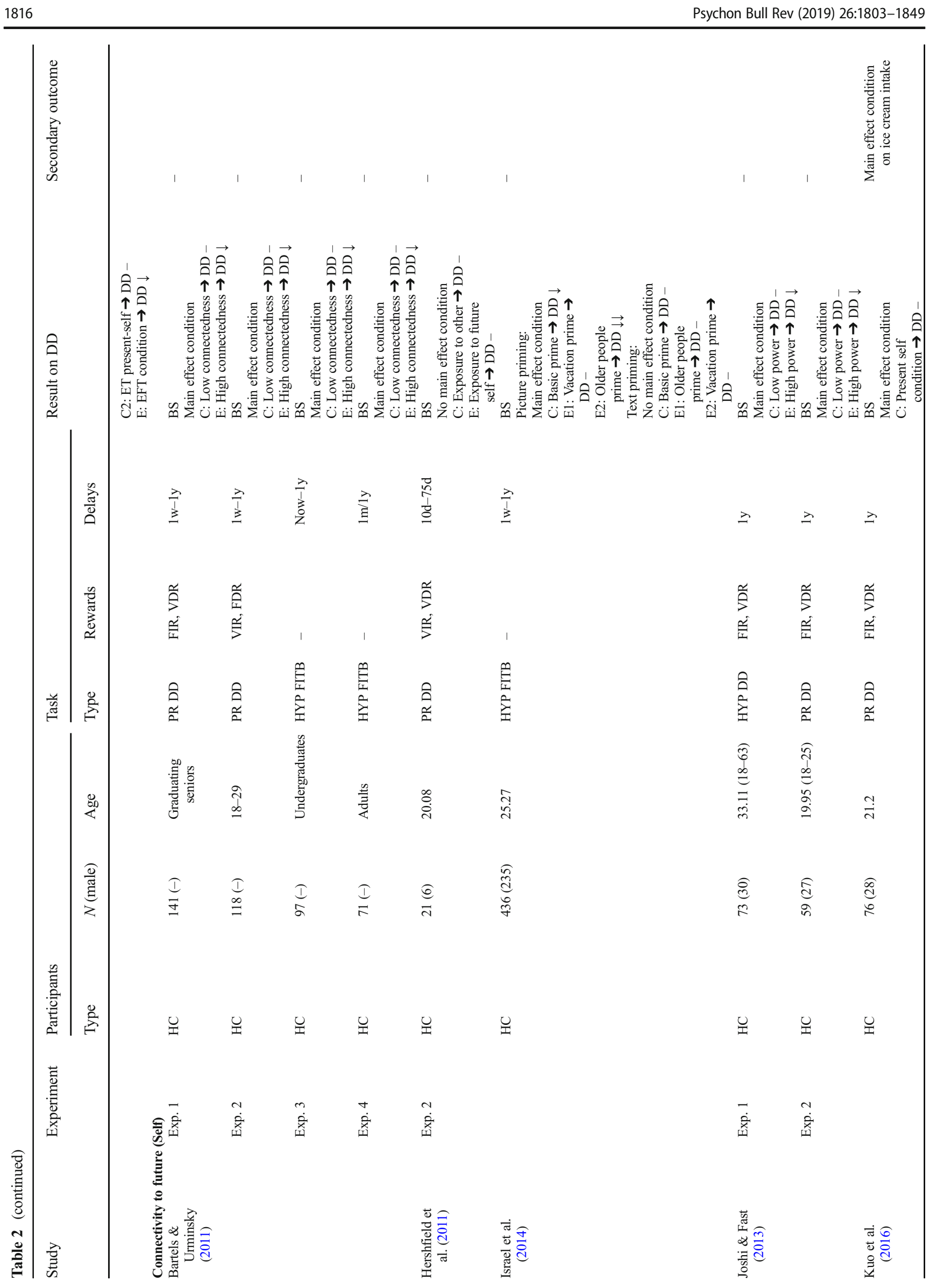

里 Springer 


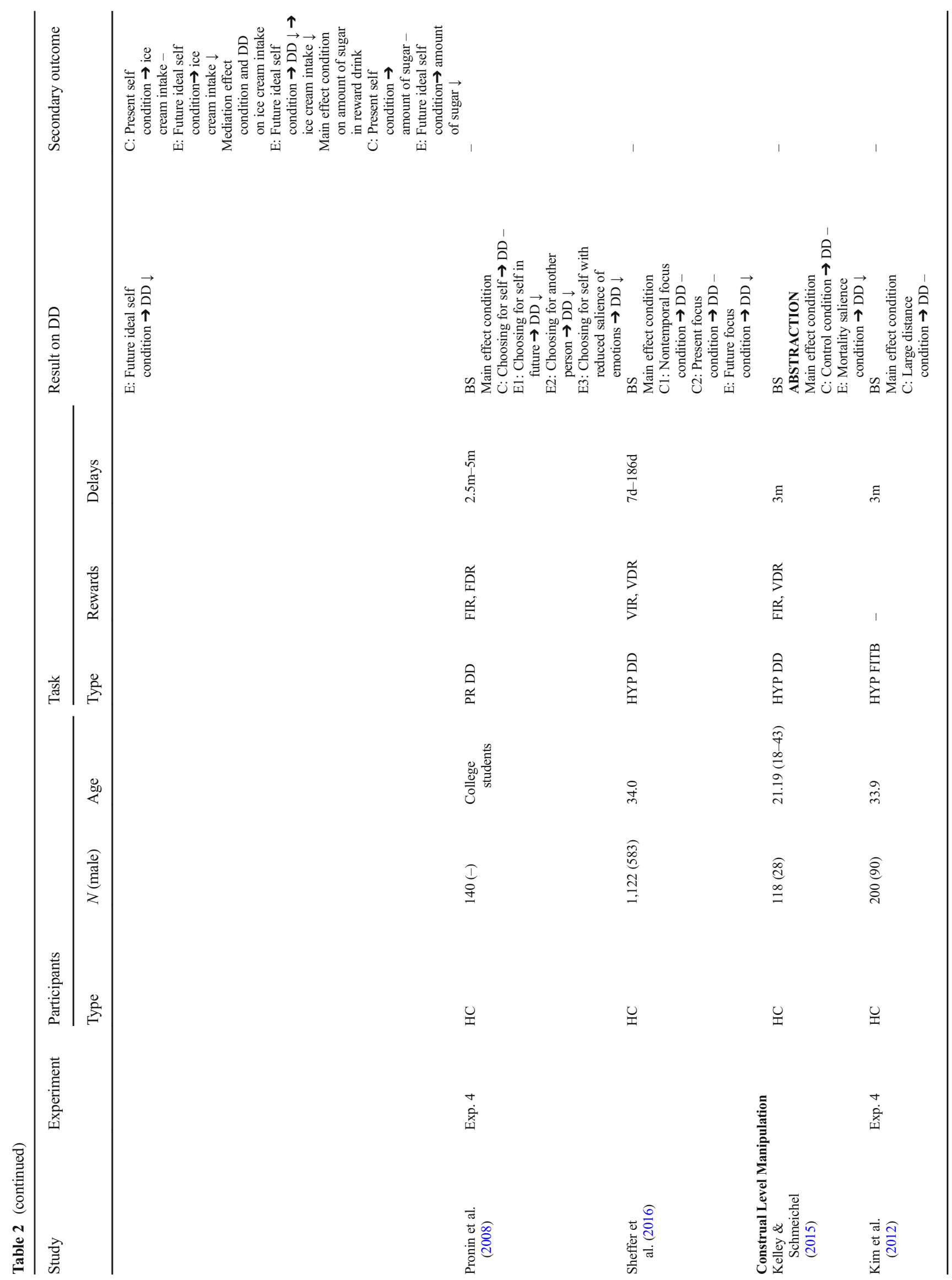




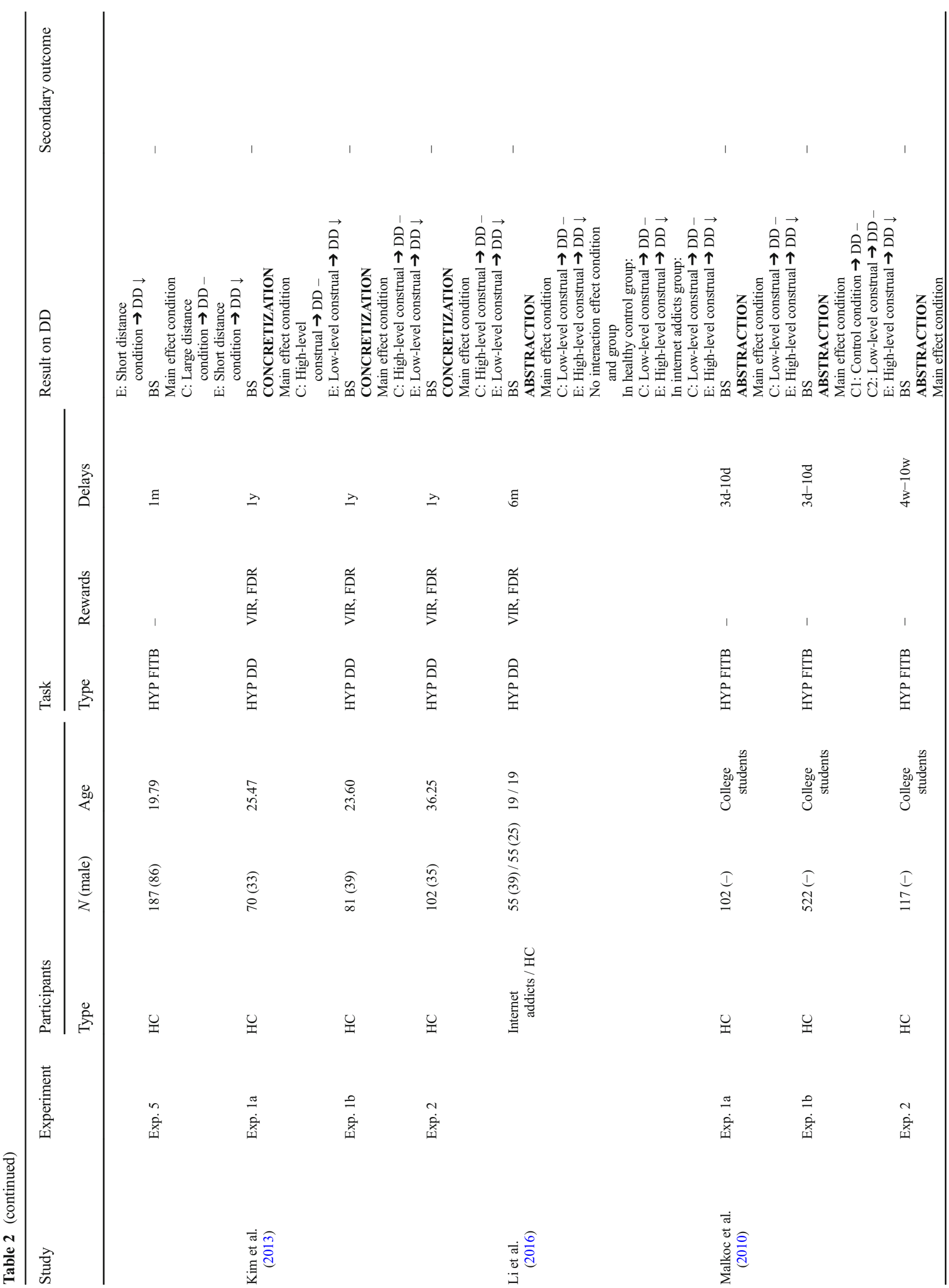




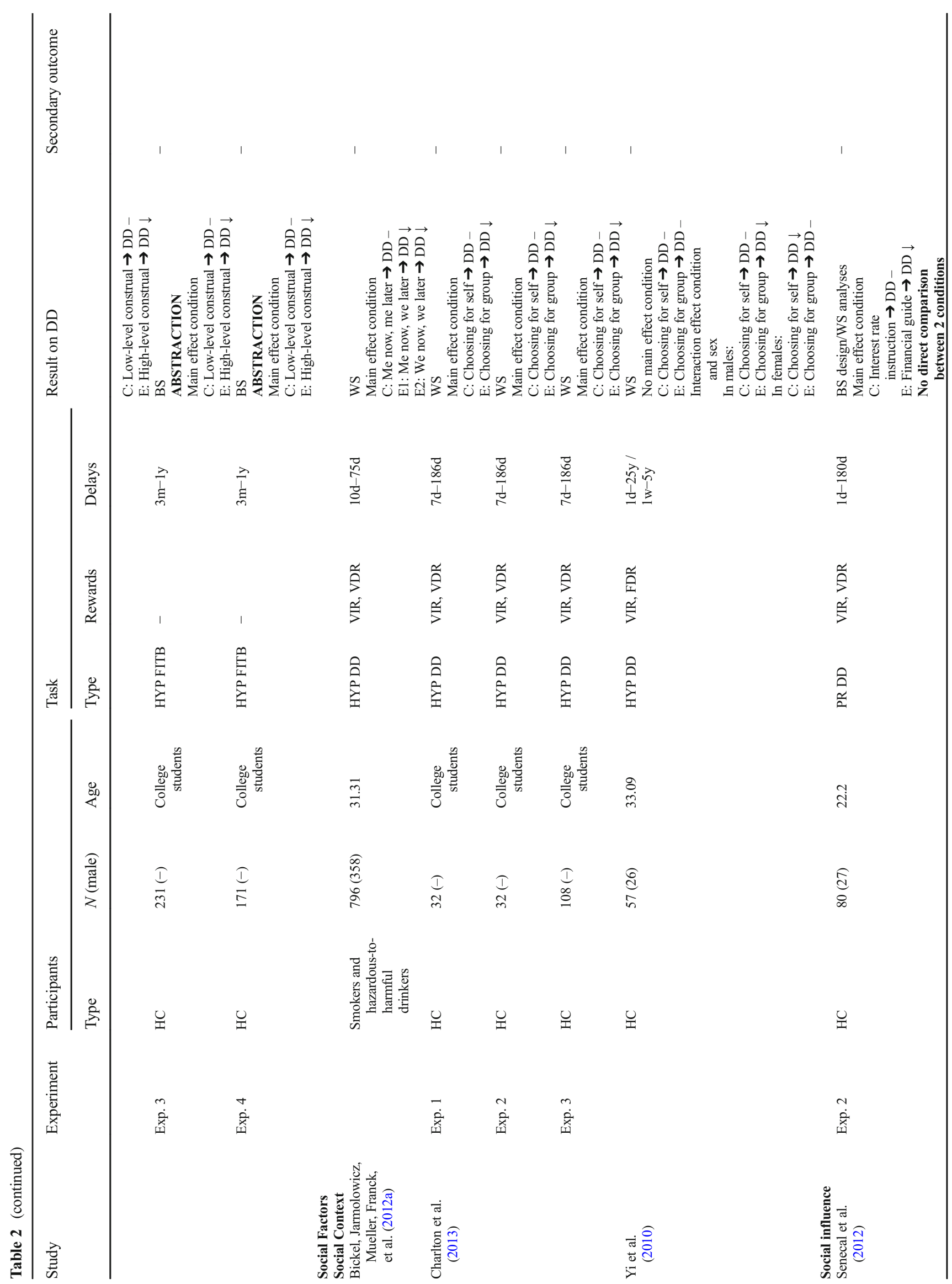




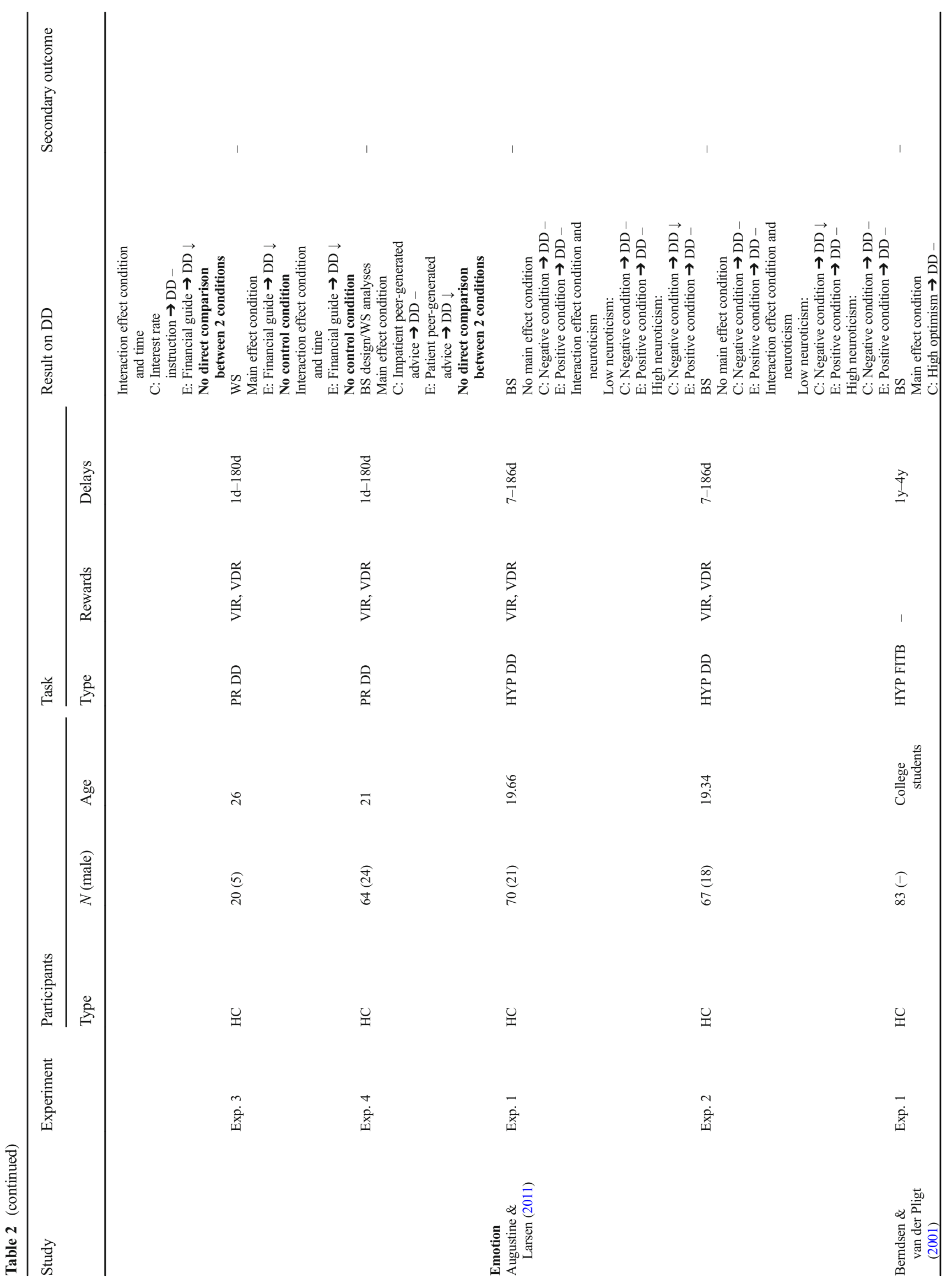




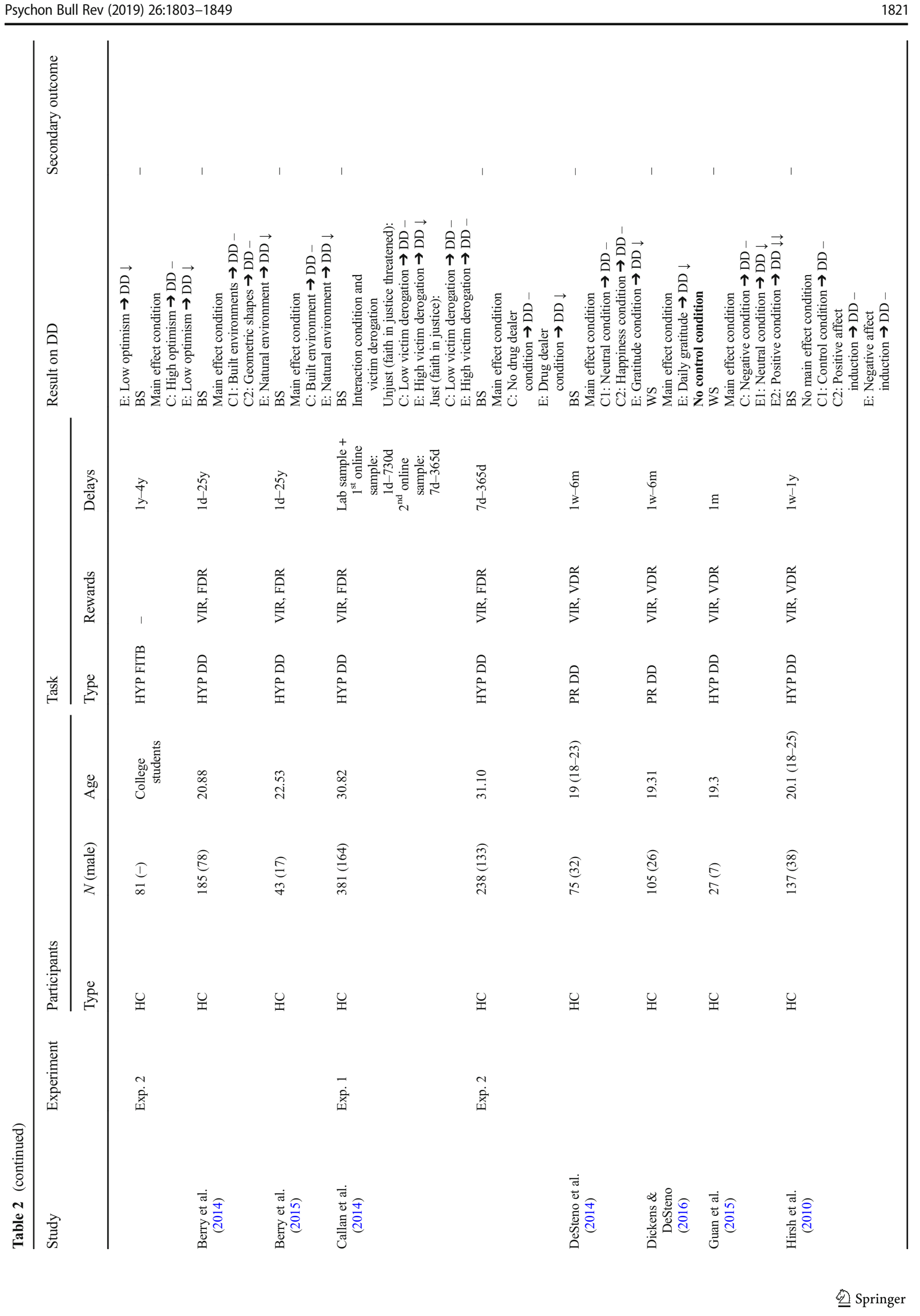




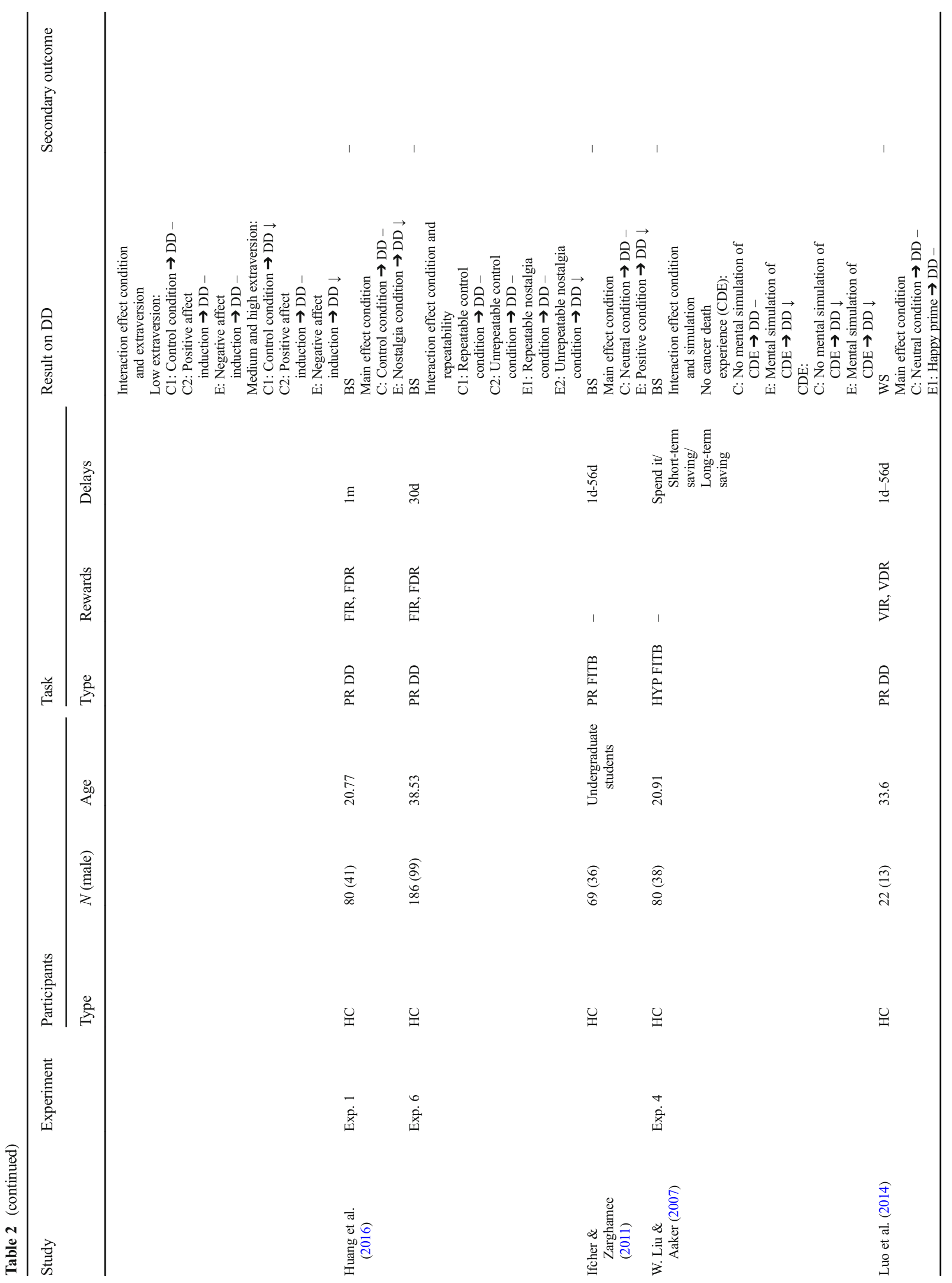




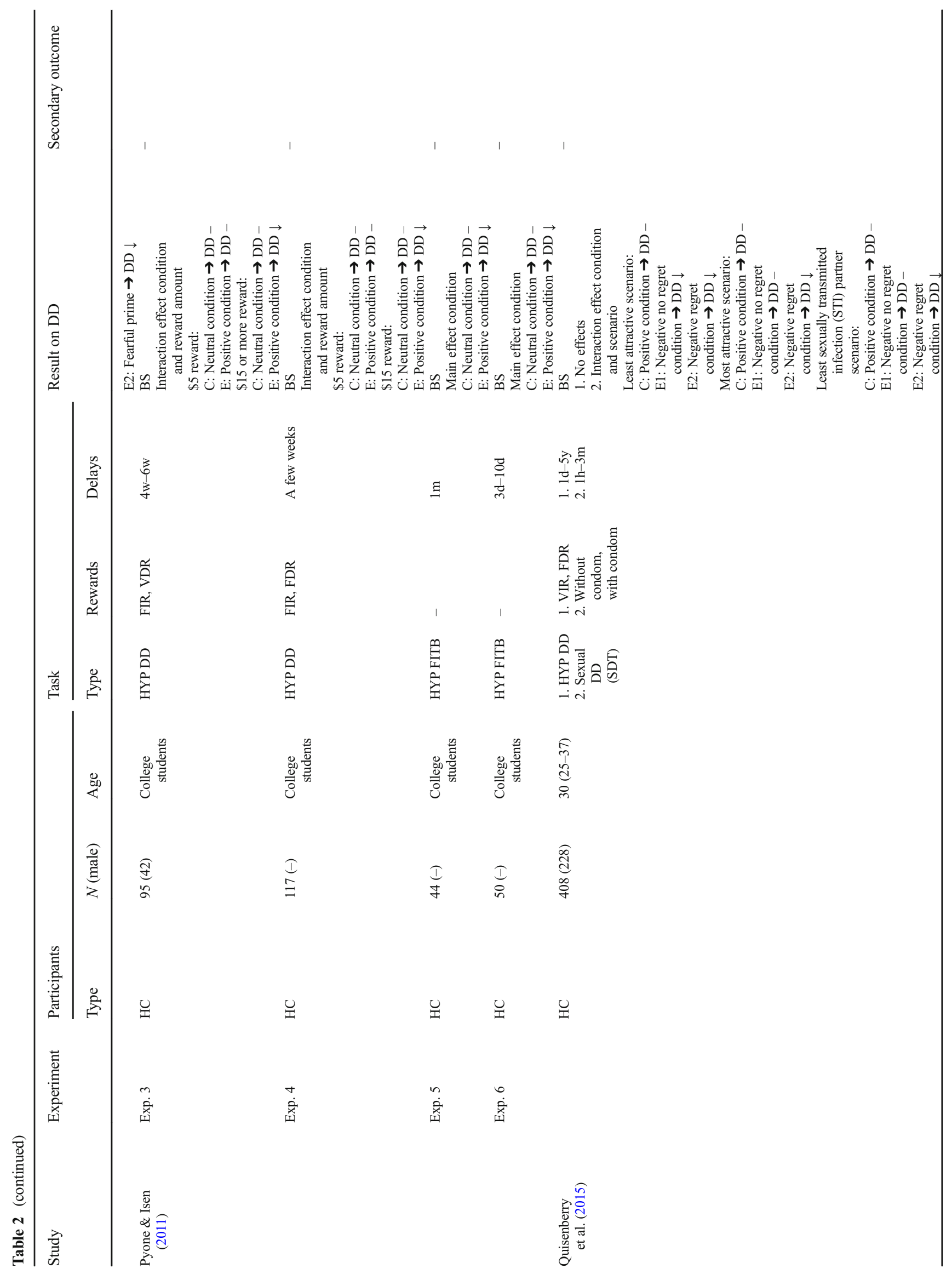




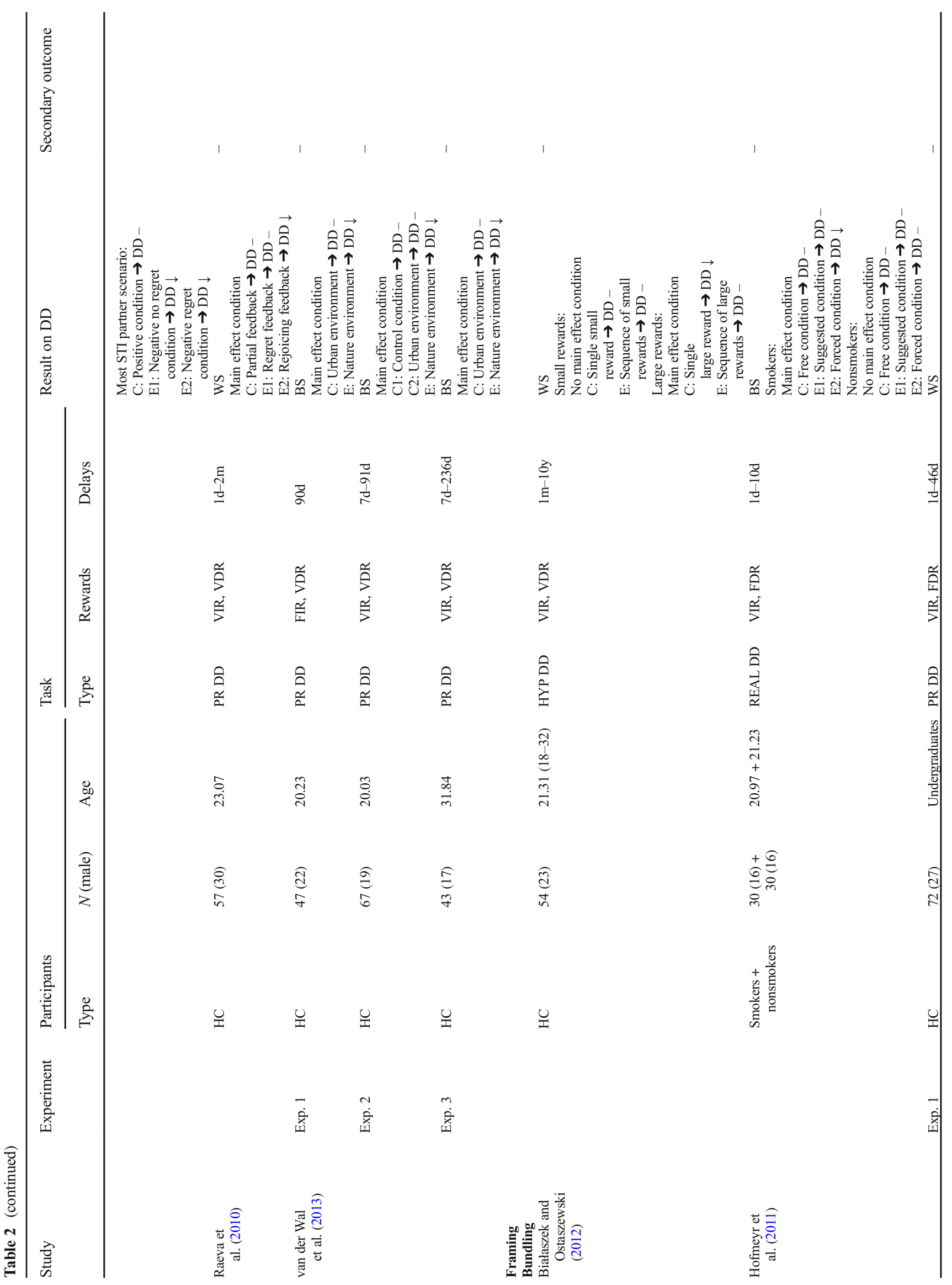




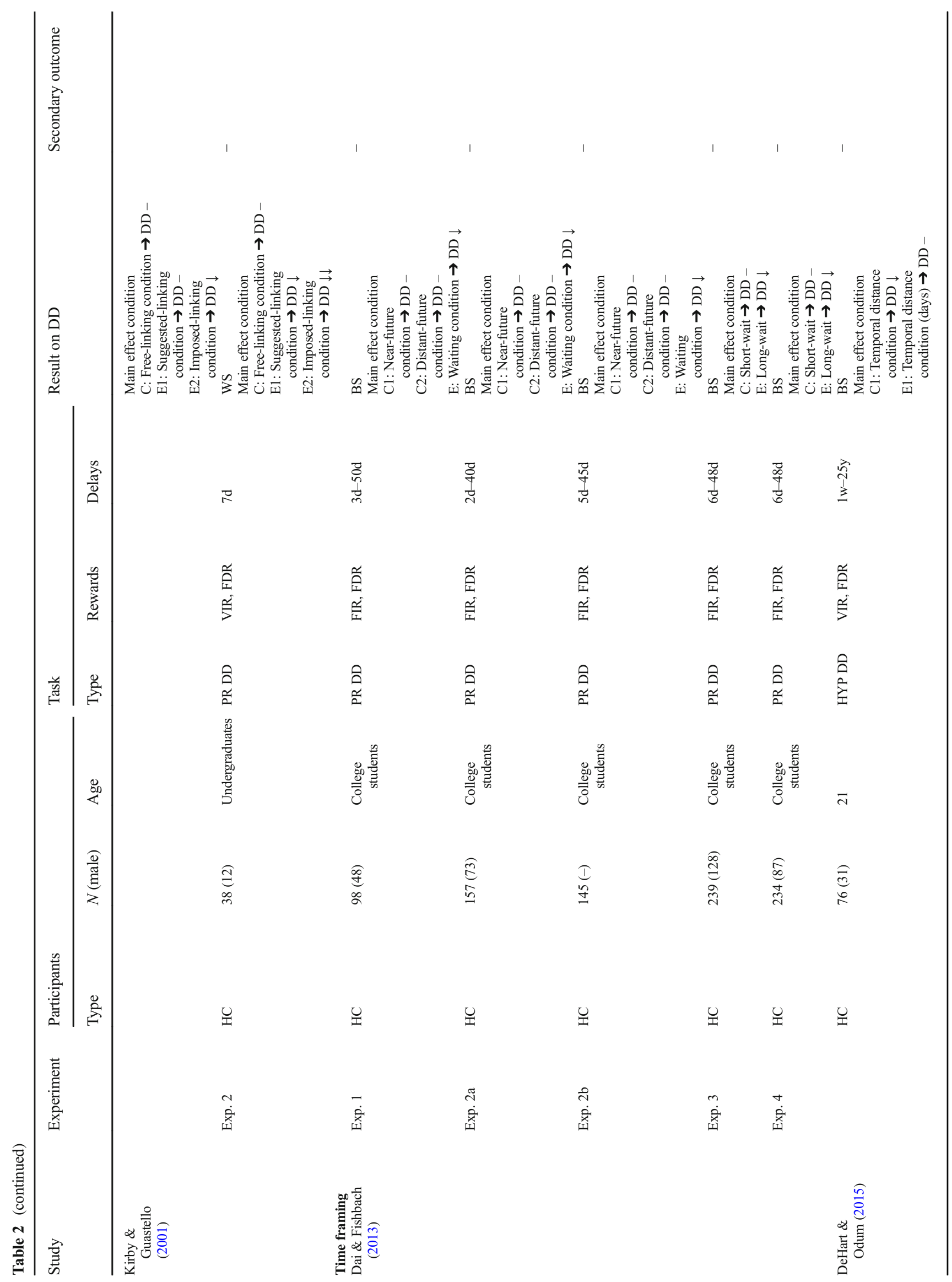




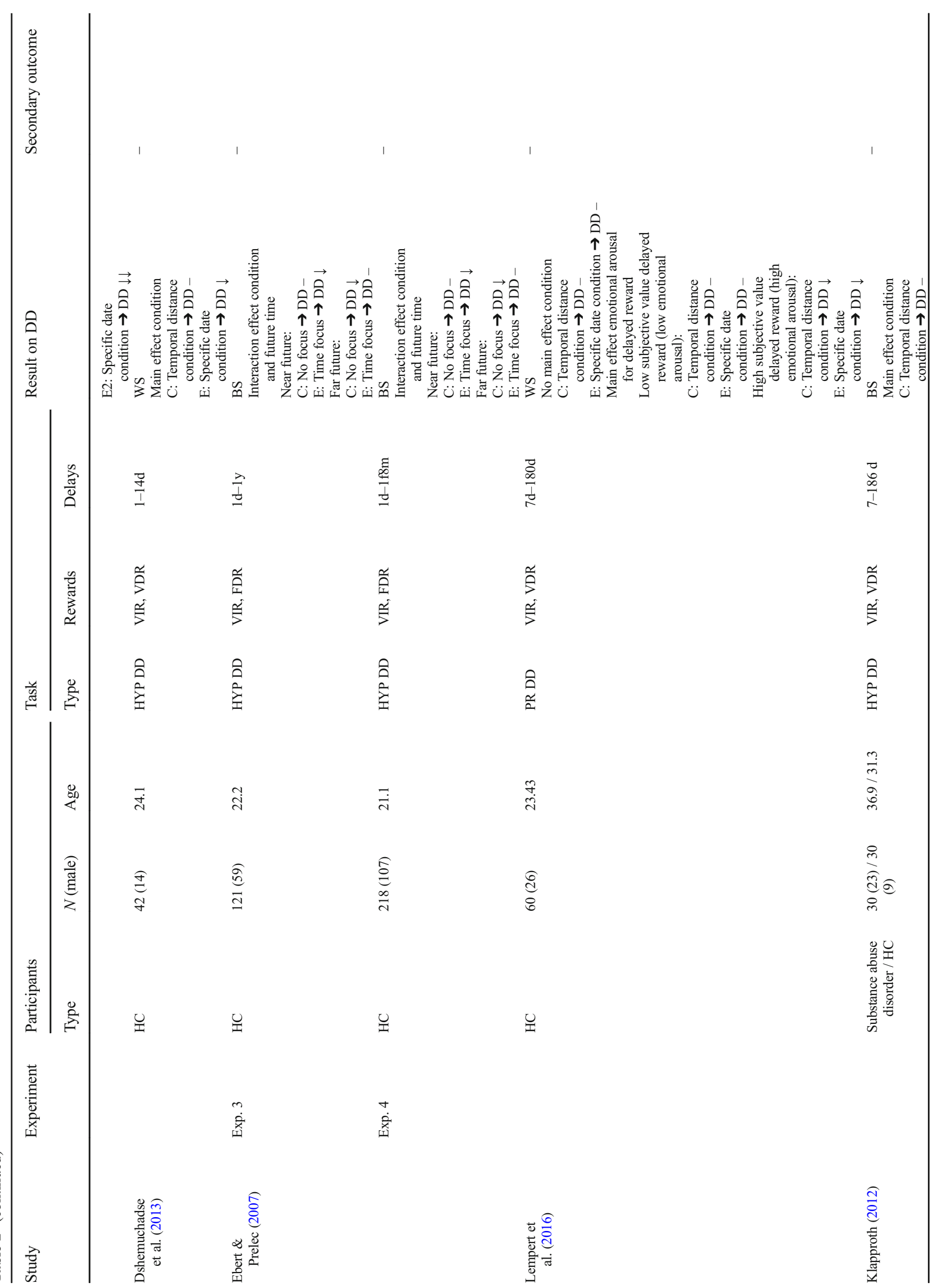




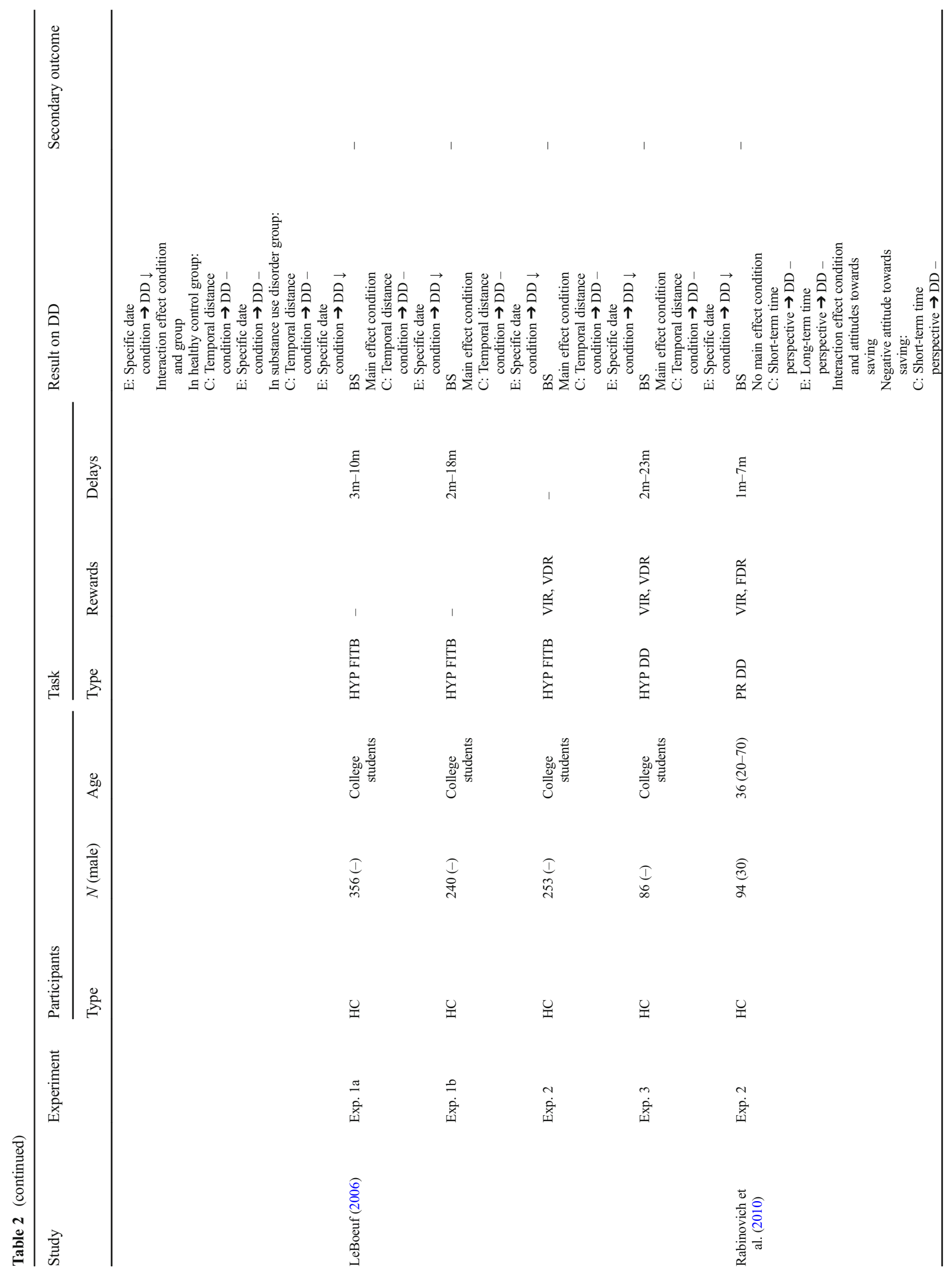




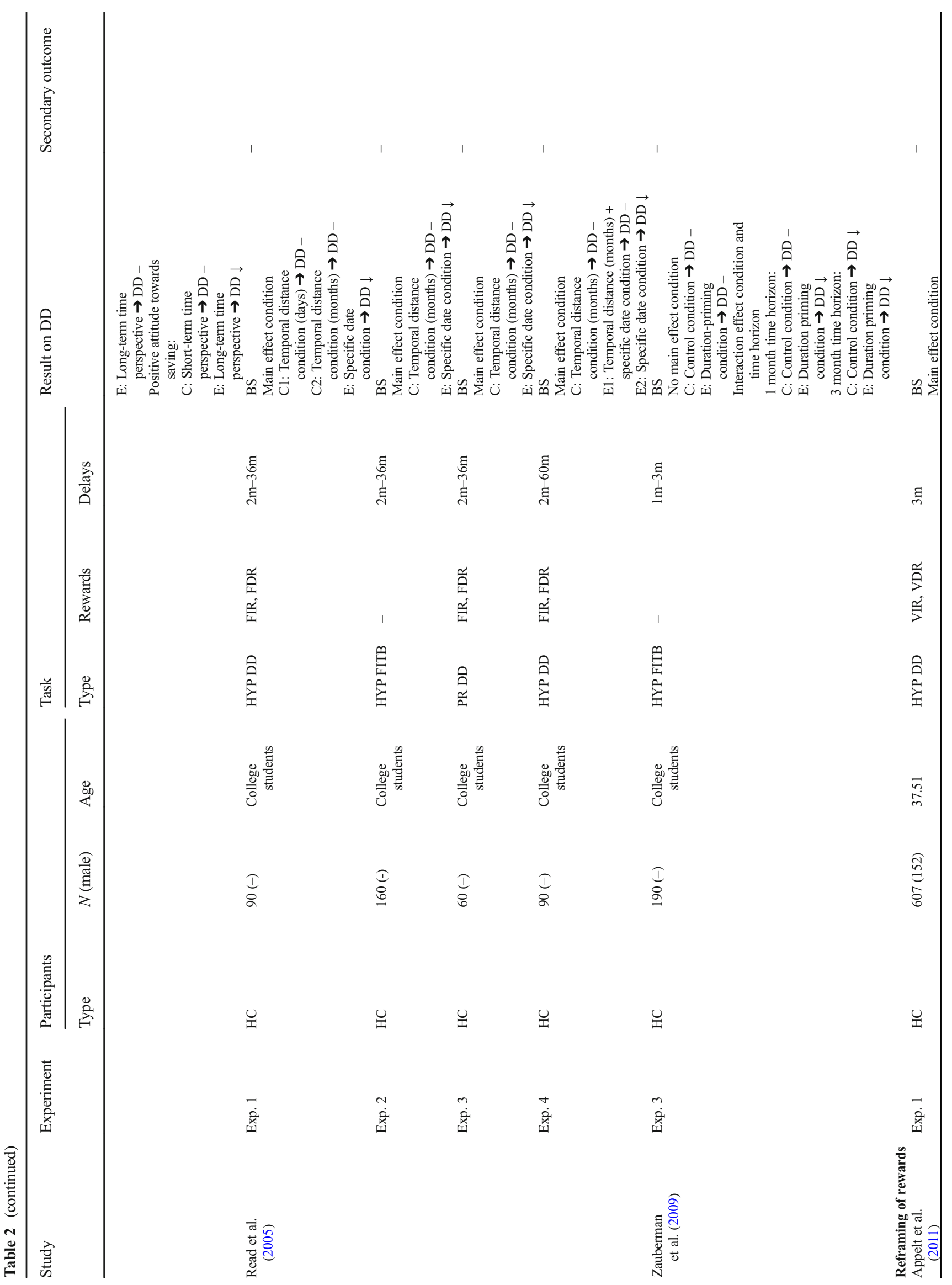




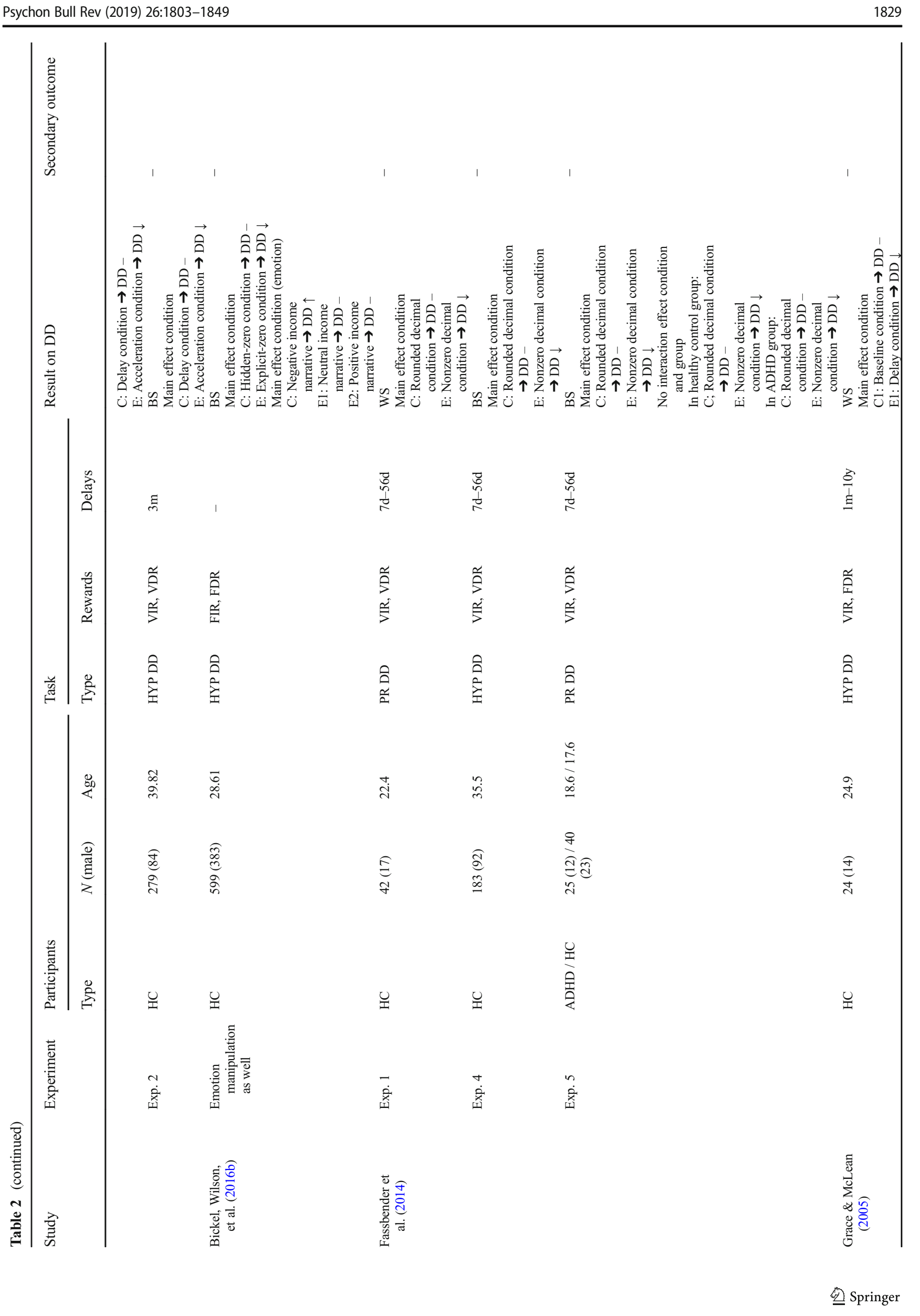




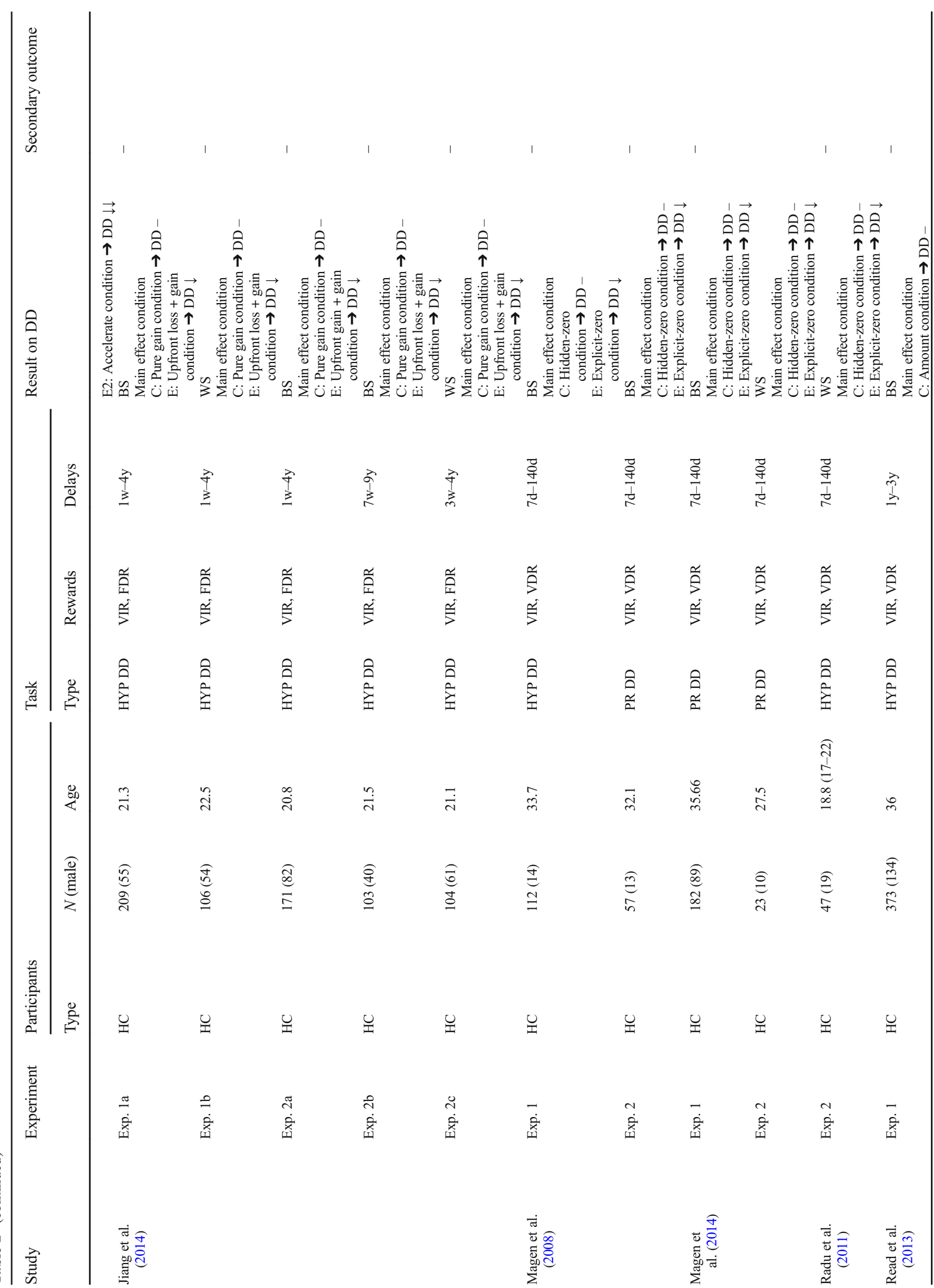




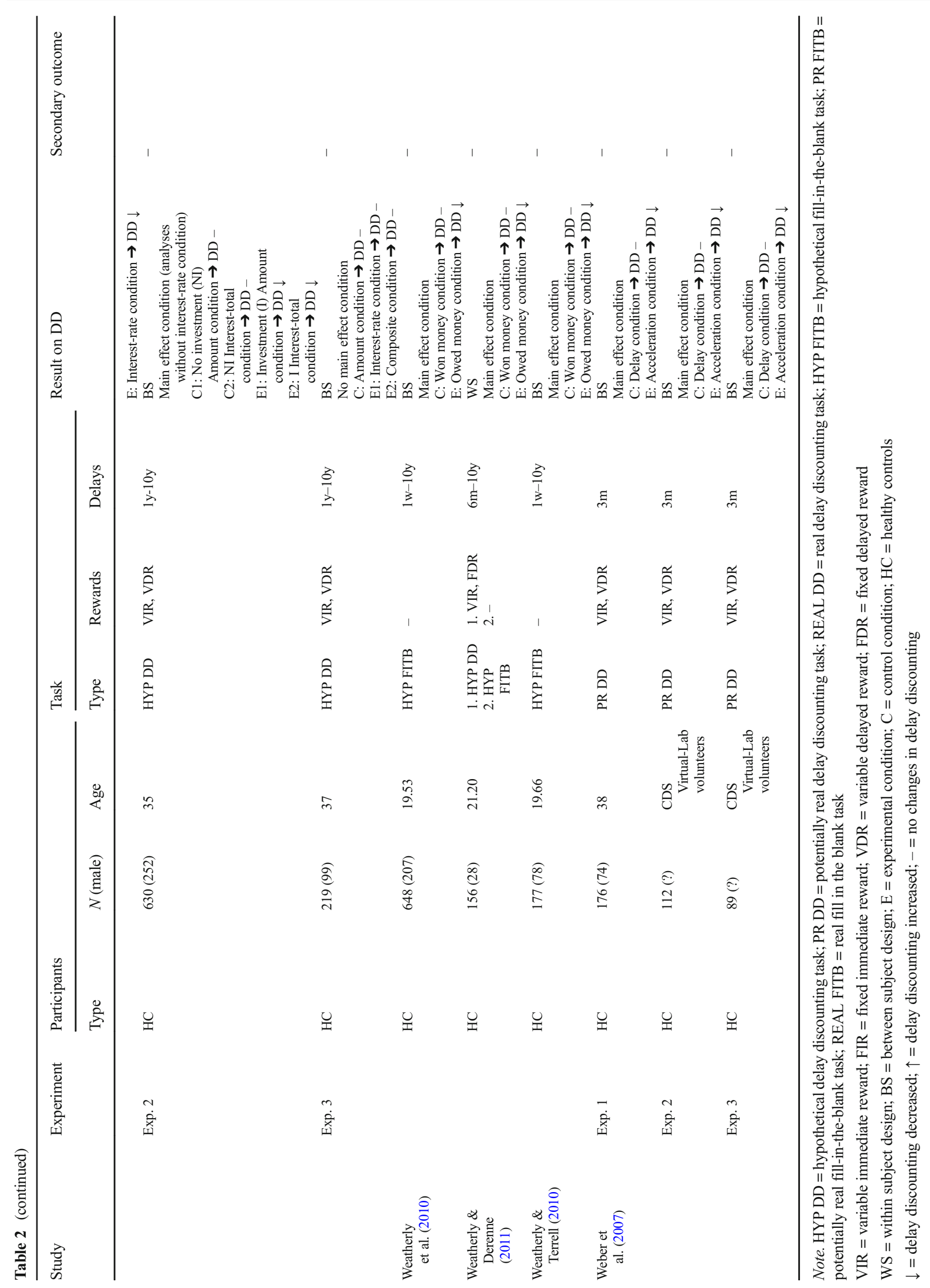


Regarding the studies evaluating the effects of manipulations on DD, $86 \%(n=114)$ found the expected reductions in DD, $13 \%(n=17)$ found null results or unexpected increases in DD and $1 \%(n=1)$ found mixed results (i.e., only effects in healthy control group, not in amnestic patients). These results indicate that DD can be decreased, showing that DD is profoundly context dependent and changeable.

\section{Trainings}

Contingency management Contingency management $(\mathrm{CM})$ is a well-researched and effective behavioral training to increase drug abstinence across substance-dependent disorders (Stanger et al., 2013). It promotes abstinence by delivering material incentives contingent on biochemically verified abstinence (Higgins, Silverman, \& Heil, 2008). Simply put, participants are paid for not using drugs. CM attempts to directly influence decision-making processes by shifting preferences for immediate rewards to delayed rewards (Stanger et al., 2013). Six studies examined the effect of a CM training, four studies included smokers (Kurti \& Dallery, 2014; Weidberg, Landes, García-Rodríguez, Yoon, \& Secades-Villa, 2015; Yi et al., 2008; Yoon, Higgins, Bradstreet, Badger, \& Thomas, 2009), one study included opioid-dependent patients (Landes, Christensen, \& Bickel, 2012), and one study included marijuana-dependent individuals (Peters, Petry, LaPaglia, Reynolds, \& Carroll, 2013). One study (16.5\%) found expected reductions in DD, one found mixed results on two different DD tasks (16.5\%), and four found null results or unexpected increases in DD (67\%). Regarding behavioral outcomes, four studies $(67 \%)$ found significant reductions in smoking behavior. None of the studies tested whether decreases in substance use were mediated by decreases in DD rates.

The four studies that included smokers or treatmentseeking smokers examined effects on both DD and smoking behavior. Yi et al. (2008) included two DD tasks-one employing monetary rewards and one employing cigarette rewards. They found that monetary as well as cigarette DD was decreased in the CM condition, whereas no changes were found in the control condition. However, the CM condition was not directly compared with the control condition in the statistical analyses. Furthermore, a decrease in carbon monoxide (CO) levels, measuring how much carbon monoxide is present in the exhaled air of the smoker as a proxy of smoking behavior (Deveci, Deveci, Açik, \& Ozan, 2004) over time was found in the $\mathrm{CM}$ condition. Yet no results on $\mathrm{CO}$ levels were provided for the control condition, which did not allow a direct comparison between both conditions.

Yoon et al. (2009) performed two DD tasks, one including monetary rewards available immediately and after a delay. The other task included cigarette rewards available immediately and monetary rewards available after a delay.
They found attenuated DD in the CM condition on the task comparing monetary and cigarette rewards, but no effects on the monetary DD task. Moreover, participants in the CM condition had lower CO levels posttraining than participants in the control condition did. Weidberg et al. (2015) did not find direct effects of $\mathrm{CM}$ on DD, but they demonstrated an increase in smoking abstinence in the $\mathrm{CM}$ condition at posttest though not at follow-up. In a study by Kurti and Dallery (2014), CM and exercise were tested in several combinations to see what effects could be found on DD. Neither exercise nor CM decreased DD rates. However, the conditions including $\mathrm{CM}$ found increased latencies to smoke and decreased total puffs in smokers compared with conditions without $\mathrm{CM}$.

Landes et al. (2012) found that DD decreased after a CM training in opioid-dependent patients; however, the control condition that only received buprenorphine also showed attenuated levels of DD. Peters et al. (2013) compared a CBTonly condition with three conditions including $\mathrm{CM}$ in marijuana-dependent individuals and found increases in DD in the CBT-only group, whereas DD rates remained stable in the $\mathrm{CM}$ conditions. Both studies did not find effects on marijuana (Peters et al., 2013) and opioid use (Landes et al., 2012).

In summary, findings regarding $\mathrm{CM}$ and its ability to decrease DD are mixed. Studies that included a substance-specific DD task (Yi et al., 2008; Yoon et al., 2009) yielded more positive effects than studies that used monetary DD tasks. The two studies with expected or mixed effects included a substance-specific DD task. These latter findings, in combination with the promising effects of CM on behavior (67\%), could be an indication that the effects of $\mathrm{CM}$ are substance specific and do not transfer to monetary DD tasks. More research is needed to confirm whether DD functions as a mediator that reduces substance use by $\mathrm{CM}$ or whether other mechanisms are at work to explain the behavioral effects.

Money-management-based training Two studies exposed their participants to some sort of money-management-based training, based on the idea that more knowledge of money management increases the salience of future rewards and makes those more concrete. One study found null results for $\mathrm{DD}$, but the expected results for cocaine abstinence; the other study found the expected reductions in DD. Black and Rosen (2011) allocated their participants either to the advisor-teller money manager (ATM) training condition - which is a multicomponent training that includes substance abuse treatment in the context of discussions on other money-management concerns - or to a control condition. Patients in the ATM condition were stimulated to create monthly budgets that reflect long-term goals, broken down into short-term spending plans. The authors found that discounting rates increased and cocaine abstinence rates decreased in the control condition and 
both discounting rates and cocaine abstinence remained stable in the ATM condition. DeHart and colleagues (DeHart, Friedel, Lown, \& Odum, 2016) tested college students that were either following a personal finance course focused on basic financial education or an abnormal psychology course. DD decreased in the financial education condition at the end of the semester, whereas there was no change found in DD rates in the abnormal psychology condition.

In summary, the two studies provide mixed evidence for decreases in DD as a function of money-management-based trainings. More research is needed to get a better understanding of the underlying mechanisms driving this effect and the relevance of this effect in clinical populations.

Brief motivational training in combination with substancefree activity session Brief motivational trainings are often used as trainings for substance-use problems, by including substance-related risks, personalized feedback about substance-use patterns, and harm-reduction strategies using a motivational interviewing style (Miller \& Rollnick, 2002). In the two studies described here, a brief motivational training was combined with a substance-free activity session (SFAS) and compared with either an education session as a control condition (Dennhardt, Yurasek, \& Murphy, 2015) or a relaxation training as a control condition (Murphy et al., 2012). SFAS was delivered to heighten engagement in substancefree alternative activities, increase the importance of academic and career goals, and draw attention to the negative link between substance use and reaching goals. Both studies did not find any effects on DD. However, Murphy and colleagues found decreased self-reports of alcohol problems in the condition that received the brief motivational training in combination with SFAS. In summary, brief motivational training in combination with SFAS do not seem to be effective in reducing DD rates. Yet there is tentative evidence suggesting that they could reduce alcohol problems.

Cognitive behavioral therapy The group-based addiction cognitive behavioral therapy (CBT) programs employed in the two experiments by De Wilde, Bechara, Sabbe, Hulstijn, and Dom (2013) in polysubstance dependent alcoholics and the study by Secades-Villa and colleagues (Secades-Villa, Weidberg, García-Rodríguez, Fernández-Hermida, \& Yoon, 2014) in treatment0seeking smokers included among other components psychoeducation, self-monitoring, coping-skills training, stress management, and relapse-prevention strategies. Both studies did not find effects of CBT on DD at posttest. Secades-Villa et al. (2014) found a difference between smokers and abstainers on DD on 12-month follow-up, suggesting that DD rates were decreased for abstainers compared with smokers, although they did not include a control condition. Both studies did not include measurements of smoking behavior to test for changes in smoking behavior over time. In summary, there is currently no evidence supporting that CBT reduces DD.

Acceptance-based/mindfulness-based trainings Most studies hypothesize that participants with heightened DD demonstrate an increased focus on immediate rewards and attempt to train participants away from the present moment to a futureorientated state. Others hypothesized that participants with heightened DD focus on the aversive properties of waiting and therefore should be trained to concentrate on the present moment and accept all feelings experienced at that moment. For example, if aversive events such as craving are intolerable, then a smoker will escape or avoid these events by smoking (i.e., choosing for the immediate reward). Acceptance-based and mindfulness-based strategies endorse an individual's willingness to experience what cannot be controlled, such as stress or craving, and support choices that are grounded in awareness of the present moment (Zettle, 2007).

Four studies included an acceptance-based or mindfulness-based approach, two of which found significant decreases in DD and two of which found mixed results. In a study by Morrison and colleagues (Morrison, Madden, Odum, Friedel, and Twohig, 2014), a brief acceptance-based training, designed to increase willingness to experience discomfort, successfully decreased DD. Yao et al. (2017) compared a healthy control sample with a sample of individuals with Internet gaming disorder (IGD) and found that discounting rates and IGD symptoms decreased in the IGD group after an acceptance-based training. Yet, at baseline, the IGD group already showed higher DD rates than the healthy control group, and no active control condition was included. These two factors make it difficult to fully interpret the findings, since decreases in DD rates can also be caused by other factors than the training itself, such as learning effects, regression to the mean, or expectations (Boot, Simons, Stothart, \& Stutts, 2013; Cohen, Cohen, West, \& Aiken, 2013). In addition, in two studies by Hendrickson and Rasmussen (2013, 2017), a mindfulness training was tested to examine the effects on impulsive choice patterns for food and money. The participants in the mindfulness training condition showed attenuated discounting rates for food, but not for money, compared with the control condition. Although the number of studies is limited, acceptance-based or mindfulness-based strategies seem to be a promising avenue to be continued in future research.

Working memory training Working memory (WM) is a core component of executive functioning and is defined as the ability to briefly hold in mind and manipulate small amounts of information to use in the execution of cognitive tasks (Cowan, 2014). WM training constitutes, for example, memorizing a sequence of numbers in the original and reverse order or 
recognizing a list of words out of bigger list of words. Research has demonstrated significant correlations between measures of WM and DD (Bobova et al., 2009; Shamosh et al., 2008). These correlations are substantiated by brain areas of functional overlap during tasks of WM and DD (Wesley \& Bickel, 2014). Improving WM could therefore possibly also decrease discounting rates. Two studies employed a WM training to reduce $\mathrm{DD}$, one with results in the expected direction on DD whereas the other study did not find any effects.

In the study by Bickel et al. (2011b) in stimulantdependent individuals during substance-abuse treatment, decreased discounting rates were found for participants in the WM training condition compared with the control condition. In contrast, Rass et al. (2015) applied almost the same WM training and did not find a difference in DD rates between the WM and control condition. Though the content of the WM training in both studies was almost the same, several other differences between studies could have caused the contradicting results. Each study included different substance-addicted population in different addiction stages (stimulant-dependent vs. methadonemaintenance patients), and the studies also differed in training dosage (Bickel et al., b: 4-15 training sessions vs. Rass et al., 2015: 25 training sessions). Furthermore, the study by Bickel et al. (2011b) included $74 \%$ males, whereas the study by Rass et al. (2015) included $46 \%$ males. In conclusion, it still has to be discovered whether WM training is effective in decreasing DD rates and what factors could possibly affect training effects.

Visualization training Some theoretical models of discounting hypothesize that delayed outcomes are less concrete or less vivid than immediate outcomes, and therefore individuals tend to prefer immediate outcomes over delayed ones (Rick \& Loewenstein, 2008; Trope \& Liberman, 2003). Increasing the ability to vividly imagine future events by visualization training could then theoretically lead to a decrease in discounting rates. Yet, the study by Parthasarathi and colleagues (Parthasarathi, McConnell, Luery, \& Kable, 2017) employed a visualization training and did not find the expected effects on DD. In a 4-week training study, participants in the visualization condition received 1-hour guided meditation sessions followed by goal-oriented guided visualization. Participants had to focus on a future-oriented goal and had to vividly imagine scenarios overcoming the obstacles in their way and experiencing the feelings associated with achieving the goal. The control group received guided relaxation, without visualization or future thinking. Based on this one study, it still has to be seen whether visualization training is effective in decreasing DD (however, see Episodic Future Thinking results below).

\section{Manipulations}

\section{Future}

Episodic future thinking Episodic future thinking (EFT) is the ability to vividly imagine the future (Benoit, Gilbert, \& Burgess, 2011) and thereby to preexperience future events (Atance \& O'Neill, 2001). Although small differences between experiments exist, most EFT manipulations ask participants to first compile a list of upcoming events (e.g., wedding, party, vacation) at several moments in time in the future and rate them on variables such as personal relevance, valence, and arousal (Peters \& Büchel, 2010). Thereafter, participants need to perform a different version of the DD task in which the amounts of money in the larger future reward were paired with a subject-specific verbal episodic tag indicating to the participants which event they had planned at the respective day of reward delivery (Peters \& Büchel, 2010). The content of control conditions differed between studies; for example, some studies asked participants to complete a standard DD task, whereas others instructed their participants to imagine recent events instead of future events. Twenty out of the 24 experiments (83\%) employing an EFT manipulation found the expected reductions in DD in the EFT manipulation compared with the control condition. Five studies (Chiou \& Wu, 2016; Daniel et al., 2013b; Dassen et al., 2016; Snider, LaConte, \& Bickel, 2015; Stein et al., 2016) also tested for effects on behavior and found reductions in smoking, caloric intake, and hypothetical alcohol purchase. For example, in the study by Daniel et al. (2013b) they found that the participants in the EFT condition showed lower DD rates and lower caloric intake, compared with the control condition.

Three experiments (13\%) did not find that EFT reduced DD and one experiment (4\%) found mixed results (i.e., DD decreased in healthy control sample after EFT, but not in the amnestic patients' sample). In Experiment 2 of the study by L. Liu, Feng, Chen, and Li (2013), a negative future thinking manipulation (i.e., EFT manipulation with negative events to be imagined) was tested against a control condition. DD rates increased in the negative EFT condition. In Experiment 3, a neutral future thinking manipulation (i.e., EFT manipulation with neutral events to be imagined) was tested against a control condition, and no differences were found between both conditions. The authors concluded that the valence of the imagined future reward matters for the effectiveness of the manipulation, since a decrease in DD rates was found in Experiment 1, where a positive future thinking manipulation (i.e., EFT manipulation with positive events to be imagined) was employed. In Experiment 1 of the study by Palombo and colleagues (Palombo, Keane, \& Verfaellie, 2016), amnestic and healthy control subjects performed either a standard DD task (control condition) or a DD task with 
EFT manipulation. EFT reduced DD in healthy control subjects, but not in amnestic subjects.

In conclusion, EFT manipulations are one of the more thoroughly researched categories, and the results on DD and behavior are mostly positive and promising. Nevertheless, the few studies that reported null findings suggest that EFT needs to be positive in valence, and individuals' episodic memory needs to be intact for the manipulation to be effective.

Connectivity to future (self) Manipulating one's connectedness to the future (self) could lead to more patient behavior, based on the notion that a higher connectedness to the future (self) implies a greater willingness to defer benefits to the future self. Eleven experiments tested manipulations to heighten connectivity to the future (self) and $10(91 \%)$ were effective in reducing DD rates. Bartels and Urminsky (2011) employed multiple experiments and discovered that directly informing people that identity is constant over time and implicitly inducing the opinion that personality stays the same over time reduced DD. Kuo, Lee, and Chiou (2016) showed participants with the intention to lose weight either a weight-reduced "ideal" self or their present self in a virtual reality environment. Compared with the control group, participants who viewed their weight-reduced avatars showed attenuated DD. Furthermore, participants in the weight-reduced condition also ate less ice cream in a taste test and were more likely to choose a sugar-free drink as a reward, and this effect was mediated by discounting rate.

In an experiment by Sheffer et al. (2016), participants were exposed to a set of words with either a present focus (PF; i.e., instant), future focus (FF; i.e., self-control), or nontemporal focus (NTF; i.e., pale). Participants in the FF condition exhibited significantly lower discounting rates than those in the PF or NTF conditions. Israel, Rosenboim, and Shavit (2014) tested a priming manipulation, where they expected attenuated DD when participants were primed with older people (as a proxy for their own older selves). Participants either saw pictures of a vacation, older people, or were not exposed to any prime. The older people prime resulted in attenuated DD, whereas the vacation prime resulted in heightened DD. Pronin and colleagues (Pronin, Olivola, \& Kennedy, 2008) found that choosing for your future self attenuated DD in comparison with choosing for the self.

In two experiments by Joshi and Fast (2013), participants were manipulated by giving them the role of a manager, or they had to think about an event where they had power over somebody else. The authors hypothesize that people with high power report higher connectedness to their future selves as compared with people with less power, and therefore show lower DD rates. Both experiments confirmed this hypothesis by significant differences between the high and low power conditions, with participants in the high power condition showing lower DD rates.
One experiment (9\%) showed a trend toward a decrease in DD $(p=.056)$, but did not convincingly show effects of the connection to future (self) manipulation on DD. In the experiment by Hershfield et al. (2011), participants in the experimental condition saw an avatar of their future self in a virtualreality environment, whereas in the control condition participants saw an aged avatar of someone else.

In summary, connectivity to future (self) manipulations can be promising in reducing DD rates. However, more research into the best method and doses to create a connection to the future (self) is needed to support these initial findings.

Construal level manipulation Construal level theory (CLT) proposes that temporal distance alters people's responses to future events by systematically changing the way people mentally represent those events (Trope \& Liberman, 2003). When temporal distances are larger, events are more likely to be represented in abstract terms that capture their central features (high-level construals) than in more concrete and incidental terms (low-level construals). The studies by Kelley and Schmeichel (2015), Li et al. (2016), and Malkoc, Zauberman, and Bettman (2010) tested the hypothesis that higher-level construals could lead to more patient behavior. This hypothesis is grounded in the argument that if a bias to the present is driven by contextual and concrete representations, then endorsing an abstract mindset should decrease the extent of these representations and thus attenuate delay discounting (Malkoc et al., 2010). All manipulations used in these studies tried to induce a higher-level construal by enhancing an abstract mindset - for example, by semantic priming of abstract and concrete words (Malkoc et al., 2010). All seven experiments found the expected effects, meaning that more abstract mindsets attenuated DD.

In contrast to the abovementioned experiments, H. Kim, Schnall, and White (2013; Studies 1a-b, 2) tested the hypothesis that lower-level construals could lead to more patient behavior. The rationale behind this hypothesis is that the more detailed information is available, the more a future event can be construed in a concrete way, corresponding to a low-level construal. In all three experiments, participants were willing to wait longer as they were offered a trip to Paris with the value of the monetary reward, instead of a monetary reward itself. As more details were given about the trip, such as sightseeing possibilities and accommodations, the effect was even stronger, suggesting that a more specified event increases patience. The effects found in the experiments of $\mathrm{H}$. Kim et al. (2013) come close to those found in the EFT and connectivity to future (self) experiments. Different theoretical frameworks and methods are used, but in the end the future event is made available and more concrete to the participant.

In addition to temporal distance, spatial distance can also influence subjective judgment of future time, an instance of metaphoric transfer (B. K. Kim, Zauberman, \& Bettman, 
2012). According to this theory, spatial distance will influence how long or short individuals judge a future time to be, when spatial distance information is available in a temporal judgment context and is associated with the judgment of future time. For example, an individual in Los Angeles may perceive the same 6-month duration from today to be longer when she is expecting to be in New York 6 months later than when she is expecting to be in San Francisco. In two experiments by B. K. Kim et al. (2012), spatial distance was manipulated by instructing participants to either mentally imagine two locations far away from each other or close to each other. Short spatial distance manipulation reduced DD, thus a smaller spatial distance between two locations leads to less delay discounting in intertemporal choices (B. K. Kim et al., 2012).

In conclusion, both abstract and concrete mindsets, including mentally imagining a smaller spatial distance, seem to be effective in decreasing DD rates. The findings regarding the concrete mindset fit the findings of EFT and connectivity to future (self) manipulations.

\section{Social factors}

Social context The presence of a social context could influence decision-making, based on the rationale that when an individual makes a choice on behalf of their group (i.e., including themselves), they prefer alternatives geared towards the group's long-term benefit (Bickel, Jarmolowicz, Mueller, Franck, et al., 2012a). Five experiments tested effects of the presence of a social context on $\mathrm{DD} ; 80 \%(n=4)$ found positive effects on DD, whereas $20 \%(n=1)$ did not find main effects of condition on DD. Experiments that found positive effects were conducted by Charlton et al. (2013). In their DD task, participants had to make choices for themselves and for a group of people, with the amount of money that an individual could earn being constant. Situations where people had to make choices for themselves were related to less patient choices than situations where people made decisions for the whole group. In comparison, Yi et al. (2008) employed the same manipulation, but did not find a positive effect of choosing for the group over choosing for the self. Finally, Bickel, Jarmolowicz, Mueller, Franck, and colleagues (2012a) tested a combination of two manipulations - namely, choosing for a present versus future self and choosing for me versus we. They found that choosing for multiple people ("we condition") was most important in bringing down DD rates. In conclusion, social context manipulations seem to reduce DD.

Social influence Three experiments by Senecal and colleagues (Senecal, Wang, Thompson, \& Kable, 2012) tested the effect of normative strategies (i.e., individuals should compare each intertemporal choice against the other investment and borrowing options available to them) and social influence by peers on DD. When information about normative strategy for economic decision-making was made available to participants, DD rates decreased, although no direct comparison between conditions was made in Experiment 1 and no control condition was used in Study 2. Furthermore, peer-generated advice about strategies for economic decisions only decreased DD when this advice was written down in a patient versus impatient way (yet see our discussion of experimenterdemand effects in the discussion). Based on this one study, social influence manipulations seem to reduce DD, but more research is needed.

Emotion Emotion is multidimensional and can influence many cognitions, including attention, sensory perception, and memory. Twenty-six experiments all used very different forms of inducing affect or emotional priming with the aim to decrease DD, and 22 (85\%) found a decrease in DD rates. Guan, Cheng, Fan, and Li (2015) showed their participants positive, neutral, and negative pictures and then asked them to perform a DD task. They found that DD was attenuated in the neutral condition and even more decreased in the positive condition, compared with the negative condition. Ifcher and Zarghamee (2011) used short movie clips, and Pyone and Isen (2011) used words to induce positive or neutral affect, and both found that positive affect reduced DD. In contrast, Augustine and Larsen (2011) and Hirsh, Guindon, Morisano, and Peterson (2010) did not find a reduction in DD rates while using the same sort of affect induction.

In five experiments by Berry and colleagues (Berry, Sweeney, Morath, Odum, \& Jordan, 2014; Berry et al., 2015) and van der Wal and colleagues (van der Wal, Schade, Krabbendam, \& Van Vugt, 2013), participants were exposed to natural versus built environments (and geometric shapes in the Berry et al., 2014, study). Participants in the natural environment manipulation showed attenuated DD rates compared with participants in the urban environment manipulation. There are several possible explanations for these findings. For example, exposure to natural environments decreases stress, increases happiness, improves mood, and restores attention (Berto, 2005; Bowler, Buyung-Ali, Knight, \& Pullin, 2010; White, Alcock, Wheeler, \& Depledge, 2013). Natural environments are serene, thereby increasing attentional capacity and/or reducing general arousal, and by viewing them perception of time is lengthened (Berry et al., 2014; Berry et al., 2015). Another, evolutionary, explanation states that natural environments indicate resource abundance, and therefore individuals choose more often for larger but future outcomes (van der Wal et al., 2013). Built environments may indicate competition for resources and mates, and therefore individuals more often choose for smaller but immediate outcomes.

In the experiments by DeSteno, Dickens, and Lerner (2014) and Dickens and Desteno (2016), a gratitude manipulation was used, and both experiments found that this manipulation led to lower discounting rates, although the 
experiment by Dickens and Desteno (2016) did not include a proper control condition. In two experiments by Huang, Huang, and Wyer (2016), a nostalgia manipulation (i.e., reminiscing about positive events in the past) was used and participants in the nostalgia conditions showed decreased DD rates compared with the control condition. In the experiment by Raeva and colleagues (Raeva, Mittone, \& Schwarzbach, 2010), both regret and rejoicing were induced. Results suggested that when regret was experienced, participants preferred the immediate rewards, whereas when rejoicing was experienced, participants chose the delayed reward more often.

Berndsen and van der Pligt (2001) used an optimism manipulation and found that participants in the low-optimism condition showed decreased discounting rates compared with the high-optimism condition. In addition, Luo, Ainslie, and Monterosso (2014) induced fear, happiness, and neutrality by using facial expressions whereby fear decreased DD rates compared with the happiness and neutrality conditions. Callan, Harvey, and Sutton (2014) demonstrated in two experiments that a manipulation regarding the derogation of victims of misfortune, although damaging to others, yielded a psychological benefit for the self by choosing more often for the larger-later rewards than for the smaller-sooner rewards. W. Liu and Aaker (2007) proposed that an experience of the death of someone close prompts people to notice and reflect upon their long-term futures, causing changes in their intertemporal decisions. In one of their experiments, they showed that besides the actual experience of a cancer death, mental simulation of experiencing cancer death leads to decreases in DD rates as well. This effect could be interpreted as increased salience and concreteness regarding one's future life course, shifting focus away from the present toward the long run, hence fitting nicely with the studies on EFT and making the future more concrete. The experiment of Quisenberry and colleagues (Quisenberry, Eddy, Patterson, Franck, \& Bickel, 2015) on delay to sexual gratification employed three conditions: a positive health consequence condition, a negative health consequence condition, or a negative health consequence with the expression of regret condition. No effects were found on DD.

To summarize, most experiments $(85 \%)$ in the emotion priming category found positive results on DD. Sixteen experiments induced positive affect or primed positive emotions and thereby found decreased DD rates, whereas six other experiments induced negative affect or primed negative emotions and found decreased DD rates. Thus, both positive and negative affect/emotional priming can result in decreases in DD; yet there were also some studies, with both positive and negative affect/emotion inductions, that did not find effects in the expected direction (15\%). These inconsistent findings leave the exact interaction between emotion and DD to be uncovered.

\section{Framing}

Bundling Bundling refers to aggregating choices between temporally extended series of smaller-sooner/larger-later alternatives rather than case-by-case choices (Ainslie, 2001). Four experiments have employed a bundling manipulation, of which three $(75 \%)$ found positive results on DD and one (25\%) did not. In the experiments by Hofmeyr, Ainsli, Charlton, and Ross (2011) and Kirby and Guastello (2001), participants were allocated to either a free, suggested, or forced condition. In the free condition, participants could choose between a smaller-sooner reward and a larger-later reward at several consecutive moments (trials) over time (one choice today, one choice in 2 weeks, one choice in 4 weeks, etc.). In the suggested condition, participants were offered the same choices as in the free condition at several moments over time; however, accompanying the first choice, it was suggested to participants that their choice made in this first trial most of the time predicts their choices in the future. After this, participants were still free to make different choices in the later trials than in the first trial. In the forced condition, participants had to choose in the first trial for the rest of all trials, thus for a set of rewards. In both studies, discounting rates decreased when participants were allocated to the suggested condition and even more in the forced condition. Choosing for a set of rewards in the future instead of making those choices one by one thus seems to decrease DD rates. In contrast, in the study by Białaszek and Ostaszewski (2012) this effect was not found - in fact, the effect was reversed for large rewards; DD rates decreased when participants choose for a single large reward instead of a sequence of large rewards. Based on the four studies, bundling seems to decrease DD rates, but may partly depend on reward magnitude. Long-term effects and behavioral relevance need to be distinguished.

Time framing Time framing manipulations make subtle changes to the time component in standard DD tasks, where most of the experiments altered the way delays were described. Twentyone experiments attempted to decrease DD by time framing manipulations, 16 (76\%) found the expected effects on DD, and five (24\%) did not find effects on DD. In the experiments by DeHart and Odum (2015); Dshemuchadse, Scherbaum, and Goschke (2013); LeBoeuf (2006); Klapproth (2012); and Read and colleagues (Read, Frederick, Orsel, \& Rahman, 2005), delays were either construed as temporal distances (e.g., 6 days, 2 months) or specific dates (e.g., November 21). All experiments found attenuated DD when delays were presented as specific dates instead of temporal distances. The experiment by Lempert, Johnson, and Phelps (2016) employed the same manipulation but did not replicate the findings of the previous studies. One important difference between studies that could explain this failure to replicate is that Lempert et al. (2016) used 
a within-subject design with randomly intermixed trials, whereas all other studies employed a between-subject design or used a within-subject design but presented the date and delay conditions in separate blocks. Since discount rates are susceptible to order presentation (Robles \& Vargas, 2008), this may explain the failure to replicate the date/delay effect.

Another time framing manipulation was performed by Dai and Fishbach (2013). In this study, participants were either allocated to a near-future, distant-future, or waiting condition. In the near-future condition, participants chose between, for example, (a) $\$ 50$ in 3 days and (b) $\$ 55$ in 23 days. In the distant-future condition, participants chose between, for example, (a) $\$ 50$ in 30 days and (b) $\$ 55$ in 50 days. In the waiting condition, participants read about two choice options: (a) $\$ 50$ in 30 days and (b) $\$ 55$ in 50 days (similar to the distant-future condition), but they did not need to make any choice right away. After 27 days of waiting, the experimenter send the participants a note asking them to choose. At that time, participants were facing options identical to those in the near-future condition. It was found that participants in the waiting condition showed decreased DD compared with participants in both the near-future and distant-future conditions.

Of the other four experiments that did not find effects, the experiment by Zauberman and colleagues (Zauberman, Kim, Malkoc, \& Bettman, 2009) manipulated participants by making duration more salient to them by having them estimate the duration of several activities. Ebert and Prelec (2007) specifically instructed their participants to focus particularly on the future arrival time of the reward they could earn. The experiment by Rabinovich and colleagues (Rabinovich, Morton, \& Postmes, 2010) asked participants to think about what their financial circumstances were likely to be after 1 month (shortterm time perspective condition) or after 5 years (long-term time perspective condition).

In conclusion, the majority of time framing manipulations found decreases in DD rates. Yet the long-term effects and clinical relevance need investigation.

Reframing of rewards In DD tasks, participants often have to choose between two amounts of money. However, the way these two amounts are described seem to matter according to 26 experiments. Of these 26 experiments, 25 (96\%) found positive results of the reframing of reward manipulation on DD. An explicit zero manipulation was employed by Magen, Dweck, and Gross (2008); Magen, Kim, Dweck, Gross, and McClure (2014); and Radu et al. (2011). Participants in the hidden zero ( = control) condition chose between a smaller-sooner ( $\$ 5$ today) and a larger-later (\$50 in 2 weeks) reward, whereas participants in the explicit zero condition chose between a smallersooner reward ( $\$ 5$ today and $\$ 0$ in the future or $\$ 0$ today and $\$ 50$ in 2 weeks). Explicitly referring to the hidden zero in each choice alternative decreased DD rates. In three experiments by
Fassbender et al. (2014), half of the trials existed of rounded decimal values (e.g., \$11.00), whereas the other half of the trials were nonzero decimal values (e.g., \$11.72). Discount rates decreased when intertemporal choices were constructed of monetary outcomes with nonzero decimal values.

Weatherly, Derenne, \& Terrell (2010), Weatherly and Derenne (2011), and Weatherly and Terrell (2010) gave a DD task to participants in two conditions: In the "won" condition, participants were told that the amounts were money they had won; in the "owed" condition, participants were told that the amounts were money they owed (e.g., your own money that you lent to someone and need to get back). Results showed that participants had lower discounting rates when money was "owed" than when money was "won," indicating that won money was less valued than their own money. In two experiments by Read and colleagues (Read, Frederick, \& Scholten, 2013, Experiments 1 and 2), conditions including investment language in the choice alternatives (i.e., "Would you rather receive $\$ 70,000$ now or invest it for 1 year at an $8 \%$ interest rate?") decreased DD rates, whereas Experiment 3 did not replicate this effect.

Appelt, Hardisty, and Weber (2011); Grace \& McLean (2005); and Weber et al. (2007) compared effects of delay versus acceleration frames on discounting rates. Participants in an acceleration frame (i.e., receiving $\$ 75$ in 3 months or receiving a smaller amount now) more often chose the delayed reward than the immediate reward, than did participants in a delay frame (i.e., receiving $\$ 50$ now or receiving a larger amount in 3 months). Finally, Jiang, Hu, and Zhu (2014) introduced up-front losses as well as gains; participants in the control responded to the typical choice pairs (i.e., gain $\$ 120$ in a week vs. gain $\$ 150$ in 4 weeks), whereas in the up-front loss or win condition, both rewards options began with a same immediate loss or win (i.e., lose [or win] \$100 now and gain $\$ 120$ in a week vs. lose [or win] $\$ 100$ now and gain $\$ 150$ in 4 weeks). The addition of both up-front losses and gains in the choice pairs reduced DD.

In sum, manipulations that reframe rewards, such as explicitly referring to the hidden zero in choices and including nonzero decimal values, seem to be highly effective in decreasing DD rates. Yet, again, the long-term and clinical relevance effects need to be investigated.

\section{Discussion}

The current systematic review provides an overview of all studies that have attempted to decrease DD by means of behavioral trainings or manipulations. In this review, 98 studies were discussed regarding their effectiveness in reducing DD, but also in changing real-life behavior if measured. 


\section{Overall effectiveness of trainings and manipulations}

Generally, the majority of published studies ( $n=119 ; 79 \%$ ) were able to reduce $\mathrm{DD}$, indicating that although there may be between-subject stability to DD, it is also profoundly context dependent within individuals. Of the 132 manipulation experiments, 114 (86\%) were able to decrease DD, whereas from the 19 trainings, only five (26\%) were able to decrease DD. One would expect that a more thorough, longer lasting, and active training would be more effective than a short manipulation, especially since most trainings have been performed in populations with initially steep discount rates, leaving room for rate dependence and regression to the mean (Bickel, Quisenberry, and Snider, 2016a). Yet we found the opposite, and there are multiple reasons to explain this finding.

First, the manipulation studies more often employed a within-subject design ( $n=38,29 \%)$ compared with training studies $(n=4,21 \%)$. Within-subject designs have more power to detect effects than between-subject designs do (Charness, Gneezy, \& Kuhn, 2012). Second, the majority of trainings tried to find effects over longer time periods, while the effects of most manipulations were tested just after the manipulation. We know that training effects tend to decay over time, with effect sizes generally being the largest at posttest and decreasing at follow-up (Cuijpers, van Straten, Smit, Mihalopoulos, \& Beekman, 2008; Moyer, Finney, Swearingen, \& Vergun, 2002; Prendergast, Podus, Finney, Greenwell, \& Roll, 2006; Wilfley et al., 2007).

Third, trainings were mostly conducted in clinical populations and the manipulations (with a few exceptions) in healthy populations. Attrition in clinical studies is common and is frequently seen in studies with substance-abuse samples (Brorson, Arnevik, Rand-Hendriksen, \& Duckert, 2013). Attrition in the training studies reported in this systematic review was on average $15 \%$ (range: $0 \%-50 \%$ ), with higher dropout rates in more severely affected populations. Following intention-to-treat principles, all participants should be included in analyses, regardless of whether they actually received treatment, and thus dropouts are included in the analyses as nonabstainers (Brorson et al., 2013; Montori and Guyatt, 2001). Hence, comparing manipulations in healthy control samples with a higher chance of success with trainings in clinical samples can lead to biased interpretations.

Finally, publication bias could have introduced an overestimation of the actual effect of trainings and manipulations on DD (Hopewell, Clarke, Stewart, \& Tierney, 2007; Mervis, 2014). In the current systematic review, the publication rate of null results of training studies (74\%) was higher than the publication rate of null results of manipulation studies (14\%). It is likely that publication bias is more prevalent in the manipulation studies, given that these studies are less complex to perform compared with training studies. With the scientific field moving forward, transparency and replicability have become increasingly important. Future well-designed studies in the field will likely adhere to the three core practices of disclosure, registration, and preanalysis plans, as well as providing open access to data and material, and will go a long way toward addressing this file-drawer problem (Miguel et al., 2014; Simmons, Nelson, \& Simonsohn, 2011).

\section{Implications: Most promising strategies to reduce DD}

Trainings Based on the results of the training studies, the acceptance-based/mindfulness-based trainings seem to be most promising in reducing DD. The precise mechanisms by which these mindfulness-based trainings work, however, are still unclear. Most intervention theories related to elevated DD rates attempt to change individuals' heightened emphasis on immediate rewards toward a more future-oriented focus, whereas acceptance-based/mindfulness-based trainings concentrate on experiencing and accepting the aversiveness of the present moment (Ashe, Newman, \& Wilson, 2015). This latter view provides another lens on impulsivity in general: more impulsive people might find waiting in the moment particularly aversive, and their prime motivation is to escape those negative feelings by choosing immediate rewards (see delay aversion theory by Sonuga-Barke, 2005). Training them to mindfully attend to the present can help them to get through these moments and choose for the future reward. Considering the transference of effects to behavior, one might, for example, think that through acceptance-based/mindfulness-based trainings, individuals with addictive problems learn to accept negative feelings associated with moments of cravings and therefore get through these moments and stay abstinent (Ashe et al., 2015). Indeed, this alternative focus on improving DD by decreasing the aversiveness of the present moment is strengthened with significant effects on behavior, such as food behaviors (for review, see Olson \& Emery, 2015), addictive behaviors (e.g., Gifford et al., 2004; Petersen \& Zettle, 2009), and other mental and physical health problems (for review, see ATjak et al., 2015).

Although the effects regarding CM on DD rates in this systematic review are mixed (only $33.3 \%$ found the expected decreases in DD), most of these studies (66.6\%) found positive effects on health outcomes. This is further supported by a high number of studies in the literature that directly measured effects of $\mathrm{CM}$ on health outcomes in clinical samples (and not measuring DD rates). Multiple systematic reviews and meta-analyses show that $\mathrm{CM}$ has beneficial effects on abstinence rates in a range of substance-abuse samples (Dutra et al., 2008; Giles, Robalino, McColl, Sniehotta, \& Adams, 2014; Griffith, Rowan-Szal, Roark, \& Simpson, 2000; Lussier, Heil, Mongeon, Badger, \& Higgins, 2006; Prendergast et al., 2006; Schumacher et al., 2007). However, it remains unclear whether changes in behavior are mediated by changes 
in DD and, if so, whether these effects are substance specific (Stanger et al., 2013). Future research should test this mediation hypothesis and, if necessary, come up with alternative explanations for the effects of $\mathrm{CM}$ on behavior.

Manipulations The majority of the manipulations (86\%) seem to significantly reduce DD rates. However, decades of intervention research have shown that health behaviors or substance abuse are not easily changeable (Jeffery, 2004). In addition, the effects of the manipulations could very well be short-lived and context-specific effects that quickly disappear over time. For instance, framing effects might be useful as a "nudge" if the choice environment can be controlled, but perhaps less useful for bringing about durable person-level change. Therefore, the field would benefit from identifying (with tightly controlled experiments) the most promising manipulations; these manipulations should be informed by theoretical models that link predicted changes in DD as well as in behavior, ultimately.

With those recommendations in mind, the most encouraging line of research regarding manipulations seems to be the "future" category, especially "future episodic thinking" and "connectivity to future (self)" manipulations with $83 \%$ and $91 \%$ effectiveness rates, respectively. These studies are grounded in solid theory, find robust effects on DD rates, and the EFT studies include healthy $(62 \%)$ as well as different clinical samples (38\%) and find promising effects on smoking behavior (40\%), caloric intake (40\%) and hypothetical alcohol purchase $(20 \%)$. Thus, while many studies show that manipulations involving a future orientation reduce DD rates and have promising effects on a variety of health behaviors, recent research has started to evaluate alternative driving factors of these effects, such as demand characteristics. In a study specifically focusing on EFT, Rung and Madden (2018a) state that demand characteristics will probably be inherent to EFT procedures, as participants are asked to create future thinking cues that in turn are embedded in the DD tasks they have to perform later on. Being aware of the hypothesized effects in a study may bias participants' answers and behaviors, potentially driving the effect of EFT on DD and behavior (Rung \& Madden, 2018a). Besides effects on EFT, demand characteristics could likely play a role in "connectivity to future (self)" manipulations and "construal level thinking manipulations (concretization)."

To optimize these effects, it is recommended to extend these "future" manipulations into longer, multiple session trainings and use rigorous transparent designs to test effects in the long term in adequately powered samples (Boot et al., 2013; Miguel et al., 2014; Simmons et al., 2011). These recommendations could be elegantly implemented by the use of technological tools. In particular, video games are a ubiquitous part of our current society (Granic, Lobel, \& Engels, 2014) and are able to evoke intrinsic motivation to engage people in the treatment process (Ryan, Rigby, \& Przybylski, 2006). Moreover, video games can promote long-term training by incorporating repetitive actions and encouraging repetitive gameplay without evoking boredom (Granic et al., 2014; C. S. Green \& Bavalier, 2012). Finally, to illustrate its promise and clinical relevance, some of these manipulations have already been included in trainings with relevant clinical populations: Solanto (2011) developed a CBT program for adults with ADHD focusing on executive functions and integrated the visualization of long-term rewards and positive outcomes (episodic future thinking) as an important part of this effective intervention.

\section{Overarching mechanisms of change}

Although the content of the trainings and manipulations differed broadly between studies, there are some overarching mechanisms of change that could explain results over different trainings and manipulations, content wise. Please bear in mind that we have subjectively divided all studies into different categories, for structuring and clarification purposes. However, it could well be that multiple categories of trainings and manipulations originated from the same theoretical framework.

First, the perception of time within individuals is an important factor influencing DD rates (Baumann \& Odum, 2012). Killeen (2015) defines impulsivity as greater control by events close in psychological time and space than by those more distal: Attention is captured by the now more eagerly than by the when. Indeed, individuals showing steeper discounting also show a more present orientation and a shorter future time perspective, which is associated with a range of problematic behaviors (Teuscher \& Mitchell, 2011). For example, individuals with ADHD symptoms show a larger present orientation and a more negative view of the future than the controls (Carelli \& Wiberg, 2012). Furthermore, present time perspective is significantly correlated with risky driving (Zimbardo, Keough, \& Boyd, 1997) and substance use (Wills, Sandy, \& Yaeger, 2001). Thus, shifting individuals' time perception by making future rewards appear closer, more concrete, or easier to imagine might decrease DD rates. The perceived closeness of future rewards can be manipulated in different ways, such as by changing the way future delays (time framing manipulations) or rewards (reframing of reward manipulations) are perceived, by providing a richer and salient context for the future reward (EFT, construal level: concretization manipulations) or making the future easier to imagine (connection to future [self] manipulations, visualization training).

Yet Sonuga-Barke and colleagues (Sonuga-Barke, 2005; Sonuga-Barke, Taylor, Sembi, \& Smith, 1992) have hypothesized that choosing for immediate rewards, and thus steep discounting, is the result of a high aversion to delay. Especially in the ADHD field there has been an emphasis on this theoretical account, and it has been shown that individuals with ADHD experience relatively strong negative emotions 
during waiting times, resulting in a preference to escape delay (Mies, Ma, De Water, Buitelaar, \& Scheres, 2018; Scheres, Tontsch, \& Thoeny, 2013b; Van Dessel et al., 2018). Acceptance-based/mindfulness-based trainings that train individuals to mindfully attend to the present can help them to get through these moments and choose for the future reward.

Second, affective and emotional states can change DD rates, but likely depend on the specific properties of the affective state (see emotion manipulations for decreases in DD for both negative and positively valenced primes). Making the delayed reward more rewarding or emotionally salient could be the driving force behind these effects (EFT, emotion, reframing of rewards, and time framing manipulations).

Finally, another overarching mechanism driving many effects is attention. Delay is often considered as a negative characteristic of the future, whereas the magnitude of the future reward is considered as positive, since it often exceeds the value of the immediate reward. Drawing attention toward magnitude and away from delay should lead to decreased DD rates (Lempert \& Phelps, 2016). Changing the way reward magnitudes are presented (reframing of reward manipulations; decimal effects) or drawing the attention to the "costs" of the immediate reward (reframing of reward manipulations; explicit-zero effects; CM trainings; money-managementbased trainings) are ways to change discount rates.

Taking all this together could imply that different strategies may reduce DD by working on different components of the DD process. For some individuals, for whom delay aversion is the main reason for steep DD, acceptance-based/mindfulness-based trainings may be more appropriate, whereas for others, who are driven by reward immediacy in steep DD, the future manipulations may be more effective. These overarching mechanisms of change might become building blocks for DD theories focused on altering this trans-disease mechanism, thereby building a very strong multicomponent intervention where different mechanisms may actually complement each other.

Both thorough, longer lasting, and active trainings as well as more short lived on-off manipulations could be successful in changing DD rates and behavior, depending on the purpose of a certain intervention. One might expect that trainings are better suitable in shifting "trait" discount rates than manipulations, thereby targeting steeper baseline discount rates in more clinical samples. Yet it might also be the case that it is rather difficult to change "trait" discount rates, which makes on-off manipulations (i.e., state manipulations) more interesting to change DD rates in the moment a "critical" time points (i.e., at moments when you are deciding whether to save money for retirement or to eat a piece of pie or not). We do not have the empirical evidence to back up these speculations, and thus more research investigating longer-term effects of trainings on DD and behavior, as well as the effect of frequent "in the moment" manipulations on DD and behavior, would be very helpful for future intervention design.

\section{Limitations and recommendations}

The widespread variability in trainings and manipulations (e.g., working memory training, future-based manipulations, framing manipulations) complicates comparison between studies. Furthermore, given the large heterogeneity between studies and the nature of this systematic review, we could not formally check for publication bias. A method to differentiate between effective studies and make comparisons more objectively, is to compute a measure of effect size (e.g., Cohen's $d$; Cohen, 1988). Unfortunately, the vast majority of the included studies did not report effect sizes or give statistics that would allow us to calculate effect sizes. Future work could build on the current review by having a more specific focus on content (e.g., only including "future-based" manipulations) and apply meta-analytic methods to dive into more specific questions regarding the effectiveness of the included studies.

As a first recommendation, we would advise to adopt a structured procedure to operationalize and test predictions regarding reductions in DD rates. An important initial step is to figure out whether certain trainings and manipulations are able to decrease DD in healthy populations with heightened DD rates to create proof of concept for DD as a mechanism that is changeable. By testing the training or manipulation first in a healthy sample with a broad range of DD rates (from very low to very high), we can contrast these different groups and control for ceiling and floor effects. By doing this, we circumvent high costs and effort and we can exclude noneffective trainings and manipulations early in the process. When effects are established in healthy populations, the training or manipulation could be introduced to a clinical sample. Though high DD rates are associated with unhealthy behaviors, it could still be possible that decreasing DD rates does not translate into a reduction of unhealthy behaviors. In other words, at this point we do not know whether this relation between DD rates and health behaviors is correlational or causal in nature; the mere fact that discounting is correlated with psychopathology does not necessarily mean that reducing discounting would reduce psychopathology. Introducing the training or manipulation to a clinical sample using rigorous designs and long-term followups will help us disentangle whether DD is causally related to changes in health behaviors. Prospective longitudinal studies, such as the study by Audrain-McGovern et al. (2009), are another method to unravel the role of DD in psychopathology. As a final step, the same training or manipulation should be tested in a different clinical sample to deliver evidence for DD as transdiagnostic mechanism. This three-step approach would allow us to more efficiently test promising trainings and manipulations and provide evidence for the underlying theoretical framework of DD as transdiagnostic mechanism.

Secondly, we recommend extending the primary focus of this literature - to reduce DD rates and thereby change behavior-to an emphasis on the mechanisms that cause 
changes in DD and behavior. Although it is critical to test whether trainings or manipulations are able to effectively decrease DD and problematic behaviors, we also need to understand how and why they achieve this effect. Analyzing mechanisms of change, such as a focus on the valence of the future reward, can help us answer these how and why questions. Related to this, not only has heightened DD been correlated with health and disorder-related outcomes, but lower-thanaverage discount rates have also been associated with pathology (e.g., anorexia; Decker, Figner, \& Steinglass, 2015). A focus on the broad range of discounting patterns and their possible effects on behavior is therefore recommended.

Thirdly, we want to make a call for an upgrade of the quality of studies and the sharing of measures and designs over studies. Differences between studies are high: Some studies did not include a proper control condition, some did not directly compare the experimental and control condition, and others included poorly powered designs or did not report effect sizes or statistics to calculate effect sizes. Furthermore, different methods were used to assess $\mathrm{DD}$, and these methods vary systematically in their outcomes (Scheres, de Water, et al., 2013a; Weatherly, 2014). This is especially relevant as some of the "effective" trainings and manipulations in this systematic review have failed to replicate in more recent studies. For example, Zhang and Smith (2018) did not find an effect of power on DD in two preregistered, close-replication studies of Joshi and Fast's study in 2013; Sweeney et al. (2018) failed to replicate the effects of a working memory training on DD in adolescents with cannabis use disorders; and Kable et al. (2017) showed that cognitive training (including working memory training) was unable to decrease DD in healthy controls. We recommend adopting a basic set of principles and methods based on transparency and replicability guidelines (Miguel et al., 2014; Simmons et al., 2011) which would upgrade the quality of studies in general and make it easier to perform replication studies and compare across studies.

Finally, we advise including more varied samples, in age as well as in clinical diagnosis, and including possible moderators of the effect of DD on behavior (e.g., motivation to change). For example, in the current systematic review, only two experiments included a sample younger than 18 years of age, with all other studies heavily relying on healthy control college student samples. From both a human impact and economic perspective, there is a strong rationale to focus more on youth (Coughlan et al., 2013; McGorry, 2013; McGorry, Purcell, Hickie, \& Jorm, 2007; Patel, Flisher, Hetrick, \& McGorry, 2007). As an example, we know that the major burden of smoking-related diseases falls on the adult population, but there are several reasons why smoking cessation among adolescents deserves special attention (Fanshawe et al., 2017). For example, smoking during adolescence has a direct negative effect on youth's health and is a significant predictor of nicotine dependence in adulthood (Mermelstein,
2003), while without intervention, very few adolescent smokers quit smoking (Mermelstein, 2003). Therefore, delaying interventions until adulthood is undesirable, and a focus on youth is imperative.

\section{Conclusion}

The current paper systematically reviewed behavioral trainings and manipulations that aimed to reduce DD in human participants. Overall, results showed that DD can be decreased and thus that DD is a changeable construct; manipulation effects on DD are easier demonstrated than effects of trainings. Most promising avenues to pursue in future research seem to be acceptance-based/mindfulness-based trainings, and even more so future-oriented manipulations. Furthermore, we call for more emphasis on the underlying theoretical framework of DD as transdiagnostic mechanism and more coherence in high-quality research methods across studies.

\section{Compliance with ethical standards}

Open practices statement There are no newly collected data or newly created materials associated with this systematic review, and this systematic review was not preregistered.

Open Access This article is distributed under the terms of the Creative Commons Attribution 4.0 International License (http:// creativecommons.org/licenses/by/4.0/), which permits unrestricted use, distribution, and reproduction in any medium, provided you give appropriate credit to the original author(s) and the source, provide a link to the Creative Commons license, and indicate if changes were made.

\section{References}

References marked with an asterisk indicate studies included in the systematic review.

Ainslie, G. (1975). Specious reward: A behavioral theory of impulsiveness and impulse control. Psychological Bulletin, 82, 463-496. https://doi.org/10.1037/h0076860

Ainslie, G. (1992). Picoeconomics. Cambridge: Cambridge University Press.

Ainslie, G. (2001). Breakdown of will. New York: Cambridge University Press.

Amlung, M., \& MacKillop, J. (2014). Clarifying the relationship between impulsive delay discounting and nicotine dependence. Psychology of Addictive Behaviors, 28, 761-768. https://doi.org/10.1037/ a0036726

Amlung, M., Petker, T., Jackson, J., Balodis, I., \& MacKillop, J. (2016). Steep discounting of delayed monetary and food rewards in obesity: A meta-analysis. Psychological Medicine, 46, 2423-2434. https:// doi.org/10.1017/S0033291716000866

*Appelt, K. C., Hardisty, D. J., \& Weber, E. U. (2011). Asymmetric discounting of gains and losses: A query theory account. Journal of Risk and Uncertainty, 43, 107-126. https://doi.org/10.1007/ s11166-011-9125-1 
Ashe, M. L., Newman, M. G., \& Wilson, S. J. (2015). Delay discounting and the use of mindful attention versus distraction in the treatment of drug addiction: A conceptual review. Journal of the Experimental Analysis of Behavior, 103, 234-248. https://doi.org/10.1002/jeab. 122

Atance, C. M., \& O’Neill, D. K. (2001). Episodic future thinking. Trends in Cognitive Sciences, 5, 533-539. https://doi.org/10.1016/S13646613(00)01804-0

A-tjak, J. G., Davis, M. L., Morina, N., Powers, M. B., Smits, J. A., \& Emmelkamp, P. M. (2015). A meta-analysis of the efficacy of acceptance and commitment therapy for clinically relevant mental and physical health problems. Psychotherapy and Psychosomatics, 84, 30-36. https://doi.org/10.1159/000365764

Audrain-McGovern, J., Rodriguez, D., Epstein, L. H., Cuevas, J., Rodgers, K., \& Wileyto, E. P. (2009). Does delay discounting play an etiological role in smoking or is it a consequence of smoking? Drug and Alcohol Dependence, 103, 99-106. https://doi.org/10. 1016/j.drugalcdep.2008.12.019

*Augustine, A. A., \& Larsen, R. J. (2011). Affect regulation and temporal discounting: Interactions between primed, state, and trait affect. Emotion, 11, 403-412. https://doi.org/10.1037/a0021777

Ayduk, O., Mendoza-Denton, R., Mischel, W., Downey, G., Peake, P. K., \& Rodriguez, M. (2000). Regulating the interpersonal self: Strategic self-regulation for coping with rejection sensitivity. Journal of Personality and Social Psychology, 79, 776-792. https://doi.org/ 10.1037/0022-3514.79.5.776

Baker, F., Johnson, M. W., \& Bickel, W. K. (2003). Delay discounting in current and never-before cigarette smokers: Similarities and differences across commodity, sign, and magnitude. Journal of Abnormal Psychology, 112, 382-392. https://doi.org/10.1037/0021-843X.112. 3.382

*Bartels, D. M., \& Urminsky, O. (2011). On intertemporal selfishness: How the perceived instability of identity underlies impatient consumption. Journal of Consumer Research, 38, 182-198. https://doi. org/10.1086/658339

Baumann, A. A., \& Odum, A. L. (2012). Impulsivity, risk taking, and timing. Behavioural Processes, 90, 408-414. https://doi.org/10. 1016/j.beproc.2012.04.005

*Benoit, R. G., Gilbert, S. J., \& Burgess, P. W. (2011). A neural mechanism mediating the impact of episodic prospection on farsighted decisions. The Journal of Neuroscience, 31, 6771-6779. https:// doi.org/10.1523/JNEUROSCI.6559-10.2011

*Berndsen, M., \& van der Pligt, J. (2001). Time is on my side: Optimism in intertemporal choice. Acta Psychologica, 108, 173-186. https:// doi.org/10.1016/S0001-6918(01)00029-4

*Berry, M. S., Sweeney, M. M., Morath, J., Odum, A. L., \& Jordan, K. E. (2014). The nature of impulsivity: Visual exposure to natural environments decreases impulsive decision-making in a delay discounting task. PLOS ONE, 9, e97915. https://doi.org/10.1371/ journal.pone.0097915

*Berry, M. S., Repke, M. A., Nickerson, N. P., Conway, L. G., III, Odum, A. L., \& Jordan, K. E. (2015). Making time for nature: Visual exposure to natural environments lengthens subjective time perception and reduces impulsivity. PLOS ONE, 10, e0141030. https://doi.org/ 10.1371/journal.pone. 014103

Berto, R. (2005). Exposure to restorative environments helps restore attentional capacity. Journal of Environmental Psychology, 25, 249259. https://doi.org/10.1016/j.jenvp.2005.07.001

*Białaszek, W., \& Ostaszewski, P. (2012). Discounting of sequences of delayed rewards of different amounts. Behavioural Processes, 89, 39-43. https://doi.org/10.1016/j.beproc.2011.10.014

Bickel, W. K. (2015). Discounting of delayed rewards as an endophenotype. Biological Psychiatry, 77, 846-847.

*Bickel, W. K., Jarmolowicz, D. P., Mueller, E. T., Franck, C. T., Carrin, C., \& Gatchalian, K. M. (2012a). Altruism in time: Social temporal discounting differentiates smokers from problem drinkers.
Psychopharmacology, 224, 109-120. https://doi.org/10.1007/ s00213-012-2745-6

Bickel, W. K., Jarmolowicz, D. P., Mueller, E. T., Koffarnus, M. N., \& Gatchalian, K. M. (2012b). Excessive discounting of delayed reinforcers as a trans-disease process contributing to addiction and other disease-related vulnerabilities: Emerging evidence. Pharmacology \& Therapeutics, 134, 287-297. https://doi.org/10.1016/j. pharmthera.2012.02.004

Bickel, W. K., Landes, R. D., Christensen, D. R., Jackson, L., Jones, B. A., Kurth-Nelson, Z., \& Redish, A. D. (2011a). Single-and crosscommodity discounting among cocaine addicts: The commodity and its temporal location determine discounting rate. Psychopharmacology, 217, 177-187. https://doi.org/10.1007/ s00213-011-2272-x

Bickel, W. K., Quisenberry, A. J., Moody, L., \& Wilson, A. G. (2015). Therapeutic opportunities for self-control repair in addiction and related disorders change and the limits of change in trans-disease processes. Clinical Psychological Science, 3, 140-153. https://doi. org $/ 10.1177 / 2167702614541260$

Bickel, W. K., Quisenberry, A. J., \& Snider, S. E. (2016a). Does impulsivity change rate dependently following stimulant administration? A translational selective review and re-analysis. Psychopharmacology, 233, 1-18. https://doi.org/10.1007/s00213015-4148-y

*Bickel, W. K., Wilson, A. G., Chen, C., Koffarnus, M. N., \& Franck, C. T. (2016b). Stuck in time: Negative income shock constricts the temporal window of valuation spanning the future and the past. PLOS ONE, 11, e0163051. https://doi.org/10.1371/journal.pone. 0163051

Bickel, W. K., Yi, R., Kowal, B. P., \& Gatchalian, K. M. (2008). Cigarette smokers discount past and future rewards symmetrically and more than controls: Is discounting a measure of impulsivity?. Drug and Alcohol Dependence, 96, 256-262. https://doi.org/10.1016/j. drugalcdep.2008.03.009

*Bickel, W. K., Yi, R., Landes, R. D., Hill, P. F., \& Baxter, C. (2011b). Remember the future: Working memory training decreases delay discounting among stimulant addicts. Biological Psychiatry, 69, 260-265. https://doi.org/10.1016/j.biopsych.2010.08.017

*Black, A. C., \& Rosen, M. I. (2011). A money management-based substance use treatment increases valuation of future rewards. Addictive Behaviors, 36, 125-128. https://doi.org/10.1016/j. addbeh.2010.08.014.

Bobova, L., Finn, P. R., Rickert, M. E., \& Lucas, J. (2009). Disinhibitory psychopathology and delay discounting in alcohol dependence: Personality and cognitive correlates. Experimental and Clinical Psychopharmacology, 17, 51-61. https://doi.org/10.1037/a0014503

Boot, W. R., Simons, D. J., Stothart, C., \& Stutts, C. (2013). The pervasive problem with placebos in psychology why active control groups are not sufficient to rule out placebo effects. Perspectives on Psychological Science, 8, 445-454. https://doi.org/10.1177/ 1745691613491271

Bowler, D. E., Buyung-Ali, L. M., Knight, T. M., \& Pullin, A. S. (2010). A systematic review of evidence for the added benefits to health of exposure to natural environments. BMC Public Health, 10, 456. https://doi.org/10.1186/1471-2458-10-456

Breaux, R. P., Griffith, S. F., \& Harvey, E. A. (2016). Preschool neuropsychological measures as predictors of later attention deficit hyperactivity disorder. Journal of Abnormal Child Psychology, 44, 1455 1471. https://doi.org/10.1007/s10802-016-0140-1

Brorson, H. H., Arnevik, E. A., Rand-Hendriksen, K., \& Duckert, F. (2013). Drop-out from addiction treatment: A systematic review of risk factors. Clinical Psychology Review, 33, 1010-1024. https://doi. org/10.1016/j.cpr.2013.07.007

*Bulley, A., \& Gullo, M. J. (2017). The influence of episodic foresight on delay discounting and demand for alcohol. Addictive Behaviors, 66, 1-6. https://doi.org/10.1016/j.addbeh.2016.11.003 
Campbell, S. B., \& Von Stauffenberg, C. (2009). Delay and inhibition as early predictors of ADHD symptoms in third grade. Journal of Abnormal Child Psychology, 37, 1-15. https://doi.org/10.1007/ s10802-008-9270-4

*Callan, M. J., Harvey, A. J., \& Sutton, R. M. (2014). Rejecting victims of misfortune reduces delay discounting. Journal of Experimental Social Psychology, 51, 41-44. https://doi.org/10.1016/j.jesp.2013. 11.002

Carelli, M. G., \& Wiberg, B. (2012). Time out of mind: Temporal perspective in adults with ADHD. Journal of Attention Disorders, 16, 460-466. https://doi.org/10.1177/1087054711398861

Chapman, G. B. (1996). Temporal discounting and utility for health and money. Journal of Experimental Psychology: Learning, Memory, \& Cognition, 22, 771-791. https://doi.org/10.1037/0278-7393.22.3. 771

*Charlton, S. R., Yi, R., Porter, C., Carter, A. E., Bickel, W., \& Rachlin, H. (2013). Now for me, later for us? Effects of group context on temporal discounting. Journal of Behavioral Decision Making, 26, 118-127. https://doi.org/10.1002/bdm.766

Charness, G., Gneezy, U., \& Kuhn, M. A. (2012). Experimental methods: Between-subject and within-subject design. Journal of Economic Behavior \& Organization, 81, 1-8. https://doi.org/10.1016/j.jebo. 2011.08.009

*Cheng, Y. Y., Shein, P. P., \& Chiou, W. B. (2012). Escaping the impulse to immediate gratification: The prospect concept promotes a futureoriented mindset, prompting an inclination towards delayed gratification. British Journal of Psychology, 103, 129-141. https://doi.org/ 10.1111/j.2044-8295.2011.02067.x

Chesson, H. W., Leichliter, J. S., Zimet, G. D., Rosenthal, S. L., Bernstein, D. I., \& Fife, K. H. (2006). Discount rates and risky sexual behaviors among teenagers and young adults. Journal of Risk and Uncertainty, 32, 217-230. https://doi.org/10.1007/ s11166-006-9520-1

*Chiou, W., \& Wu, W. (2016). Episodic future thinking involving the nonsmoking self can induce lower discounting and cigarette consumption. Journal of Studies on Alcohol and Drugs, 78, 106-112.

Cohen, J. (1988). Statistical power analysis for the behavioral sciences. Hillsdale: Erlbaum.

Cohen, J., Cohen, P., West, S. G., \& Aiken, L. S. (2013). Applied multiple regression/correlation analysis for the behavioral sciences, Abingdon: Routledge.

Coughlan, H., Cannon, M., Shiers, D., Power, P., Barry, C., Bates, T., ... Duffy, M. (2013). Towards a new paradigm of care: The International Declaration on Youth Mental Health. Early Intervention in Psychiatry, 7, 103-108. https://doi.org/10.1111/eip. 12048

Cowan, N. (2014). Working memory underpins cognitive development, learning, and education. Educational Psychology Review, 26, 197223. https://doi.org/10.1007/s10648-013-9246-y

Critchfield, T. S., \& Kollins, S. H. (2001). Temporal discounting: Basic research and the analysis of socially important behavior. Journal of Applied Behavior Analysis, 34, 101-122. https://doi.org/10.1901/ jaba.2001.34-101

Cuijpers, P., van Straten, A., Smit, F., Mihalopoulos, C., \& Beekman, A. (2008). Preventing the onset of depressive disorders: A metaanalytic review of psychological interventions. American Journal of Psychiatry, 165, 1272-1280. https://doi.org/10.1176/appi.ajp. 2008.07091422

*Dai, X., \& Fishbach, A. (2013). When waiting to choose increases patience. Organizational Behavior and Human Decision Processes, 121, 256-266. https://doi.org/10.1016/j.obhdp.2013.01. 007

*Daniel, T. O., Sawyer, A., Dong, Y., Bickel, W. K., \& Epstein, L. H. (2016). Remembering versus imagining: When does episodic retrospection and episodic prospection aid decision making? Journal of
Applied Research in Memory and Cognition, 5, 352-358. https:// doi.org/10.1016/j.jarmac.2016.06.005

*Daniel, T. O., Stanton, C. M., \& Epstein, L. H. (2013a). The future is now: Comparing the effect of episodic future thinking on impulsivity in lean and obese individuals. Appetite, 71, 120-125. https://doi. org/10.1016/j.appet.2013.07.010

*Daniel, T. O., Stanton, C. M., \& Epstein, L. H. (2013b). The future is now: Reducing impulsivity and energy intake using episodic future thinking. Psychological Science, 24, 2339-2342. https://doi.org/10. 1177/0956797613488780

*Dassen, F. C., Jansen, A., Nederkoorn, C., \& Houben, K. (2016). Focus on the future: Episodic future thinking reduces discount rate and snacking. Appetite, 96, 327-332. https://doi.org/10.1016/j.appet. 2015.09.032

Decker, J. H., Figner, B., \& Steinglass, J. E. (2015). On weight and waiting: Delay discounting in anorexia nervosa pretreatment and posttreatment. Biological Psychiatry, 78, 606-614. https://doi.org/ 10.1016/j.biopsych.2014.12.016

*De Wilde, B., Bechara, A., Sabbe, B., Hulstijn, W., \& Dom, G. (2013). Risky decision-making but not delay discounting improves during inpatient treatment of polysubstance dependent alcoholics. Frontiers in Psychiatry, 4, 1-7. https://doi.org/10.3389/fpsyt.2013.00091

*DeHart, W. B., Friedel, J. E., Lown, J. M., \& Odum, A. L. (2016). The effects of financial education on impulsive decision making. PLOS ONE, 11, e0159561. https://doi.org/10.1371/journal.pone.0159561

*DeHart, W. B., \& Odum, A. L. (2015). The effects of the framing of time on delay discounting. Journal of the Experimental Analysis of Behavior, 103, 10-21. https://doi.org/10.1002/jeab.125

Demurie, E., Roeyers, H., Baeyens, D., \& Sonuga-Barke, E. (2012). Temporal discounting of monetary rewards in children and adolescents with ADHD and autism spectrum disorders. Developmental Science, 15, 791-800. https://doi.org/10.1111/j.1467-7687.2012.01178.x

*Dennhardt, A. A., Yurasek, A. M., \& Murphy, J. G. (2015). Change in delay discounting and substance reward value following a brief alcohol and drug use intervention. Journal of the Experimental Analysis of Behavior, 103, 125-140. https://doi.org/10.1002/jeab.121

*DeSteno, D., Li, Y., Dickens, L., \& Lerner, J. S. (2014). Gratitude a tool for reducing economic impatience. Psychological Science, 25, 1262-1267. https://doi.org/10.1177/0956797614529979

Deveci, S. E., Deveci, F., Açik, Y., \& Ozan, A. T. (2004). The measurement of exhaled carbon monoxide in healthy smokers and nonsmokers. Respiratory Medicine, 98, 551-56. https://doi.org/10. 1016/j.rmed.2003.11.018

*Dickens, L., \& DeSteno, D. (2016). The grateful are patient: Heightened daily gratitude is associated with attenuated temporal discounting. Emotion, 16, 421-425. https://doi.org/10.1037/emo0000176

*Dshemuchadse, M., Scherbaum, S., \& Goschke, T. (2013). How decisions emerge: Action dynamics in intertemporal decision making. Journal of Experimental Psychology: General, 142, 93-100. https:// doi.org/10.1037/a0028499

Dutra, L., Stathopoulou, G., Basden, S. L., Leyro, T. M., Powers, M. B., \& Otto, M. W. (2008). A meta-analytic review of psychosocial interventions for substance use disorders. American Journal of Psychiatry, 165, 179-187. https://doi.org/10.1176/appi.ajp.2007. 06111851

*Ebert, J. E., \& Prelec, D. (2007). The fragility of time: Time-insensitivity and valuation of the near and far future. Management Science, 53, 1423-1438. https://doi.org/10.1287/mnsc.1060.0671

Fanshawe, T. R., Halliwell, W., Lindson, N., Aveyard, P., LivingstoneBanks, J., \& Hartmann-Boyce, J. (2017). Tobacco cessation interventions for young people. Cochrane Database of Systematic Reviews 2017, 11, 1-120. https://doi.org/10.1002/14651858. CD003289.pub6.

*Fassbender, C., Houde, S., Silver-Balbus, S., Ballard, K., Kim, B., Rutledge, K. J., ... McClure, S. M. (2014). The decimal effect: Behavioral and neural bases for a novel influence on intertemporal 
choice in healthy individuals and in ADHD. Journal of Cognitive Neuroscience, 26, 2455-2468. https://doi.org/10.1162/jocn_a 00642

Fields, S., Leraas, K., Collins, C., \& Reynolds, B. (2009). Delay discounting as a mediator of the relationship between perceived stress and cigarette smoking status in adolescents. Behavioural Pharmacology, 20, 455-460. https://doi.org/10.1097/FBP. 0b013e328330dcff

Gifford, E. V., Kohlenberg, B. S., Hayes, S. C., Antonuccio, D. O., Piasecki, M. M., Rasmussen-Hall, M. L., \& Palm, K. M. (2004). Acceptance-based treatment for smoking cessation. Behavior Therapy, 35, 689-705. https://doi.org/10.1016/S0005-7894(04) 80015-7

Giles, E. L., Robalino, S., McColl, E., Sniehotta, F. F., \& Adams, J. (2014). The effectiveness of financial incentives for health behaviour change: Systematic review and meta-analysis. PLOS ONE, 9, e90347. https://doi.org/10.1371/journal.pone.0090347

*Grace, R. C., \& McLean, A. P. (2005). Integrated versus segregated accounting and the magnitude effect in temporal discounting. Psychonomic Bulletin \& Review, 12, 732-739. https://doi.org/10. 3758/BF03196765

Granic, I., Lobel, A., \& Engels, R. C. M. E. (2014). The benefits of playing video games. American Psychologist, 69, 66-78. https:// doi.org/10.1037/a0034857

Gray, J. C., \& MacKillop, J. (2015). Impulsive delayed reward discounting as a genetically-influenced target for drug abuse prevention: A critical evaluation. Frontiers in Psychology, 6. https://doi. org/10.3389/fpsyg.2015.01104

Green, C. S., \& Bavelier, D. (2012). Learning, attentional control, and action video games. Current biology, 22(6), R197-R206. https://doi. org/10.1016/j.cub.2012.02.012

Green, L., \& Myerson, J. (1993). Alternative frameworks for the analysis of self-control. Behavior and Philosophy, 21, 37-47.

Green, L., \& Myerson, J. (2004). A discounting framework for choice with delayed and probabilistic rewards. Psychological Bulletin, 130, 769-792. https://doi.org/10.1037/0033-2909.130.5.769

Griffith, J. D., Rowan-Szal, G. A., Roark, R. R., \& Simpson, D. D. (2000). Contingency management in outpatient methadone treatment: A meta-analysis. Drug and Alcohol Dependence, 58, 55-66. https://doi.org/10.1016/S0376-8716(99)00068-X

*Guan, S., Cheng, L., Fan, Y., \& Li, X. (2015). Myopic decisions under negative emotions correlate with altered time perception. Frontiers in Psychology, 6, 468-468. https://doi.org/10.3389/fpsyg.2015. 00468

Hamilton, K. R., Mitchell, M. R., Wing, V. C., Balodis, I. M., Bickel, W. K., Fillmore, M., ... Mathias, C. W. (2015). Choice impulsivity: Definitions, measurement issues, and clinical implications. Personality Disorders: Theory, Research, and Treatment, 6, 182198. https://doi.org/10.1037/per0000099

*Hendrickson, K. L., \& Rasmussen, E. B. (2013). Effects of mindful eating training on delay and probability discounting for food and money in obese and healthy-weight individuals. Behaviour Research and Therapy, 51, 399-409. https://doi.org/10.1016/j.brat. 2013.04.002

*Hendrickson, K. L., \& Rasmussen, E. B. (2017). Mindful eating reduces impulsive food choice in adolescents and adults. Health Psychology, 36, 226-235. https://doi.org/10.1037/hea0000440

*Hershfield, H. E., Goldstein, D. G., Sharpe, W. F., Fox, J., Yeykelis, L., Carstensen, L. L., \& Bailenson, J. N. (2011). Increasing saving behavior through age-progressed renderings of the future self. Journal of Marketing Research, 48, S23-S37. https://doi.org/10. 1509/jmkr.48.SPL.S23

Higgins, S. T., Silverman, K., \& Heil, S. H. (2008). Contingency management in substance abuse treatment. New York: Guilford Press.
*Hirsh, J. B., Guindon, A., Morisano, D., \& Peterson, J. B. (2010). Positive mood effects on delay discounting. Emotion, 10, 717721. https://doi.org/10.1037/a0019466

*Hofmeyr, A., Ainslie, G., Charlton, R., \& Ross, D. (2011). The relationship between addiction and reward bundling: An experiment comparing smokers and non-smokers. Addiction, 106, 402-409. https:// doi.org/10.1111/j.1360-0443.2010.03166.x

Hopewell, S., Clarke, M. J., Stewart, L., \& Tierney, J. (2007). Time to publication for results of clinical trials. The Cochrane Library, 2, 113. https://doi.org/10.1002/14651858.MR000011.pub2

*Hu, X., Kleinschmidt, H., Martin, J. A., Han, Y., Thelen, M., Meiberth, D., ... Weber, B. (2017). A reduction in delay discounting by using episodic future imagination and the association with episodic memory capacity. Frontiers in Human Neuroscience, 10, 1-20. https:// doi.org/10.3389/fnhum.2016.00663

*Huang, X. I., Huang, Z. T., \& Wyer, R. S. (2016). Slowing down in the good old days: The effect of nostalgia on consumer patience. Journal of Consumer Research, 43, 372-387. https://doi.org/10. 1093/jcr/ucw033

*Ifcher, J., \& Zarghamee, H. (2011). Happiness and time preference: The effect of positive affect in a random-assignment experiment. The American Economic Review, 101, 3109-3129. https://doi.org/10. 1257/aer.101.7.3109

*Israel, A., Rosenboim, M., \& Shavit, T. (2014). Using priming manipulations to affect time preferences and risk aversion: An experimental study. Journal of Behavioral and Experimental Economics, 53, 36-43. https://doi.org/10.1016/j.socec.2014.08.006

Jackson, J. N., \& MacKillop, J. (2016). Attention-deficit/hyperactivity disorder and monetary delay discounting: A meta-analysis of casecontrol studies. Biological Psychiatry: Cognitive Neuroscience and Neuroimaging, 1, 316-325. https://doi.org/10.1016/j.bpsc.2016.01. 007

Jeffery, R. W. (2004). How can health behavior theory be made more useful for intervention research?. International Journal of Behavioral Nutrition and Physical Activity, 1, 1-10. https://doi. org/10.1186/1479-5868-1-10

*Jiang, C. M., Hu, F. P., \& Zhu, L. F. (2014). Introducing upfront losses as well as gains decreases impatience in intertemporal choices with rewards. Judgment and Decision Making, 9, 297-302.

*Joshi, P. D., \& Fast, N. J. (2013). Power and reduced temporal discounting. Psychological Science, 24, 432-438. https://doi.org/ 10.1177/0956797612457950

Kable, J. W., Caulfield, M. K., Falcone, M., McConnell, M., Bernardo, L., Parthasarathi, T., ... Diefenbach, P. (2017). No effect of commercial cognitive training on brain activity, choice behavior, or cognitive performance. Journal of Neuroscience, 37, 7390-7402. https://doi.org/10.1523/JNEUROSCI.2832-16.2017

*Kelley, N. J., \& Schmeichel, B. J. (2015). Thinking about death reduces delay discounting. PLOS ONE, 10, e0144228. https://doi.org/10. 1371/journal.pone. 0144228

Khurana, A., Romer, D., Betancourt, L. M., Brodsky, N. L., Giannetta, J. M., \& Hurt, H. (2013). Working memory ability predicts trajectories of early alcohol use in adolescents: The mediational role of impulsivity. Addiction, 108, 506-515. https://doi.org/10.1111/add.12001

Killeen, P. R. (2015). Models of ADHD: Five ways smaller sooner is better. Journal of Neuroscience Methods, 252, 2-13. https://doi. org/10.1016/j.jneumeth.2015.01.011

*Kim, B. K., Zauberman, G., \& Bettman, J. R. (2012). Space, time, and intertemporal preferences. Journal of Consumer Research, 39, 867880. https://doi.org/10.1086/666464

*Kim, H., Schnall, S., \& White, M. P. (2013). Similar psychological distance reduces temporal discounting. Personality and Social Psychology Bulletin, 39, 1005-1016. https://doi.org/10.1177/ 0146167213488214

*Kirby, K. N., \& Guastello, B. (2001). Making choices in anticipation of similar future choices can increase self-control. Journal of 
Experimental Psychology: Applied, 7, 154-164. https://oi.org/10. 1037/1076-898X.7.2.154

Kirby, K. N., \& Petry, N. M. (2004). Heroin and cocaine abusers have higher discount rates for delayed rewards than alcoholics or nondrug-using controls. Addiction, 99, 461-471. https://doi.org/10. $1111 / \mathrm{j} .1360-0443.2003 .00669 . x$

*Klapproth, F. (2012). The date-delay framing effect in temporal discounting depends on substance abuse. Behavioural Processes, 90, 420-423. https://doi.org/10.1016/j.beproc.2012.03.013

Koffarnus, M. N., Jarmolowicz, D. P., Mueller, E. T., \& Bickel, W. K. (2013). Changing delay discounting in the light of the competing neurobehavioral decision systems theory: A review. Journal of Experimental Analysis of Behavior, 99, 32-57. https://doi.org/10.1002/jeab.2.

Krishnan-Sarin, S., Reynolds, B., Duhig, A. M., Smith, A., Liss, T., McFetridge, A., ... \& Potenza, M. N. (2007). Behavioral impulsivity predicts treatment outcome in a smoking cessation program for adolescent smokers. Drug and Alcohol Dependence, 88(1), 79-82.

*Kuo, H. C., Lee, C. C., \& Chiou, W. B. (2016). The power of the virtual ideal self in weight control: Weight-reduced avatars can enhance the tendency to delay gratification and regulate dietary practices. Cyberpsychology, Behavior, and Social Networking, 19, 80-85. https://doi.org/10.1089/cyber.2015.0203.

*Kurti, A. N., \& Dallery, J. (2014). A laboratory-based evaluation of exercise plus contingency management for reducing cigarette smoking. Drug and Alcohol Dependence, 144, 201-209. https:// doi.org/10.1016/j.drugalcdep.2014.09.012

*Kwan, D., Craver, C. F., Green, L., Myerson, J., Gao, F., Black, S. E., \& Rosenbaum, R. S. (2015). Cueing the personal future to reduce discounting in intertemporal choice: Is episodic prospection necessary?. Hippocampus, 25, 432-443. https://doi.org/10.1002/hipo.22431

*Landes, R. D., Christensen, D. R., \& Bickel, W. K. (2012). Delay discounting decreases in those completing treatment for opioid dependence. Experimental and Clinical Psychopharmacology, 20, 302. https://doi.org/10.1037/a0027391

*LeBoeuf, R. A. (2006). Discount rates for time versus dates: The sensitivity of discounting to time-interval description. Journal of Marketing Research, 43, 59-72. https://doi.org/10.1509/jmkr.43.1.59

*Lempert, K. M., Johnson, E., \& Phelps, E. A. (2016). Emotional arousal predicts intertemporal choice. Emotion, 16, 647-656. https://doi. org $/ 10.1037 /$ emo0000168

Lempert, K. M., \& Phelps, E. A. (2016). The malleability of intertemporal choice. Trends in Cognitive Sciences, 20, 64-74. https://doi.org/10. 1016/j.tics.2015.09.005

*Li, H., Jin, S., \& Guo, Y. (2016). How do construal levels affect the intertemporal choices of Internet addicts?. Computers in Human Behavior, 60, 173-178. https://doi.org/10.1016/j.chb.2016.02.016

*Lin, H., \& Epstein, L. H. (2014). Living in the moment: Effects of time perspective and emotional valence of episodic thinking on delay discounting. Behavioral Neuroscience, 128, 12. https://doi.org/10. 1037/a0035705

*Liu, L., Feng, T., Chen, J., \& Li, H. (2013). The value of emotion: How does episodic prospection modulate delay discounting?. PLOS ONE, 8, e81717. https://doi.org/10.1371/journal.pone.0081717

*Liu, W., \& Aaker, J. (2007). Do you look to the future or focus on today? The impact of life experience on intertemporal decisions. Organizational Behavior and Human Decision Processes, 102, 212-225. https://doi.org/10.1016/j.obhdp.2006.02.004

Logue, A. W. (1988). Research on self-control: An integrating framework. Behavioral and Brain Sciences, 11, 665-679. https://doi.org/ 10.1017/S0140525X00053978

*Luo, S., Ainslie, G., \& Monterosso, J. (2014). The behavioral and neural effect of emotional primes on intertemporal decisions. Social Cognitive and Affective Neuroscience, 9, 83-291. https://doi.org/ $10.1093 /$ scan/nss 132

Lussier, J. P., Heil, S. H., Mongeon, J. A., Badger, G. J., \& Higgins, S. T. (2006). A meta-analysis of voucher-based reinforcement therapy for substance use disorders. Addiction, 101, 192-203. https://doi.org/ 10.1111/j.1360-0443.2006.01311.x

MacKillop, J., Amlung, M. T., Few, L. R., Ray, L. A., Sweet, L. H., \& Munafò, M. R. (2011). Delayed reward discounting and addictive behavior: A meta-analysis. Psychopharmacology, 216, 305-321. https://doi.org/10.1007/s00213-011-2229-0

*Magen, E., Dweck, C. S., \& Gross, J. J. (2008). The hidden-zero effect representing a single choice as an extended sequence reduces impulsive choice. Psychological Science, 19, 648-649. https://doi.org/ 10.1111/j.1467-9280.2008.02137.x

*Magen, E., Kim, B., Dweck, C. S., Gross, J. J., \& McClure, S. M. (2014). Behavioral and neural correlates of increased self-control in the absence of increased willpower. Proceedings of the National Academy of Sciences, 111, 9786-9791. https://doi.org/10.1073/pnas. 1408991111

*Malkoc, S. A., Zauberman, G., \& Bettman, J. R. (2010). Unstuck from the concrete: Carryover effects of abstract mindsets in intertemporal preferences. Organizational Behavior and Human Decision Processes, 113, 112-126. https://doi.org/10.1016/j.obhdp.2010.07. 003

McGorry, P. (2013). Prevention, innovation and implementation science in mental health: The next wave of reform. The British Journal of Psychiatry, 202, s3-s4. https://doi.org/10.1192/bjp.bp.112.119222

McGorry, P. D., Purcell, R., Hickie, I. B., \& Jorm, A. F. (2007). Investing in youth mental health is a best buy. Medical Journal of Australia, 187, S5-S7.

Mermelstein, R. (2003). Teen smoking cessation. Tobacco Control, 12, i25-i34. https://doi.org/10.1136/tc.12.suppl 1.i25

Mervis, J. (2014). Why null results rarely see the light of day. Science, 345, 992-992. https://doi.org/10.1126/science.345.6200.992

Mies, G. W., Ma, I., de Water, E., Buitelaar, J. K., \& Scheres, A. (2018). Waiting and working for rewards: Attention-deficit/hyperactivity disorder is associated with steeper delay discounting linked to amygdala activation, but not with steeper effort discounting. Cortex, 106, 164-173. https://doi.org/10.1016/j.cortex.2018.05.018

Miguel, E., Camerer, C., Casey, K., Cohen, J., Esterling, K. M., Gerber, A., ... Laitin, D. (2014). Promoting transparency in social science research. Science, 343, 30-31. https://doi.org/10.1126/science. 1245317

Miller, W. R., \& Rollnick, S. (2002). Motivational interviewing: Preparing people to change addictive behavior. New York: Guilford Press.

Mitchell, J. M., Fields, H. L., D’Esposito, M., \& Boettiger, C. A. (2005). Impulsive responding in alcoholics. Alcoholism: Clinical and Experimental Research, 29, 2158-2169. https://doi.org/10.1097/ 01.alc.0000191755.63639.4a

Moher, D., Liberati, A., Tetzlaff, J., Altman, D. G., \& The PRISMA Group. (2009). Preferred reporting items for systematic reviews and meta-analyses: The PRISMA statement. Annals of Internal Medicine, 151, 264-269. https://doi.org/10.7326/0003-4819-1514-200908180-00135

Monterosso, J., \& Ainslie, G. (1999). Beyond discounting: Possible experimental models of impulse control. Psychopharmacology, 146, 339-347. https://doi.org/10.1007/PL00005480

Monterosso, J. R., Ainslie, G., Xu, J., Cordova, X., Domier, C. P., \& London, E. D. (2007). Frontoparietal cortical activity of methamphetamine-dependent and comparison subjects performing a delay discounting task. Human Brain Mapping, 28, 383-393. https://doi.org/10.1002/hbm.20281

Montori, V. M., \& Guyatt, G. H. (2001). Intention-to-treat principle. Canadian Medical Association Journal, 165(10), 1339-1341

*Morrison, K. L., Madden, G. J., Odum, A. L., Friedel, J. E., \& Twohig, M. P. (2014). Altering impulsive decision making with an acceptance-based procedure. Behavior Therapy, 45, 630-639. https://doi.org/10.1016/j.beth.2014.01.001 
Moyer, A., Finney, J. W., Swearingen, C. E., \& Vergun, P. (2002). Brief interventions for alcohol problems: A meta-analytic review of controlled investigations in treatment-seeking and non-treatmentseeking populations. Addiction, 97, 279-292. https://doi.org/10. 1046/j.1360-0443.2002.00018.x

*Murphy, J. G., Dennhardt, A. A., Skidmore, J. R., Borsari, B., Barnett, N. P., Colby, S. M., \& Martens, M. P. (2012). A randomized controlled trial of a behavioral economic supplement to brief motivational interventions for college drinking. Journal of Consulting and Clinical Psychology, 80, 876886. https://doi.org/10.1037/a0028763

Odum, A. L. (2011). Delay discounting: Trait variable?. Behavioural Processes, 87, 1-9. https://doi.org/10.1016/j.beproc.2011.02.007.

Olson, K. L., \& Emery, C. F. (2015). Mindfulness and weight loss: A systematic review. Psychosomatic Medicine, 77, 59-67. https://doi. org/10.1097/PSY.0000000000000127

*Palombo, D. J., Keane, M. M., \& Verfaellie, M. (2015). The medial temporal lobes are critical for reward-based decision making under conditions that promote episodic future thinking. Hippocampus, 25 , 345-353. https://doi.org/10.1002/hipo.22376

*Palombo, D. J., Keane, M. M., \& Verfaellie, M. (2016). Using future thinking to reduce temporal discounting: Under what circumstances are the medial temporal lobes critical?. Neuropsychologia, 89, 437444. https://doi.org/10.1016/j.neuropsychologia.2016.07.002

*Parthasarathi, T., McConnell, M. H., Luery, J., \& Kable, J. W. (2017). The vivid present: Visualization abilities are associated with steep discounting of future rewards. Frontiers in Psychology, 8, 289. https://doi.org/10.3389/fpsyg.2017.00289

Passetti, F., Clark, L., Mehta, M. A., Joyce, E., \& King, M. (2008). Neuropsychological predictors of clinical outcome in opiate addiction. Drug and Alcohol Dependence, 94, 82-91. https://doi.org/10. 1016/j.drugalcdep.2007.10.008

Patel, V., Flisher, A. J., Hetrick, S., \& McGorry, P. (2007). Mental health of young people: A global public-health challenge. The Lancet, 369, 1302-1313. https://doi.org/10.1016/S0140-6736(07)60368-7

Patros, C. H., Alderson, R. M., Kasper, L. J., Tarle, S. J., Lea, S. E., \& Hudec, K. L. (2016). Choice-impulsivity in children and adolescents with attention-deficit/hyperactivity disorder (ADHD): A metaanalytic review. Clinical Psychology Review, 43, 162-174. https:// doi.org/10.1016/j.cpr.2015.11.001

*Peters, J., \& Büchel, C. (2010). Episodic future thinking reduces reward delay discounting through an enhancement of prefrontalmediotemporal interactions. Neuron, 66, 138-148. https://doi.org/ 10.1016/j.neuron.2010.03.026

*Peters, E. N., Petry, N. M., LaPaglia, D. M., Reynolds, B., \& Carroll, K. M. (2013). Delay discounting in adults receiving treatment for marijuana dependence. Experimental and Clinical Psychopharmacology, 21, 46-54. https://doi.org/10.1037/a0030943

Petersen, C. L., \& Zettle, R. D. (2009). Treating inpatients with comorbid depression and alcohol use disorders: A comparison of acceptance and commitment therapy versus treatment as usual. The Psychological Record, 59, 521-536.

Prendergast, M., Podus, D., Finney, J., Greenwell, L., \& Roll, J. (2006). Contingency management for treatment of substance use disorders: A meta-analysis. Addiction, 101, 1546-1560. https://doi.org/10. $1111 / \mathrm{j} .1360-0443.2006 .01581 . x$

*Pronin, E., Olivola, C. Y., \& Kennedy, K. A. (2008). Doing unto future selves as you would do unto others: Psychological distance and decision making. Personality and Social Psychology Bulletin, 34, 224-236. https://doi.org/10.1177/0146167207310023

*Pyone, J. S., \& Isen, A. M. (2011). Positive affect, intertemporal choice, and levels of thinking: Increasing consumers' willingness to wait. Journal of Marketing Research, 48, 532-543. https://doi.org/10. 1509/jmkr.48.3.532

*Quisenberry, A. J., Eddy, C. R., Patterson, D. L., Franck, C. T., \& Bickel, W. K. (2015). Regret expression and social learning increases delay to sexual gratification. PLOS ONE, 10, e0135977. https://doi.org/ 10.1371/journal.pone.0135977

*Rabinovich, A., Morton, T., \& Postmes, T. (2010). Time perspective and attitude-behaviour consistency in future-oriented behaviours. British Journal of Social Psychology, 49, 69-89. https://doi.org/10.1348/ $014466608 X 40187$

Rachlin, H. (1989). Judgment, decision and choice. New York: W. H. Freeman.

*Radu, P. T., Yi, R., Bickel, W. K., Gross, J. J., \& McClure, S. M. (2011). A mechanism for reducing delay discounting by altering temporal attention. Journal of the Experimental Analysis of Behavior, 96, 363-385. https://doi.org/10.1901/jeab.2011.96-363

*Raeva, D., Mittone, L., \& Schwarzbach, J. (2010). Regret now, take it now: On the role of experienced regret on intertemporal choice. Journal of Economic Psychology, 31, 634-642. https://doi.org/10. 1016/j.joep.2010.04.006

*Rass, O., Schacht, R. L., Buckheit, K., Johnson, M. W., Strain, E. C., \& Mintzer, M.Z. (2015). A randomized controlled trial of the effects of working memory training in methadone maintenance patients. Drug and Alcohol Dependence, 156, 38-46. https://doi.org/10.1016/j. drugalcdep.2015.08.012

*Read, D., Frederick, S., Orsel, B., \& Rahman, J. (2005). Four score and seven years from now: The date/delay effect in temporal discounting. Management Science, 51, 1326-1335. https://doi.org/ $10.1287 / \mathrm{mnsc} .1050 .0412$

*Read, D., Frederick, S., \& Scholten, M. (2013). DRIFT: An analysis of outcome framing in intertemporal choice. Journal of Experimental Psychology: Learning, Memory, and Cognition, 39, 573-588. https://doi.org/10.1037/a0029177

Reynolds, B. (2006). A review of delay-discounting research with humans: Relations to drug use and gambling. Behavioural Pharmacology, 17, 651-667. https://doi.org/10.1097/FBP. 0b013e3280115f99

Rick, S., \& Loewenstein, G. (2008). Intangibility in intertemporal choice. Philosophical Transactions of the Royal Society B: Biological Science, 363, 3813-3824. https://doi.org/10.1098/rstb.2008.0150

Robles, E., \& Vargas, P. A. (2008). Parameters of delay discounting assessment: Number of trials, effort, and sequential effects. Behavioural Processes, 78, 285-290. https://doi.org/10.1016/j. beproc.2007.10.012

Rung, J. M., \& Madden, G. J. (2018a). Demand characteristics in episodic future thinking: Delay discounting and healthy eating. Experimental and Clinical Psychopharmacology, 26, 77-84. https://doi.org/10. 1037/pha0000171

Rung, J. M., \& Madden, G. J. (2018b). Experimental reductions of delay discounting and impulsive choice: A systematic review and metaanalysis. Journal of Experimental Psychology: General, 147, 13491381. https://doi.org/10.1037/xge0000462

Ryan, R. M., Rigby, C. S., \& Przybylski, A. (2006). The motivational pull of video games: A self-determination theory approach. Motivation and Emotion, 30, 344-360. https://doi.org/10.1007/s11031-0069051-8

*Sasse, L. K., Peters, J., \& Brassen, S. (2017). Cognitive control modulates effects of episodic simulation on delay discounting in aging. Frontiers in Aging Neuroscience, 9, 1-11. https://doi.org/10.3389/ fnagi.2017.00058

*Sasse, L. K., Peters, J., Büchel, C., \& Brassen, S. (2015). Effects of prospective thinking on intertemporal choice: The role of familiarity. Human Brain Mapping, 36, 4210-4221. https://doi.org/10.1002/ hbm. 22912

Scheres, A., de Water, E., \& Mies, G. W. (2013a). The neural correlates of temporal reward discounting. Wiley Interdisciplinary Reviews: Cognitive Science, 4, 523-545. https://doi.org/10.1002/wcs.1246

Scheres, A., Tontsch, C., \& Thoeny, A. L. (2013b). Steep temporal reward discounting in ADHD-Combined type: Acting upon feelings. 
Psychiatry Research, 209, 207-213. https://doi.org/10.1016/j. psychres.2012.12.007

Scheres, A., Tontsch, C., Thoeny, A. L., \& Kaczkurkin, A. (2010). Temporal reward discounting in attention-deficit/hyperactivity disorder: The contribution of symptom domains, reward magnitude, and session length. Biological Psychiatry, 67, 641-648. https://doi. org/10.1016/j.biopsych.2009.10.033

Schumacher, J. E., Milby, J. B., Wallace, D., Meehan, D. C., Kertesz, S., Vuchinich, R., ... Usdan, S. (2007). Meta-analysis of day treatment and contingency-management dismantling research: Birmingham Homeless Cocaine Studies (1990-2006). Journal of Consulting and Clinical Psychology, 75, 823-828. https://doi.org/10.1037/ 0022-006X.75.5.823

*Secades-Villa, R., Weidberg, S., García-Rodríguez, O., FernándezHermida, J. R., \& Yoon, J. H. (2014). Decreased delay discounting in former cigarette smokers at one year after treatment. Addictive Behaviors, 39, 1087-1093. https://doi.org/10.1016/j.addbeh.2014. 03.015

*Senecal, N., Wang, T., Thompson, E., \& Kable, J. W. (2012). Normative arguments from experts and peers reduce delay discounting. Judgment and Decision Making, 7, 568-589.

Shamosh, N. A., DeYoung, C. G., Green, A. E., Reis, D. L., Johnson, M. R., Conway, A. R. A., ... Gray, J. R. (2008). Individual differences in delay discounting: Relation to intelligence, working memory, and anterior prefrontal cortex. Psychological Science, 19, 904-911. https://doi.org/10.1111/j.1467-9280.2008.02175.x

*Sheffer, C. E., Mackillop, J., Fernandez, A., Christensen, D., Bickel, W. K., Johnson, M. W., ... Mathew, M. (2016). Initial examination of priming tasks to decrease delay discounting. Behavioural Processes, 128, 144-152. https://doi.org/10.1016/j.beproc.2016.05.002

Sheffer, C., MacKillop, J., McGeary, J., Landes, R., Carter, L., Yi, R., ... Bickel, W. (2012). Delay discounting, locus of control, and cognitive impulsiveness independently predict tobacco dependence treatment outcomes in a highly dependent, lower socioeconomic group of smokers. American Journal on Addictions, 21, 221-232. https:// doi.org/10.1111/j.1521-0391.2012.00224.x

Simmons, J. P., Nelson, L. D., \& Simonsohn, U. (2011). False-positive psychology undisclosed flexibility in data collection and analysis allows presenting anything as significant. Psychological Science, 22, 1359-1366. https://doi.org/10.1177/0956797611417632

*Snider, S. E., LaConte, S. M., \& Bickel, W. K. (2016). Episodic future thinking: Expansion of the temporal window in individuals with alcohol dependence. Alcoholism: Clinical and Experimental Research, 40, 1558-1566. https://doi.org/10.1111/acer.13112

Solanto, M. V. (2011). Cognitive-behavioral therapy for adult ADHD: Targeting executive dysfunction. New York: Guilford Press.

Sonuga-Barke, E. J. (2005). Causal models of attention-deficit/hyperactivity disorder: From common simple deficits to multiple developmental pathways. Biological Psychiatry, 57, 1231-1238. https://doi. org/10.1016/j.biopsych.2004.09.008

Sonuga-Barke, E. J. S., Taylor, E., Sembi, S., \& Smith, J. (1992). Hyperactivity and delay aversion-I. The effect of delay on choice. Journal of Child Psychology and Psychiatry, 33, 387-398. https:// doi.org/10.1111/j.1469-7610.1992.tb00874.x

Stanger, C., Budney, A. J., \& Bickel, W. K. (2013). A developmental perspective on neuroeconomic mechanisms of contingency management. Psychology of Addictive Behaviors, 27, 403-415. https://doi. org/10.1037/a0028748

Stanger, C., Ryan, S. R., Fu, H., Landes, R. D., Jones, B. A., Bickel, W. K., \& Budney, A. J. (2012). Delay discounting predicts adolescent substance abuse treatment outcome. Experimental and Clinical Psychopharmacology, 20, 205-212. https://doi.org/10.1037/ a0026543

*Stein, J. S., Wilson, A. G., Koffarnus, M. N., Daniel, T. O., Epstein, L. H., \& Bickel, W. K. (2016). Unstuck in time: Episodic future thinking reduces delay discounting and cigarette smoking.
Psychopharmacology, 233, 3771-3778. https://doi.org/10.1007/ s00213-016-4410-y

Sweeney, M. M., Rass, O., DiClemente, C., Schacht, R. L., Vo, H. T., Fishman, M. J., ... Johnson, M. W. (2018). Working memory training for adolescents with cannabis use disorders: A randomized controlled trial. Journal of Child \& Adolescent Substance Abuse, 27, 211-226. https://doi.org/10.1080/1067828X.2018.1451793

Teuscher, U., \& Mitchell, S. H. (2011). Relation between time perspective and delay discounting: A literature review. The Psychological Record, 61, 613-632. https://doi.org/10.1007/BF03395780

Trope, Y., \& Liberman, N. (2003). Temporal construal. Psychological Review, 110, 403-421. https://doi.org/10.1037/0033-295X.110.3.403

Van Dessel, J., Sonuga-Barke, E., Mies, G., Lemiere, J., Van der Oord, S., Morsink, S., \& Danckaerts, M. (2018). Delay aversion in attention deficit/hyperactivity disorder is mediated by amygdala and prefrontal cortex hyper-activation. Journal of Child Psychology and Psychiatry, 59, 888-899. https://doi.org/10.1111/jcpp.12868

*van der Wal, A. J., Schade, H. M., Krabbendam, L., \& Van Vugt, M. (2013). Do natural landscapes reduce future discounting in humans?. Proceedings of the Royal Society of London B: Biological Sciences, 280, 1-6. https://doi.org/10.1098/rspb.2013. 2295

Weatherly, J. N. (2014). On several factors that control rates of discounting. Behavioural Processes, 104, 84-90. https://doi.org/ 10.1016/j.beproc.2014.01.020

*Weatherly, J. N., \& Derenne, A. (2011). Comparing delay discounting rates when using the fill-in-the-blank and multiple-choice methods. The Journal of General Psychology, 138, 300-318. https://doi.org/ 10.1080/00221309.2011.606442

*Weatherly, J. N., \& Terrell, H. K. (2010). Delay discounting of different commodities II: Confirmatory analyses. The Journal of General Psychology, 138, 35-48.

*Weatherly, J. N., Derenne, A., \& Terrell, H. K. (2010). College students discount money "won" more than money "owed". The Psychological Record, 60, 463-471.

*Weber, E. U., Johnson, E. J., Milch, K. F., Chang, H., Brodscholl, J. C., \& Goldstein, D. G. (2007). Asymmetric discounting in intertemporal choice: A query-theory account. Psychological Science, 18, 516-523. https://doi.org/10.1111/j. 1467-9280.2007.01932.x

Weller, R. E., Cook, E. W., Avsar, K. B., \& Cox, J. E. (2008). Obese women show greater delay discounting than healthy-weight women. Appetite, 51, 563-569. https://doi.org/10.1016/j.appet.2008.04.010

*Weidberg, S., Landes, R. D., García-Rodríguez, O., Yoon, J. H., \& Secades-Villa, R. (2015). Interaction effect of contingency management and sex on delay-discounting changes among treatment-seeking smokers. Experimental and Clinical Psychopharmacology, 23, 361-368. https://doi.org/10.1037/ pha0000043

Wesley, M. J., \& Bickel, W. K. (2014). Remember the future II: Metaanalyses and functional overlap of working memory and delay discounting. Biological Psychiatry, 75, 435-448. https://doi.org/ 10.1016/j.biopsych.2013.08.008

White, M. P., Alcock, I., Wheeler, B. W., \& Depledge, M. H. (2013). Would you be happier living in a greener urban area? A fixed-effects analysis of panel data. Psychological Science, 24, 920-928. https:// doi.org/10.1177/0956797612464659

White, S. F., Clanton, R., Brislin, S. J., Meffert, H., Hwang, S., Sinclair, S., \& Blair, R. J. R. (2014). Temporal discounting and conduct disorder in adolescents. Journal of Personality Disorders, 28, 518. https://doi.org/10.1521/pedi.2014.28.1.5

Wilfley, D. E., Tibbs, T. L., Van Buren, D., Reach, K. P., Walker, M. S., \& Epstein, L. H. (2007). Lifestyle interventions in the treatment of childhood overweight: A meta-analytic review of randomized controlled trials. Health Psychology, 26, 521-532. https://doi.org/10. 1037/0278-6133.26.5.521 
Wills, T. A., Sandy, J. M., \& Yaeger, A. M. (2001). Time perspective and early-onset substance use: A model based on stress-coping theory. Psychology of Addictive Behaviors, 15, 118-125. https://doi.org/10. 1037/0893-164X.15.2.118

*Wu, W. H., Cheng, W., \& Chiou, W. B. (2017). Episodic future thinking about the ideal self induces lower discounting, leading to a decreased tendency toward cheating. Frontiers in Psychology, 8, 19. https://doi.org/10.3389/fpsyg.2017.00287

*Yao, Y. W., Chen, P. R., Chiang-shan, R. L., Hare, T. A., Li, S., Zhang, J. T., ... Fang, X. Y. (2017). Combined reality therapy and mindfulness meditation decrease intertemporal decisional impulsivity in young adults with Internet gaming disorder. Computers in Human Behavior, 68, 210-216. https:/ doi.org/10.1016/j.chb.2016.11.038

*Yi, R., Johnson, M. W., Giordano, L. A., Landes, R. D., Badger, G. J., \& Bickel, W. K. (2008). The effects of reduced cigarette smoking on discounting future rewards: An initial evaluation. The Psychological Record, 58, 163-174.

*Yi, R., King, L. F., Carter, A. E., Landes, R. D., \& Bickel, W. K. (2010). Intertemporal decision-making for a group. The Psychological Record, 60, 577-586.

*Yoon, J. H., Higgins, S. T., Bradstreet, M. P., Badger, G. J., \& Thomas, C. S. (2009). Changes in the relative reinforcing effects of cigarette smoking as a function of initial abstinence. Psychopharmacology, 205, 305-318. https://doi.org/ 10.1007/s00213-009-1541-4

*Zauberman, G., Kim, B. K., Malkoc, S. A., \& Bettman, J. R. (2009). Discounting time and time discounting: Subjective time perception and intertemporal preferences. Journal of Marketing Research, 46, 543-556. https://doi.org/10.1509/jmkr.46.4.543

Zettle, R. D. (2007). ACT for depression: A clinician's guide to using acceptance and commitment therapy in treating depression. Oakland: New Harbinger Publications.

Zhang, M., \& Smith, P. K. (2018). Does power reduce temporal discounting? Commentary on Joshi and Fast (2013). Psychological Science, 29, 1010-1019. https://doi.org/10.1177/ 0956797617754219

Zimbardo, P. G., Keough, K. A., \& Boyd, J. N. (1997). Present time perspective as a predictor of risky driving. Personality and Individual Differences, 23, 1007-1023. https://doi.org/10.1016/ S0191-8869(97)00113-X

Publisher's note Springer Nature remains neutral with regard to jurisdictional claims in published maps and institutional affiliations. 